UNIVERSIDADE DE SÃO PAULO

FACULDADE DE MEDICINA DE RIBEIRÃO PRETO

DEPARTAMENTO DE PATOLOGIA E MEDICINA LEGAL

ESTUDO SOBRE OS REGISTROS DO SERVIÇO DE VERIFICAÇÃO DE ÓBITOS NO SISTEMA DE INFORMAÇÃO DE MORTALIDADE PARA O ESTADO DO TOCANTINS, 2010 - 2012

ARTHUR ALVES BORGES DE CARVALHO

RIBEIRÃO PRETO, SP

2016 


\section{ESTUDO SOBRE OS REGISTROS DO SERVIÇO DE VERIFICAÇÃO DE ÓBITOS NO SISTEMA DE INFORMAÇÃO DE MORTALIDADE PARA O ESTADO DO TOCANTINS, 2010 - 2012}

\section{VERSÃO CORRIGIDA}

A Versão Original encontra-se no Departamento de Patologia e Medicina Legal

Dissertação apresentada ao Departamento de Patologia e Medicina Legal da Faculdade de Medicina de Ribeirão Preto da Universidade de São Paulo para a obtenção do grau de Mestre em Ciências.

Área de Concentração: Patologia

Opção: Patologia Humana

Orientador: Prof. Associado Dr. Edson Garcia Soares 
Autorizo a reprodução e divulgação total ou parcial deste trabalho, por qualquer meio convencional ou eletrônico, para fins de estudo e pesquisa, desde que citada a fonte.

\section{FICHA CATALOGRÁFICA}

\section{Dados Internacionais de Catalogação na Publicação (CIP) Biblioteca FAPAC - Itpac Porto Nacional}

C331e Carvalho, Arthur Alves Borges de

Estudo sobre os registros do Serviço de Verificação de Óbitos no Sistema de Informação de Mortalidade para o Estado do Tocantins, 2010 - 2012./ Arthur Alves Borges de Carvalho. Ribeirão Preto- SP, 2016.

71 p.: il.; $30 \mathrm{~cm}$

Dissertação de Mestrado, apresentada à Faculdade de Medicina de Ribeirão Preto/USP. Área de concentração: Patologia Humana.

Orientador (a): Edson Garcia Soares.

1. Estatísticas vitais. 2. Causas de Morte. 3. Serviços de Informação. 4. Serviço de Verificação de Óbitos. 5. Responsabilidade pela Informação. I.Título II. SOARES, Edson Garcia orient. III. USP

CDD 616.07

Bibliotecária Responsável:

Raquel Modesto

CBR_2/1285 
Nome: CARVALHO, ARTHUR ALVES BORGES

Título: ESTUDO SOBRE OS REGISTROS DO SERVIÇO DE VERIFICAÇÃO DE ÓBITOS NO SISTEMA DE INFORMAÇÃO DE MORTALIDADE PARA O ESTADO DO TOCANTINS, 2010 - 2012

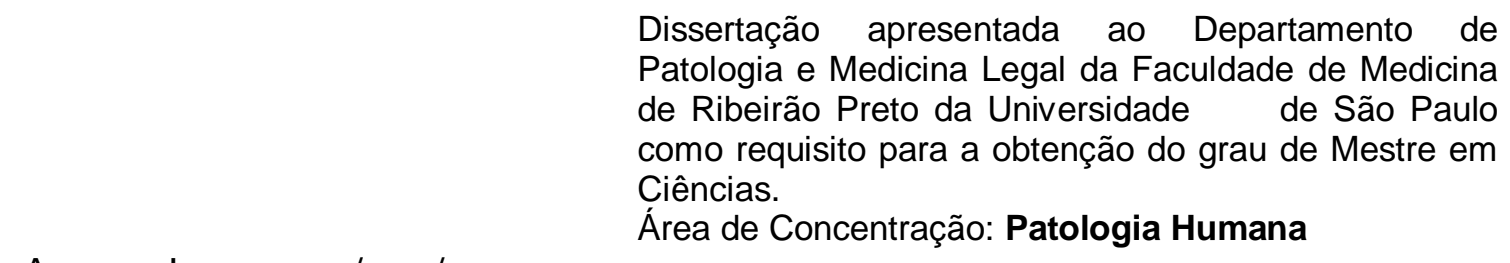

Aprovado em

Area de Concentração: Patologia Humana

BANCA EXAMINADORA

Prof.Dr. Instituição

Julgamento Assinatura

Prof.Dr. Instituição

Julgamento Assinatura

Prof.Dr. Instituição

Julgamento Assinatura

Prof.Dr. Instituição Assinatura 


\section{DEDICATÓRIA}

À minha amada esposa e amado filho com puro amor, carinho e eterna gratidão pela paciência e incentivo ao longo do período de elaboração desta dissertação. 


\section{AGRADECIMENTOS}

A Deus, sem o qual nada existe ou é permitido;

A minha amada esposa que, por meio de carinhosas palavras, afeto e amor incondicional direcionaram e direcionam meus pensamentos, minhas idéias e ideais.

Aos meus pais pelo amor, cuidado e incentivo constante ao aprimoramento moral, ético e cívico;

Ao Prof. Dr. Edson Garcia Soares e família pelos anos de convivência, pela orientação acadêmica, profissional e pessoal que muito contribuiu, para que durante o processo de trabalho, pudesse alcançar o nobre objetivo de superar meu antigo eu.

Ao Prof. Dr. Moacyr Lobo da Costa Júnior pela orientação estatística, conceitual e filosófica na definição do trabalho;

Ao Prof. Dr. Marco Aurélio Guimarães pela oportunidade a mim concedida de aprimorar os conhecimentos no campo da antropologia forense e da ética médica;

À Dra. Twiggy Batista pelo companheirismo de trabalho no Serviço de Verificação de Óbitos em Palmas e pelas revisões e supervisões da escrita científica do trabalho;

À Mestre Erlaene Tedesco pelas revisões, reflexões e ajustes na formatação desta pesquisa;

Ao Estatístico Ricardo Costa Lima pela paciência e ajustes estatísticos na elaboração dos resultados da pesquisa;

A toda equipe do Serviço de Verificação de Óbitos do Estado do Tocantins pela contribuição na logística das viagens, pesquisas e concretização da pesquisa;

A toda equipe do Serviço de Verificação de Óbitos do Interior em Ribeirão Preto pelo acolhimento e suporte durante a realização do trabalho em Ribeirão;

A Secretaria de Estado da Saúde pela oportunidade e incentivo para a realização da pesquisa. 
CARVALHO, A.A.B. Estudo sobre os registros do serviço de verificação de óbitos no sistema de informação de mortalidade para o estado do Tocantins, 2010-2012, Nf. Dissertação de Mestrado - Faculdade de Medicina de Ribeirão Preto, Universidade de São Paulo, São Paulo, 2016

\section{RESUMO}

O Serviço de Verificação de Óbitos (SVO) foi criado para elucidar causas de óbitos naturais mal definidas por meio de exames necroscópicos e registrar informações mais completas sobre as causas de morte no Sistema de Informação de Mortalidade (SIM). Desde a criação da rede nacional de SVO, poucos estudos avaliaram a qualidade dos registros de óbitos dos SVO no SIM. Foram estudados 19.780 registros de óbitos não fetais de residentes no Estado do Tocantins entre os anos de 2012, 2011 e 2012, obtidos por download do site do DATASUS do Ministério da Saúde. Além de estabelecer o perfil social demográfico dos óbitos, foram estudadas a completude das informações, as cinco principais causas de morte e as causas básicas registradas pelo SVO e demais atestantes dentro do SIM. Óbitos do sexo masculino, cor parda, casados, sem escolaridade, hospitalares de aposentados e maiores de 75 anos predominaram. A incompletude de dados registrados no SIM para o Estado do Tocantins foi superior a $10 \%$ e não houve diferença estatística significativa entre a completude de dados registrados pelo SVO e pelos demais atestantes. As doenças do aparelho circulatório foram as principais causas de morte registradas pelos atestantes, exceto pelo IML, onde as causas externas predominaram. Quinze por cento dos registros de causas básicas externas não pertenciam ao IML e o SVO apresentou uma grande proporção de registros de causas básicas mal definidas. A qualificação das informações sobre mortalidade, imprescindível à elaboração de políticas públicas sanitárias, persiste desafiadora no Estado do Tocantins. A criação de uma cultura da informação epidemiológica passa pela inserção curricular, educação e sensibilização médica continuada.

Palavras-chave: Estatísticas vitais; Causas de Morte; Serviços de Informação; Serviço de Verificação de Óbitos; Responsabilidade pela Informação. 
CARVALHO, A.A.B. Study on the records of deaths verification service in the mortality information system for the state of Tocantins, 2010-2012, 2016 Nf. Masters dissertation - Faculty of Medicine of Ribeirão Preto, University of São Paulo, Ribeirão Preto -SP, Brazil, 2016.

\begin{abstract}
The Death Verification Service (SVO) was created to elucidate causes of natural deaths poorly defined by postmortem examinations and record more complete information on the causes of death in the Mortality Information System (SIM). Since the establishment of the national network of SVO, few studies have evaluated the quality of death records of SVO SIM. We studied 19,780 no fetal death records of residents in the State of Tocantins between the years 2012, 2011 and 2012, downloaded the DATASUS website of the Ministry of Health. In addition to establishing the demographic social profile of the deaths were studied completeness information, the five leading causes of death and root causes recorded by the SVO and other informers within the SIM. Deaths male, mulatto, married, uneducated, retired hospital and over 75 years predominated. The incompleteness of data in SIM for the State of Tocantins was higher than $10 \%$ and there was no statistically significant difference between the completeness of data recorded by the SVO and the other informers. The circulatory diseases were the main causes of death recorded by informers except for IML, where external causes predominated. Fifteen percent of the records of external underline causes did not belong to the IML and the SVO had a large proportion of ill-defined basic causes records. The qualification of information on mortality, essential to the development of health policies, remains defiant in the State of Tocantins. Creating a culture of epidemiological information passes through curriculum integration, education and continuing medical awareness.
\end{abstract}

Keywords: Vital statistics; Causes of Death; Information Services; Coroner's Service; Responsibility for Information. 


\section{LISTA DE TABELAS}

Tabela 1 - População Por Situação de Domicílio 2010 A 2014.

Tabela 2 - Pessoas de 15 anos ou mais de idade, ocupadas na semana de referência, por contribuição para instituto de previdência no trabalho principal, Segundo os grupamentos de atividade do trabalho principal Tocantins - 2013

Tabela 3 - Produto Interno Bruto - PIB do Tocantins 2007 a 2014.

Tabela 4 - Valor Agregado Bruto por setores de atividade no Tocantins 2007 a 2012.

Tabela 5 - Registro Civil no Estado do Tocantins - 2009 a 2012.

Tabela 6 - Frequência absoluta e relativa de registros no SIM, segundo atestante no estado do Tocantins, Brasil, 2010 a 2012.

Tabela 7 - Frequência absoluta e relativa de registros com todas as variáveis preenchidas e registros com pelo menos uma variável não preenchida ou vazia no SIM para o Estado do Tocantins, segundo atestante, 2010 a 2012

Tabela 8 - Frequência absoluta e relativa de registros no SIM, segundo os principais capítulos (CID-10) de causas básicas de óbitos, Tocantins, Brasil, 2010 a 2012.

Tabela 9 - Frequência absoluta e relativa de registros no SIM, segundo principais capítulos (CID-10) de causas básicas de óbitos informado pelo atestante Assistente, Tocantins, Brasil, 2010 a 2012.

Tabela 10 - Frequência absoluta e relativa de registros no SIM, segundo os principais capítulos (CID-10) de causas básicas de óbitos informado pelo atestante Substituto, Tocantins, Brasil, 2010 a 2012.

Tabela 11 - Frequência absoluta e relativa de registros no SIM, segundo os principais capítulos (CID-10) de causas básicas de óbitos informado pelo atestante IML, Tocantins, Brasil, 2010 a 2012.

Tabela 12 - Frequência absoluta e relativa de registros no SIM, segundo os principais capítulos (CID-10) de causas básicas de óbitos informado pelo atestante SVO, Tocantins, Brasil, 2010 a 2012. 
Tabela 13 - Frequência absoluta e relativa de registros no SIM, segundo os principais capítulos (CID-10) de causas básicas de óbitos informado pelo atestante Outros, Tocantins, Brasil, 2010 a 2012.

Tabela 14 - Frequência absoluta e relativa de registros no SIM, segundo os principais capítulos (CID-10) de causas básicas de óbitos onde o campo atestante se encontra vazio, Tocantins, Brasil, 2010 a 2012.

Tabela 15 - Frequência absoluta e relativa de registros no SIM, segundo Causas Básicas de Óbito Mal Definas e atestante, Tocantins, Brasil, 2010 a 2012.

Tabela 16 - Frequência absoluta e relativa de registros inclusos no capítulo XVIII por número total de registros para cada atestante

Tabela 17 - Frequência absoluta e relativa de registros no SIM, segundo Causas Externas e atestante, Tocantins, Brasil, 2010 a 2012.

Tabela 18- Frequência absoluta e relativa de registros inclusos no capítulo XX por número total de registros para cada atestante.

Tabela 19 - Frequência absoluta e relativa de campos vazios no SIM, segundo causas de mortalidade e morbidade para o total de registros no SIM, Tocantins, Brasil, 2010 a 2012

Tabela 20 - Frequência absoluta e relativa de campos vazios no SIM, segundo causas de mortalidade e morbidade para o campo atestante Assistente, Tocantins, Brasil, 2010 a 2012

Tabela 21 - Frequência absoluta e relativa de campos vazios no SIM, segundo causas de mortalidade e morbidade para o atestante Substituto, Tocantins, Brasil, 2010 a 2012.

Tabela 22 - Frequência absoluta e relativa de campos vazios no SIM, segundo causas de mortalidade e morbidade para o atestante IML, Tocantins, Brasil, 2010 a 2012.

Tabela 23 - Frequência absoluta e relativa de campos vazios no SIM, segundo causas de mortalidade e morbidade para o atestante SVO, Tocantins, Brasil, 2010 a 2012.

Tabela 24 - Frequência absoluta e relativa de campos vazios no SIM, segundo causas de mortalidade e morbidade para o atestante Outros, Tocantins, Brasil, 2010 a 2012. 
Tabela 25 - Número e percentual de campos vazios no SIM, segundo causas de mortalidade e morbidade para o campo atestante Vazio, Tocantins, Brasil, 2010 a 2012 ...................................................................5 


\section{LISTA DE FIGURAS}

Figura 1 - Frente da Declaração de Óbito

Figura 2 - Distribuição da população por sexo, segundo os grupos de idade -Tocantins - 2010

Figura 3 - Regiões de Saúde do Estado do Tocantins - Decreto 7.508, de 28 de junho de 2011 - Resolução CIB no 161/2012, 29 de agosto de 2012 Resolução CIB o 42/2014, 20 de março de 2014........................................ 17

Figura 4 - Variáveis analisadas no estudo ............................................. 26

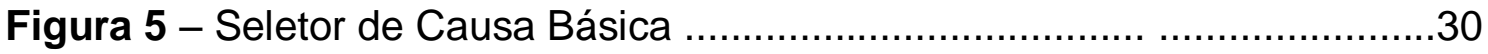

Figura 6 - Média de notificações de óbitos não fetais e residentes no Tocantins por mês do ano, ocorridos no período de 2010 a 2012.

Figura 7 - Número de óbitos não fetais e residentes no Tocantins por hora de ocorrência, no período de 2010 a 2012.

Figura 8 - Naturalidade dos óbitos não fetais e residentes, ocorridos no Tocantins no período de 2010 a 2012.

Figura 9 - Número de óbitos não fetais e residentes no Tocantins por faixa etária, ocorridos no período de 2010 a 2012.

Figura 10 - Óbitos não fetais e residentes no Tocantins por sexo ocorrido no período de 2010 a 2012.

Figura 11 - Registros de óbitos não fetais e residentes no Tocantins por raça/cor, ocorridos no período de 2010 a 2012.

Figura 12 - Número de óbitos não fetais e residentes no Tocantins por estado civil, no período de 2010 a 2012.

Figura 13 - Número de óbitos não fetais e residentes no Tocantins por escolaridade, ocorridos no período de 2010 a 2012.

Figura 14 - Número de óbitos não fetais e residentes no Tocantins por ocupação, ocorridos no período de 2010 a 2012.

Figura 15 - Número de óbitos não fetais e residentes no Tocantins por município de residência, ocorridos no período de 2010 a 2012.

Figura 16 - Número de óbitos não fetais e residentes no Tocantins por local de ocorrência, ocorridos no período de 2010 a 2012 


\section{LISTA DE ABREVIATURAS}

BIRLS - Beneficiary Identification Records Locator Subsystem

DATASUS - Departamento de Informática do Sistema Único de Saúde

DO - Declaração de Óbito

CID-10- Classificação Internacional de Doenças vol. 10

EUA- Estados Unidos da América

IBGE- Instituto Brasileiro de Geografia e Estatística

IDH- Índice de Desenvolvimento Humano

CAUSBAS- Causa Básica de Óbito

CD-ROM- Compact Disc - Read Only Memory

CGM- Coeficiente Geral de Mortalidade

CFM- Conselho Federal de Medicina

COB- Código de Ocupações Brasileiro

CRM-TO- Conselho Regional de Medicina do Estado do Tocantins

svo- Serviço de Verificação de Óbitos

SVO/TO- Serviço de Verificação de Óbitos do Estado do Tocantins

IML- Instituto Médico Legal

SAMU- Serviço de Atendimento Móvel de Urgência

SIM- Sistema de Informação de Mortalidade

MS- Ministério da Saúde

OMS- Organização Mundial de Saúde

OPAS- Organização Panamericana de Saúde

PIB- Produto Interno Bruto

POP- Plantão de Óbitos da Prefeitura de Palmas

SCB- Seletor de Causa Básica

SSA- Social Security Administration

SUS- Sistema Único de Saúde

VHA- Veterans Health Administration 


\section{SUMÁRIO}

1. INTRODUÇÃO

1.1 Sistema de Informação de Mortalidade (SIM) .................................. 1

1.2 Declaração de Óbito (DO) .................................................................. 4

1.3 Serviços de Verificação de Óbitos .................................................. 8

1.4 Completude de dados ................................................................. 11

1.5 Perfil Social e Demográfico do Tocantins ........................................ 12

1.6 Causas Básicas de Óbitos ................................................... 18

1.7 Justificativa do Estudo .............................................................. 21

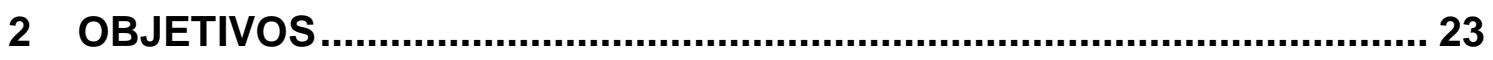

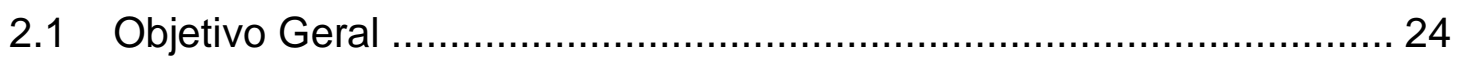

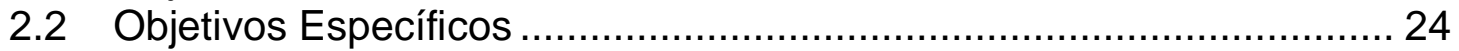

3 MATERIAIS E MÉTODOS ..................................................................... 25

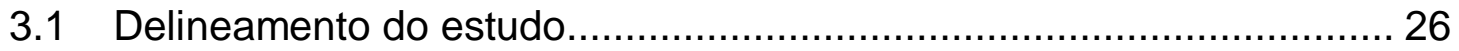

3.2 Fonte de Dados e Variáveis do Estudo ............................................. 26

3.3 Análise da Completude de Dados Gerais......................................... 29

3.4 Análise da Completude de Dados sobre Causas de Mortalidade e

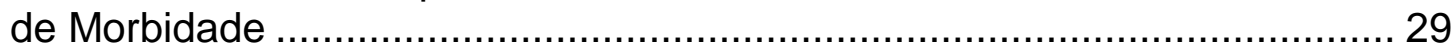

3.5 Análise dos registros das Causas Básicas ....................................... 30

3.5.1 Análise dos registros das Causas Básicas Mal Definidas .............. 31

3.5.2 Análise dos registros das Causas Básicas Externas ..................... 31

3.6 Elaboração do Perfil Social de Demográfico dos Registros de Óbitos no Sistema de Informação de Mortalidade para o Tocantins (SIM-TO)

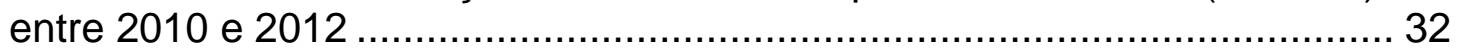

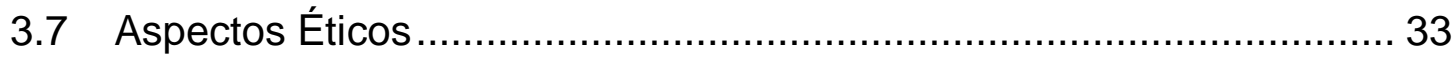

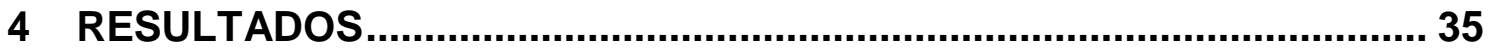

4.1 Perfil Social e Demográfico dos Registros de Óbitos no Sistema de Informação de Mortalidade para o Estado do Tocantins (SIM-TO) ................ 36 4.2 Completude de dados dentro do Sistema de Informação de Mortalidade para o Estado do Tocantins, 2010-2012 ................................. 42 4.3 Completude de dados dentro do Sistema de Informação de Mortalidade para o SVO.

4.4 Resultado da Análise sobre as "Causas Básicas" de óbitos dentro do Sistema de Informação de Mortalidade para o Estado do Tocantins, 2010-2012.

4.5 Resultado da Análise sobre a Completude dos registros sobre as "Causas de Mortalidade e Morbidade" dentro do Sistema de Informação de Mortalidade para o Estado do Tocantins, 2010-2012.

5 DISCUSSÃO

5.1 O Sistema de Informação de Mortalidade ........................................ 57

5.2 Completude de dados .................................................................... 59

5.3 Completude de Dados no Serviço de Verificação de Óbitos ................ 61

5.4 Causas básicas de óbitos............................................................ 63 
5.5 Completude dos registros sobre causas de mortalidade e

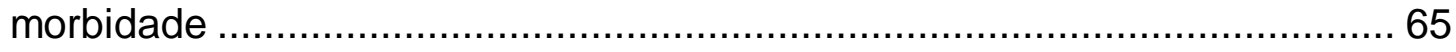

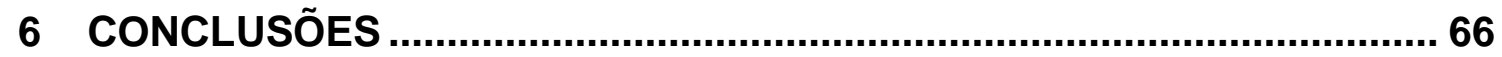

7 REFERÊNCIAS

8 ANEXO 1 
INTRODUÇÃO 


\section{INTRODUÇÃO}

\subsection{Sistema de Informação de Mortalidade (SIM)}

As estatísticas vitais sobre mortalidade carecem de acreditação em nível mundial, principalmente nos países subdesenvolvidos. Mais de dois terços da população mundial sobrevive em países cujas estatísticas de mortalidade não são fidedignas, dirimindo a qualidade e a confiabilidade dos dados utilizados para a elaboração de políticas públicas de saúde (RAMPATIGE, 2014).

Os registros populacionais sobre o Brasil são seculares e permitem uma reflexão histórica sobre a evolução e a preocupação nacional em registrar informações e criar dados. O Padre José de Anchieta já descrevia informações sobre a população brasileira em meados de 1.585 no livro "La information" (MELLO JORGE, 2007).

A existência de um sistema de informação de mortalidade é justificada pela necessidade de elaboração de estatísticas vitais para compilar uma série histórica de dados, estudarem as causas de mortes, compararem situações de saúde de diferentes áreas geográficas e promover melhorias públicas sanitárias (SWAROOP apud LAURENTI; MELLO JORGE; GOTLIEB, 2006).

No Brasil, a vontade de democratizar e aprimorar a gestão do Sistema de Saúde estimulou a implantação do Sistema de Informação em Saúde pelo Ministério da Saúde. Em 1975 foi promulgada a lei oㅜ 6. 229 de 30/10 criando o Sistema Nacional de Vigilância Epidemiológica (LAURENTI; MELLO JORGE; GOTLIEB, 2006) e, neste mesmo ano, o Ministério da Saúde criou o Sistema de Informação sobre Mortalidade (SIM) que atualmente está hospedado no Departamento de Informática do Sistema Único de Saúde (DATASUS).

O SIM surgiu como um sistema capaz de, dentre outras atividades, captar e consolidar dados sobre mortalidade. A finalidade do SIM era registrar informações de mortalidade visando aumentar a qualidade e a completude dos dados, diminuírem o sub-registro e viabilizar trabalhos epidemiológicos e estatísticos sobre mortalidade no Brasil (LAURENTI; MELLO JORGE; GOTLIEB, 2006). Quando idealizado na década de 70, o SIM deveria apoiar um estratagema de vigilância em saúde, atuando como instrumento de gestão 
governamental em saúde populacional (MELLO JORGE; LAURENTI; GOTLIEB, 2007; BRASIL, 2011a; BRASIL, 2015).

As informações para o SIM são obtidas por meio da Declaração de Óbito (DO) obrigatoriamente preenchida pelo médico segundo a lei Lei $n^{\circ} 6.015$ dos registros públicos (BRASIL, 2016a). A responsabilidade pelo preenchimento de todos os campos e variáveis contidos na DO consiste em ato médico (CONSELHO FEDERAL DE MEDICINA, 2005).

A coleta de dados para o SIM, realizada por municípios e estados da federação ocorre com o recolhimento da $1^{\underline{a}}$ via da DO preenchida por médicos atestantes assistentes, substitutos, dos institutos médicos legais, dos serviços de verificação de óbitos e outros. O preenchimento das declarações de óbitos constitui responsabilidade ética e jurídica do médico, como previsto nos artigos 82 e 83 do Código de Ética Médica de 2009 (LUCENA, 2014).

Segundo o Tribunal de Contas da União a cobertura do SIM nacional avançou na última década. Existe um considerável aumento no número de óbitos registrados no SIM nacional chegando a 1.117.498 óbitos notificados em 2011 (BRASIL, 2011a).

A região nordeste avançou de modo inquestionável em relação ao SIM. Alguns estados como Pernambuco apresentaram informações sobre mortalidade consideradas de boa qualidade entre 1990 e 2000 (FRIAS et al, 2010). A cobertura do SIM na região nordeste aprimorou as estatísticas vitais nacionais desde a criação em 1975, porém problemas relacionados à coleta e fluxo de informações persistem reduzindo a qualidade das políticas públicas de saúde (FIGUEIROA, 2013).

O coeficiente geral de Mortalidade (CGM) menor que $4 / \mathrm{mil}$ hab. indica precariedade na cobertura das informações de mortalidade. Em 2005, 43,9\% dos municípios tocantinenses possuíam CGM menor que 4/mil habitantes (BRASIL, 2005). Atualmente, com a significativa melhora de 73\% em 2006 para 90\% em 2014, a cobertura do SIM no Estado do Tocantins apresenta a maior abrangência entre os Estados da Região Norte de 2013, seguido pelos Estados do Pará e Amazonas com 83\% de cobertura (SANTOS DE JESUS et al., 2016). 


\subsection{Declaração de Óbito (DO)}

A história demonstra que a DO possuiu diversos modelos até final do século passado. Em 1925 a Organização de Saúde da Liga das Nações sugeriu uma unificação internacional. Entretanto, o modelo continua em constante reformulação em alguns países, incluindo no Brasil onde os próprios conceitos atestado de óbito, certidões de óbitos e declarações de óbitos permanecem incógnitas para a classe médica em geral. Declaração, certidão ou atestado de óbito? Citando o dicionário Aurélio no livreto: "O Atestado de Óbito", Laurenti e Mello Jorge definem e utilizam esses termos como sinônimos (LAURENTI; MELLO JORGE, 1996).

A Conferência Internacional da $6^{a}$ Revisão da Classificação de Doenças aprovou em 1948 um modelo único de DO. Para tanto, capacitações e cursos médicos em diversos países viabilizaram a implantação do modelo único na Europa, Ásia e Américas. Em 1950, a implantação em todo território brasileiro foi iniciada, porém apenas em 1976 uma DO padronizada foi adotada pelo Ministério da Saúde (LAURENTI, 1994).

A DO distribuída pelo Ministério da Saúde consiste em um formulário básico do SIM, composto de três vias pré-numeradas e autocopiativas coloridas: branca para a secretaria municipal de saúde, amarela para o cartório de registro civil e rosa para o estabelecimento de saúde. A DO contém cinquenta e nove variáveis numeradas alfanumericamente, distribuídas em nove blocos numerados em romano. Os blocos discriminam informações sobre: I-Identificação, II-Residência, III-Ocorrência, IV- Fetal ou menor de 1 ano, VCondições e causas do óbito, VI-Médico, VII-Causas externas, VIII-Cartório e IX-Localidade sem médico (BRASIL, 2011a).

As informações médicas compiladas nos campos da DO devem ser fidedignas, pois são consolidadas, codificadas e lançadas no SIM para elaboração de políticas públicas de saúde (BRASIL, 2006a). Essas informações servem para conhecer a realidade sanitária populacional visando melhorias, subsidiando civil e legalmente a emissão da "Certidão de Óbito" para sepultamentos em nível nacional (BRASIL, 2011b).

Existem cinco atestantes ou emissores de declarações de óbitos possíveis: médicos assistentes, médicos substitutos, médicos dos Institutos 
Médicos Legais, médicos dos Serviços de Verificação de Óbitos e "Outros" para médicos que não se enquadram nas definições anteriores.

Para a emissão da DO consideram-se ainda os locais de ocorrência dos óbitos (hospitalares, outros estabelecimentos de saúde, domiciliares, vias públicas, aldeias indígenas e outros) e os tipos de óbitos (fetais ou não fetais). Óbitos fetais são as mortes de produtos de concepções, antes da expulsão ou da extração completa do corpo da Mãe, independente do tempo ou duração da gravidez (CID-10), e a emissão de DO para estes casos são de responsabilidade obrigatória do médico que assistiu à mãe (CONSELHO FEDERAL DE MEDICINA, 2005).

Como os óbitos domiciliares naturais são de responsabilidade dos municípios onde os óbitos ocorreram (BRASIL, 2009a) os óbitos domiciliares naturais definidos devem ser atestados por médicos das unidades básicas de saúde (UBS) responsáveis pelas regiões onde ocorreram os óbitos ou por médicos de Outras Unidades Municipais de Saúde (Pronto Atendimentos Municipais) mais próximos do local onde o óbito ocorrera. Os óbitos naturais definidos ocorridos em hospitais ou em outras unidades de saúde (Pronto Atendimentos não Municipais, Hospitais Particulares, Manicômios) devem ser atestados por médicos assistentes, substitutos ou mesmo pela direção técnica médica da unidade.

Independente do local de ocorrência, óbitos naturais mal definidos com ou sem assistência médica, sem evidências confirmadas ou suspeitas de morte por causas externas, devem ser atestados por médicos do SVO, quando o local de ocorrência possuir cobertura deste serviço. Óbitos por causas externas definidas ou suspeitas devem ser obrigatoriamente atestados por médicos legistas. Óbitos naturais definidos ou mal definidos ocorridos em locais onde não existe médico, a DO pode ser solicitada ao cartório de registro civil pelo responsável pelo falecido, acompanhado de duas testemunhas (BRASIL, 2009a).

Para óbitos aparentemente naturais mal definidos em locais onde não existe SVO, os médicos das unidades de saúde, caso suspeitem que a causa da morte não seja evidentemente natural, deve acionar a autoridade policial local para que juntos, médicos e autoridades policiais, definam a natureza do óbito: causa externa suspeita com encaminhamento ao IML mais próximo ou 
causa natural com emissão de DO pelo médico da unidade de saúde mais próxima.

Ao declarar as informações obituárias sobre o cadáver o médico produz uma DO. Nos cartórios de registros civis, as informações contidas na segunda via da DO (amarela) são utilizadas para elaboração da certidão de óbito legalizando o sepultamento. Para o Ministério da Saúde a "Declaração de Óbito" é o documento a ser passado pelo médico. Fazer da declaração de óbito uma ferramenta epidemiológica, na coleta de dados completos e fidedignos, para produzir estatísticas vitais confiáveis sobre mortalidade, permanece um desafio para o Ministério da Saúde e para a Organização Mundial da Saúde (LAURENTI; MELLO JORGE, 1996).

A emissão de declarações de óbitos para mortes domiciliares é de responsabilidade do município de ocorrência do falecimento (BRASIL, 2009a). Em 2009, na cidade Palmas, capital do Estado do Tocantins, foi criado o Plantão de Óbitos da Prefeitura (POP) com a missão de atestar casos de óbitos naturais definidos constatados em domicílios pelo Serviço de Atendimento Móvel de Urgências.

Para casos de óbitos domiciliares em Palmas o médico do POP analisa os óbitos naturais constatados pelo SAMU e emite a DO para casos de óbitos naturais definidos e nos casos de óbitos naturais mal definidos o médico do POP, após autorização familiar, encaminha o caso ao SVO para exame necroscópico e emissão de DO. A implantação do POP tende a preservar as unidades de resgate do SAMU para atendimentos exclusivos de emergências. O fluxo de atendimento para óbito domiciliar estabelecido entre SAMU, POP e SVO caracteriza as responsabilidades dos diferentes emissores de DO.

A definição dos papeis dos atores que lidam com a constatação e emissão de DO (Figura 1) ratificam a extrema importância das informações sobre mortalidade para o planejamento de ações públicas, o desenvolvimento da gestão da saúde e a realização de estudos epidemiológicos. Torna-se também subsídio para análise de estatística vital, ensino e pesquisa (ZILMER et al, 2010). 
Republica Federativa do Bras Ministério da Saúde $1 *$ VIA - SECRETARIA DE SAUUDE

3) Dos

11] Nome do Palacio

1.20 Nomo do pas

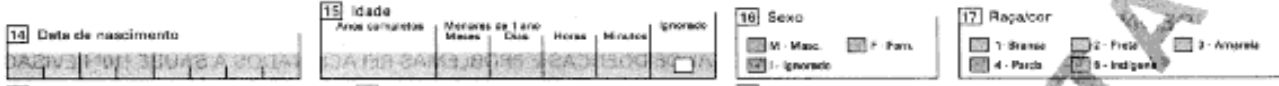
国 Lriasuc divil

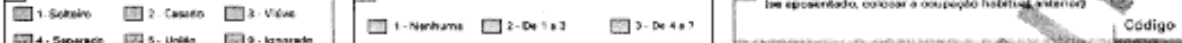

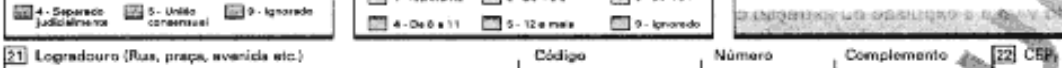

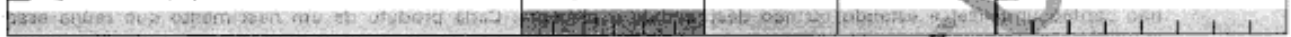

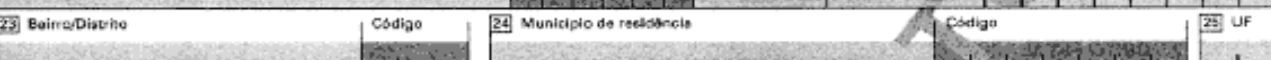

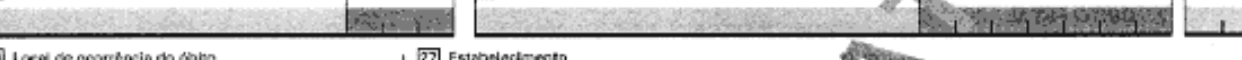

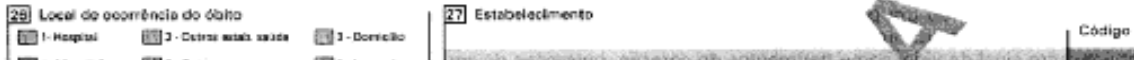

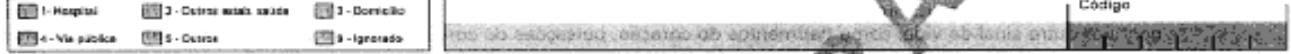

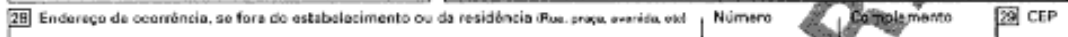

IV

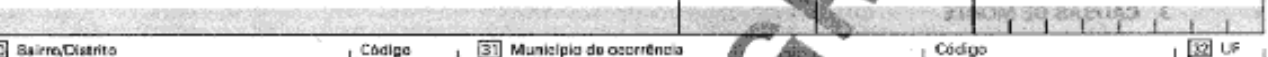

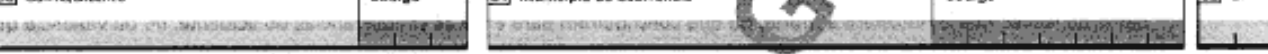

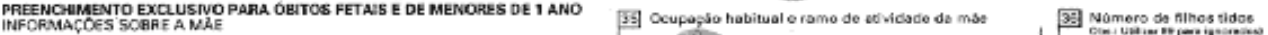

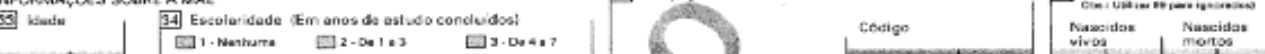

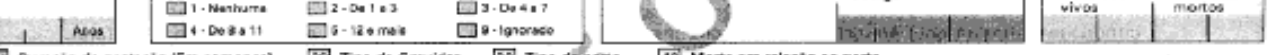

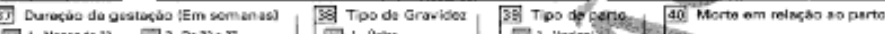

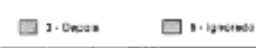

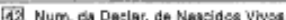

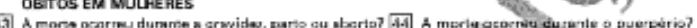

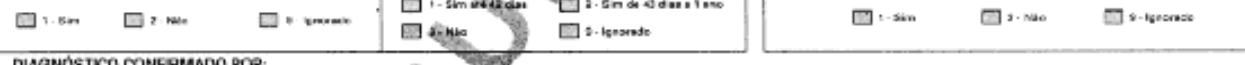

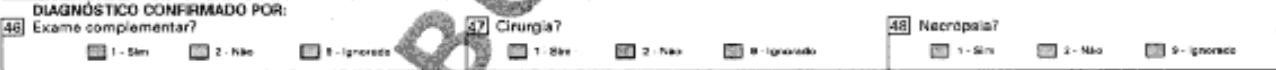

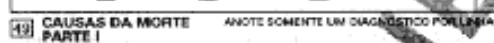

v

caules entrosents

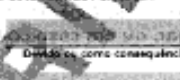

sascingit:

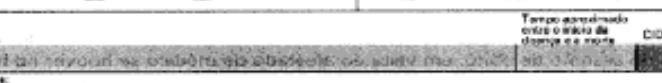

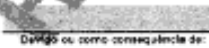

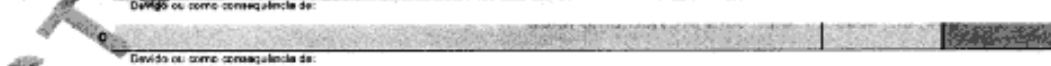

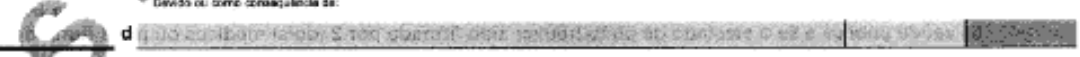
PARTE II

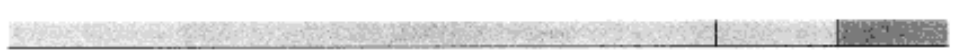
tom

50 Nomon do medion

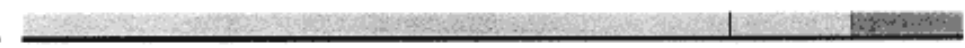

VII

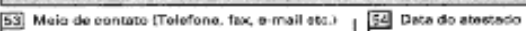

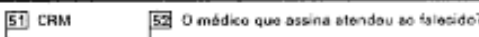

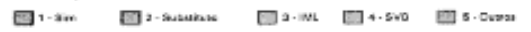

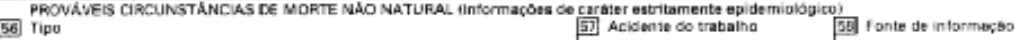

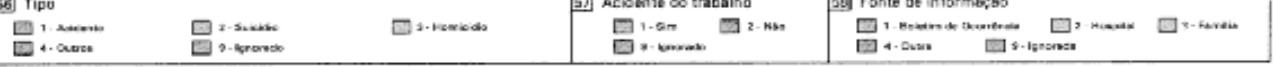

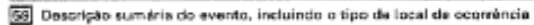

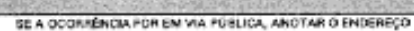

Figura 1- Frente da Declaração de Óbito

Fonte: M.S. 


\subsection{Serviços de Verificação de Óbitos}

Desde os séculos $\mathrm{XV}-\mathrm{XVI}$, os exames necroscópicos são realizados. Durante a denominada "fase orgânica da patologia", o médico patologista Giovanne Baptiste Morgagni idealizou a correlação dos achados necroscópicos com os achados clínicos como mecanismo de explicação e entendimento para as moléstias (MARCO, 1999).

Diversos estudos apontam que as necropsias favorecem um melhor diagnóstico sobre a real causa da morte e os mecanismos associados, sendo também um instrumento que pode auxiliar na avaliação da qualidade da assistência médica (CENTERS FOR DISEASE CONTROL AND PREVENTION, 2001).

Países como Estados Unidos conseguiram reduzir as estatísticas de óbitos classificados como "mal definidos", mesmo com a gradativa redução do número de necropsias em hospitais e instituições de ensino, de $42 \%$ para $10 \%$ desde a década de 1960. O declínio do número de exames necroscópicos pode ser explicado pelo avanço dos métodos diagnósticos, pela dificuldade em conseguir permissão familiar para a realização de necropsias e pelo temor dos médicos em relação a medidas legais decorrentes da discrepância entre os diagnósticos, tratamentos realizados e a causa da morte revelada após necropsia (HOYERT, 2001).

$\mathrm{Na}$ década de 30, os primeiros incentivos do Ministério da Saúde para a criação dos Serviços de Verificação de Óbitos regulamentaram a criação do primeiro SVO do país na capital paulista, por meio do Decreto Estadual 4.967 de 1931. Elucidar as causas de óbitos mal definidas com ou sem assistência médica eram os principais objetivos, porém o SVO foi rotulado por médicos apenas como emissor de declarações de óbitos (LAURENTI; MELLO JORGE; GOTLIEB, 2006).

Em 2006, a portaria 1.405 do Ministério da Saúde, criou a rede nacional de serviço de verificação de óbitos com finalidade de elucidar causas de óbitos naturais "mal definidos" com ênfase em casos com interesse epidemiológico (BRASIL, 2006b). Nas regiões que contavam com esse serviço, as causas de óbitos naturais mal definidas seriam encaminhadas para preenchimento da DO por médicos patologistas, geralmente após o esclarecimento necroscópico das 
causas de mortalidade e de morbidade. Para óbitos com suspeita ou confirmação de causa externa, seria cumprida a obrigatoriedade de encaminhá-los ao Instituto Médico Legal (IML), para averiguação necroscópica por médicos legistas (BRASIL, 1941).

Apesar de existirem poucos estudos sobre o impacto do SVO como fornecedor de dados ao SIM (NASCIMENTO et al, 2012), os SVO permitem a realização de diagnóstico isolado ou surtos de doenças emergentes, reemergentes e ainda agravos inusitados, bem como permite o aprimoramento da qualidade das informações sobre mortalidade e morbidade (ELLINGER; BEZERRA, 2011).

Os dados que alimentam o SIM proveniente do SVO advêm de informações extraídas de declarações de óbitos atestadas por médicos necropsistas. Realizada a necropsia, pressupõe-se que o médico necropsista obtenha mais informações sobre as circunstâncias da morte e produza maior quantidade e qualidade de informações ao SIM por meio de elaboração de declaração de óbito com maior completude de dados, além de maiores especificações desses dados, mormente das causas relacionadas ao óbito (REIS; CORDEIRO; CURY, 2006; STUQUE; CORDEIRO; CURY, 2003).

No Estado de São Paulo, as frequentes causas de óbitos indeterminadas suscitaram uma Diretriz Policial com intuito de imbuir às autoridades policiais a prerrogativa de classificarem óbitos de acordo suas convicções jurídicas e convencimentos formados por meio dos elementos disponíveis.

Dentre os casos de óbitos classificados como "Morte Suspeita" existem os casos de "Morte Natural" para os quais, nos Boletins de Ocorrência, deverão constar históricos fáticos e jurídicos sobre situações de óbitos verificados em domicílios, com ou sem assistência de familiares ou responsáveis, porém ausentes de atendimentos atuais por profissionais médicos ou simples inexistência de médicos para atestarem as causas de mortes.

Para estes casos de óbitos domiciliares de "Morte Natural" a Diretriz Policial prevê o encaminhamento aos Serviços de Verificação de Óbitos como se segue:

DGP 14- Artigo 3o - Será empregado o título "Morte Natural" para os casos de óbitos verificados no domicílio da vítima, ou com a assistência de familiares ou responsáveis, de causas aparentemente 
Introdução

naturais, porém ausente atendimento atual por profissional de saúde ou inexistente médico a atestar a causa da morte, com a decorrente necessidade de encaminhamento ao Serviço de Verificação de Óbito (PORTARIA DGP/SP №14, 2005).

A história da verificação necroscópica no Estado do Tocantins, tanto para causas externas quanto para causas naturais, indica que até 2006 a investigação era realizada por médicos legistas dentro dos Institutos Médicos Legais subdivididos em 14 núcleos estaduais. O grande número de causas básicas naturais mal definidas informadas no SIM pelo IML contribuía negativamente para as estatísticas vitais estaduais, justificando a idealização de um Serviço de Verificação de Óbitos Estadual que ocorreu em 2007, consoante com criação da Rede Nacional de Serviços de Verificação de Óbitos.

A portaria 119 de junho de 2007 documentou a criação de um SVO estadual, porém subordinado ao IML Estadual. As execuções dos exames necroscópicos permaneceram sob a responsabilidade de médicos legistas não patologistas, pela carência de médicos patologistas registrada no Conselho Regional de Medicina (CRM-TO), persistindo altos números absolutos de causas básicas naturais mal definidas.

As diferenças ente IML e SVO são descritas em portarias ministeriais, código de processo penal e em resoluções do Conselho Federal de Medicina (CFM). O SVO é órgão responsável por elucidar causas de óbitos naturais mal definidos, enquanto o IML investiga e elucida causas de óbitos por causas externas. (CONSELHO FEDERAL DE MEDICINA, 2005; BRASIL, 2009c; BRASIL, 1941; BRASIL, 2006b).

Entretanto, para a população em geral, para profissionais da área de saúde e mesmo para a classe médica, essas diferenças não estão muito claras, mormente a presença de casos de óbitos por causas externas encaminhados para exames necroscópicos ao SVO noticiados pela imprensa (NOROESTE, 2015). Óbitos suspeitos de erros médicos examinados pelo SVO, que necessitaram exumação pelo IML para especificação da causa de morte, encontram-se também noticiados (JUNDIAí, 2016) e mesmo casos noticiados de cadáveres em estado de decomposição encaminhados ao SVO para elucidação da causa do óbito (CARIRI, 2016). Os Serviços de Verificação de Óbitos são, por vezes, confundidos com outros serviços de plantões médicos 
que apenas emitem as declarações de óbito para causas de óbitos naturais definidas, sem realização de necropsia (CEARÁ, 2016).

\subsection{Completude de dados}

Completude de dados representa o grau de preenchimento de variáveis ou campos analisados no SIM, mesurado pela presença de dados dentro das variáveis com distinção daquelas variáveis desprovidas de dados (FÉLIX et al, 2012). Informações médicas descritas nas DO transformam-se em dados no SIM.

As estatísticas de mortalidade são de grande valia para subsídio dos indicadores de saúde, entretanto a existência de óbitos de causas mal definidas acarreta lacunas no conhecimento das verdadeiras condições de mortalidade (MELLO JORGE et al, 1992). No mundo, dois terços (38 milhões) de 57 milhões de mortes anuais não são registradas e a OMS recebe apenas dados estatísticos confiáveis sobre mortalidade de 31 dos 193 estados membros. (WHO, 2008)

A Organização Mundial de Saúde (OMS) relata que dados de mortalidade de muitos países permanecem não confiáveis para serem utilizados na elaboração de políticas públicas de saúde, persistindo urgente necessidade de melhoria nos sistemas de informação de mortalidade principalmente em países emergentes (COLIN et al 2005; PAES, 2007). Devido às barreiras que tornam falíveis e incompletos os dados do sistema de estatística vital, estes acabam sendo subutilizados em vários países da América Latina.

No Brasil, mesmo o Instituto Brasileiro de Geografia e Estatísticas (IBGE), uma das principais instituições oficiais para compilação e processamento de dados, descarta o uso do sistema de estatísticas vitais devido a não confiabilidade dos registros (PAES, ALBUQUERQUE, 1999). O SIM, apesar de enfrentar obstáculos relacionados à qualidade das informações e à incompletude dos dados, exibe sensível melhora (MENDONÇA, DRUMOND, CARDOSO, 2010). O declínio das subnotificações reflete os esforços para o aprimoramento do SIM nos níveis municipais, estaduais e federais (MELLO JORGE, GOTLIEB, LAURENTI, 2007). 


\subsection{Perfil Social e Demográfico do Tocantins}

O Estado do Tocantins foi criado em 05 de Outubro de 1988, pelo Artigo 13 do Ato das Disposições Constitucionais Transitórias da Constituição da República Federativa do Brasil.

Compreende $7,21 \%$ do território da região Norte do Brasil, abrangendo $277.720 .569 \mathrm{~km}^{2}$ Faz limites ao Norte com os Estados do Maranhão e do Pará, ao Leste com os Estados do Maranhão, Piauí e Bahia, ao sul com o Estado de Goiás e ao oeste com os Estados do Pará e do Mato Grosso. A população total cresceu menos de $2 \%$ ao ano de 2010 à 2012 e 78,8\% vive predominantemente na zona urbana (SEPLAN, 2015) (Tabela 1).

Tabela 1 - População total do Estado do Tocantins por Situação de Domicílio 2010 A 2014.

\begin{tabular}{ccccccc}
\hline Ano & $\begin{array}{c}\text { População } \\
\text { Total }^{*}\end{array}$ & $\begin{array}{c}\text { Taxa de } \\
\text { crescimento }\end{array}$ & Urbana & \%Urbana & Rural & $\begin{array}{c}\% \\
\text { Rural }\end{array}$ \\
\hline 2010 & 1.383 .445 & 1,80 & 1.090 .106 & 78,80 & 293.339 & 21,20 \\
2011 & 1.400 .892 & 1,26 & 1.103 .854 & 78,80 & 297.038 & 21,20 \\
2012 & 1.417 .694 & 1,20 & 1.117 .093 & 78,80 & 300.601 & 21,20 \\
2013 & 1.478 .164 & 4,27 & 1.164 .741 & 78,80 & 313.423 & 21,20 \\
2014 & 1.496 .880 & 1,27 & 1.179 .541 & 78,80 & 317.339 & 21,20 \\
\hline
\end{tabular}

Fonte: IBGE/Censos Demográficos/SEPLAN-TO/Diretoria de Pesquisa e Informações Econômicas

Nota: *Estimativas de População IBGE. Para a População Urbana e Rural de 2011 e 2012, foram usadas as mesmas proporções do Censo 2010.

A estrutura etária da população é predominantemente composta por cidadãos de 15 a 59 anos, seguida por menores de 15 anos e por 60 anos ou mais. O sexo masculino é majoritário e o índice de envelhecimento da população é de $29,54 \%$, a população economicamente ativa maior de 15 anos de idade encontra-se ocupada na atividade agrícola, na indústria e na indústria de transformação (Figura 2) (Tabela 2). 
Introdução

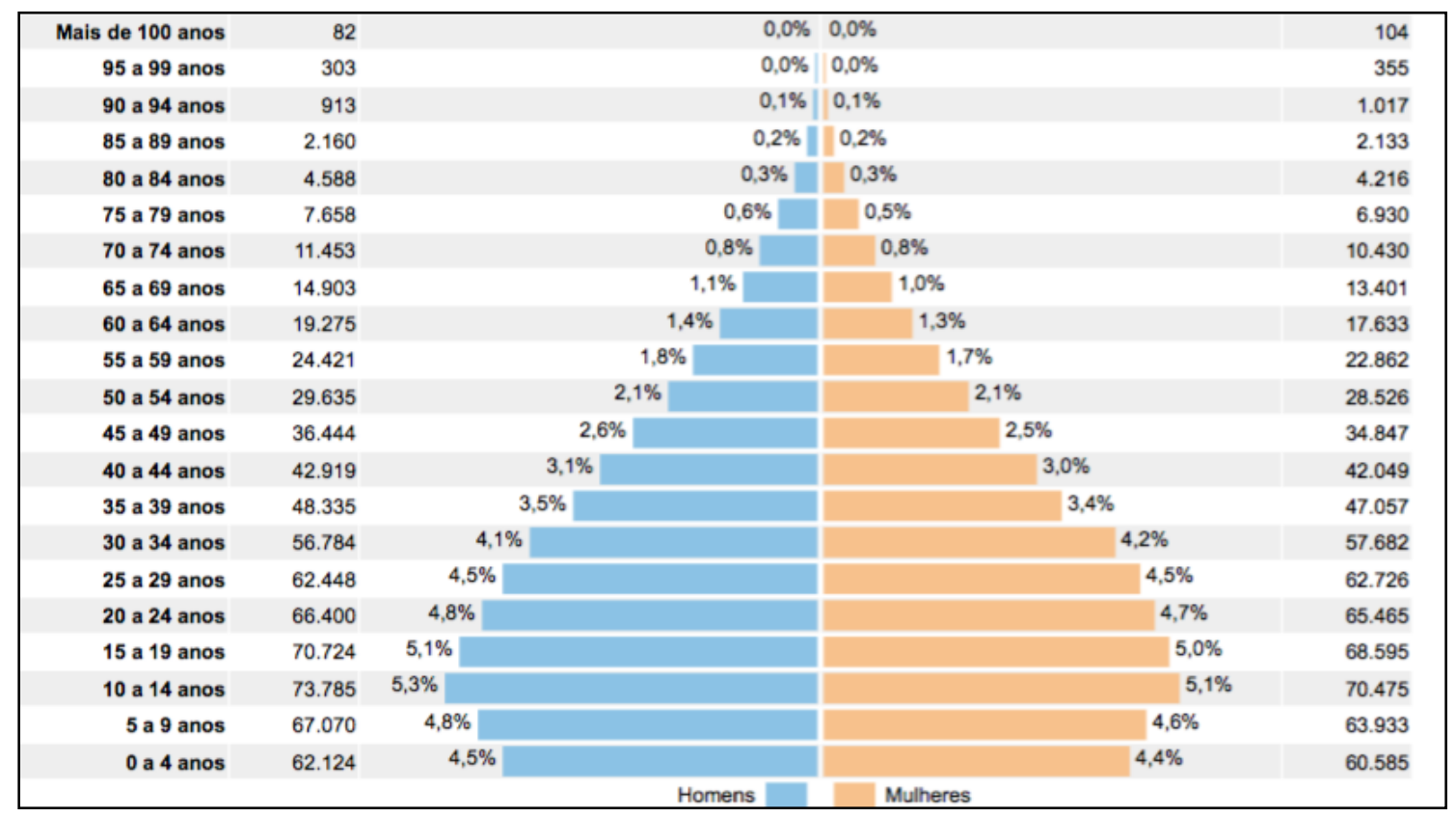

Figura 2 - Distribuição da população por sexo, segundo os grupos de idade -Tocantins - 2010.

Fonte: IBGE/PNAD2013/SEPLAN-TO/Diretoria de Pesquisa e Informações Econômicas.

Tabela 2 - Pessoas de 15 anos ou mais de idade, ocupadas na semana de referência, por contribuição para instituto de previdência no trabalho principal, Segundo os grupamentos de atividade do trabalho principal - Tocantins - 2013 .

\begin{tabular}{l|c|c|c}
\hline \multirow{2}{*}{ Grupamentos de atividade do trabalho principal } & \multirow{2}{*}{ Total } & \multicolumn{2}{|c}{$\begin{array}{c}\text { Pessoas de 10 anos ou mais de idade, ocupadas na se- } \\
\text { mana de referência (1000 pessoas) Contribuição para } \\
\text { instituto de previdência no trabalho principal }\end{array}$} \\
\cline { 3 - 4 } & & Contribuintes & Não contribuintes \\
\hline Total ${ }^{*}$ & 677 & 302 & 375 \\
\hline Agrícola & 210 & 23 & 187 \\
Indústria & 40 & 22 & 18 \\
Indústria de transformação & 36 & 19 & 17 \\
Construção & 62 & 20 & 43 \\
Comércio e reparação & 113 & 63 & 50 \\
Alojamento e alimentação & 23 & 11 & 12 \\
Transporte, armazenagem e comunicação & 22 & 12 & 10 \\
Administração pública & 58 & 56 & 2 \\
Educação, saúde e serviços sociais & 81 & 77 & 4 \\
Serviços domésticos & 45 & 11 & 33 \\
Outros serviços coletivos, sociais e pessoais & 23 & 7 & 16 \\
Outras atividades & - & - & - \\
Atividades maldefinidas & - & - & - \\
\hline Fonte: IBGE/PNAD2013/SEPLAN-TO/Dirres &
\end{tabular}

Fonte: IBGE/PNAD2013/SEPLAN-TO/Diretoria de Pesquisa e Informações Econômicas

O Produto Interno Bruto (PIB) do Tocantins evoluiu de 11 bilhões de reais em 2007 para 23 bilhões em 2014 e o PIB "per capita" anual passou de 8.921 reais para 15.990 reais neste mesmo período (Tabela 2). A agropecuária predomina seguida pela indústria e pelo setor de serviços, dentre os valores agregados brutos por setores de atividades (SEPLAN, 2015) (Tabelas 3 e 4). 
Tabela 3 - Produto Interno Bruto - PIB do Tocantins 2007 a 2014.

\begin{tabular}{lrrrrrrrr}
\hline PRODUÇÃO & $\mathbf{2 0 0 7}$ & $\mathbf{2 0 0 8}$ & $\mathbf{2 0 0 9}$ & $\mathbf{2 0 1 0}$ & $\mathbf{2 0 1 1}$ & $\mathbf{2 0 1 2}$ & $\mathbf{2 0 1 3}^{*}$ & $\mathbf{2 0 1 4}$ \\
\hline PIB (R\$ 1.000.000) & 11.094 & 13.090 & 14.571 & 17.240 & 18.059 & 19.530 & 21.573 & 23.936 \\
PIB per capita anual (R\$) & 8.921 & 10.223 & 11.278 & 12.462 & 12.891 & 13.776 & 14.595 & 15.990 \\
Taxa de crescimento real (\%) & $\mathbf{4 , 6 8}$ & $\mathbf{6 , 0 9}$ & $\mathbf{3 , 8 0}$ & $\mathbf{1 4 , 2 0}$ & $\mathbf{6 , 3 8}$ & $\mathbf{4 , 3 7}$ & $\mathbf{4 , 3 0}$ & $\mathbf{4 , 2 7}$ \\
\hline
\end{tabular}

Fonte: IBGE/SEPLAN-TO/Diretoria de Pesquisa e Informações Econômicas

Tabela 4 - Valor Agregado Bruto por setores de atividade no Tocantins - 2007 a 2012.

\begin{tabular}{lccccccccccc}
\hline Setor de Atividade & $\mathbf{2 0 0 7}$ & $\mathbf{( \% )}$ & $\mathbf{2 0 0 8}$ & $\mathbf{( \% )}$ & $\mathbf{2 0 0 9}$ & $\mathbf{( \% )}$ & $\mathbf{2 0 1 0}$ & $\mathbf{( \% )}$ & $\mathbf{2 0 1 1}$ & $\mathbf{( \% )}$ & $\mathbf{2 0 1 2}$ \\
\hline Agropecuária & 1.796 & 17,8 & 2.474 & 20,8 & 2.759 & 20,6 & 2.860 & 18,1 & 2.817 & 17,1 & 2.886 \\
Indústria & 2.430 & 24,1 & 2.805 & 23,6 & 3.047 & 22,8 & 4.002 & 25,4 & 3.532 & 21,5 & 3.398 \\
Serviços & 5.856 & 58,1 & 6.616 & 55,6 & 7.563 & 56,6 & 8.918 & 56,5 & 10.107 & 61,4 & 11.392 \\
Total & $\mathbf{1 0 . 0 8 2}$ & $\mathbf{1 0 0}$ & $\mathbf{1 1 . 8 9 6}$ & $\mathbf{1 0 0}$ & $\mathbf{1 3 . 3 6 8}$ & $\mathbf{1 0 0}$ & $\mathbf{1 5 . 7 8 0}$ & $\mathbf{1 0 0}$ & $\mathbf{1 6 . 4 5 6}$ & $\mathbf{1 0 0}$ & $\mathbf{1 7 . 6 7 6}$ \\
\hline
\end{tabular}

Fonte: IBGE/SEPLAN-TO/Diretoria de Pesquisa e Informações Econômicas

Para o triênio 2010, 2011 e 2012, as estatísticas de registro civis revelaram 70.094 nascidos vivos com 69.144 nascidos em hospitais e 818 nascidos vivos em domicílios tocantinenses, considerando o local de residência da mãe. Houve 18.735 óbitos não fetais e maiores de 1 ano no Estado do Tocantins, 11.626 faleceram em hospitais e 4.775 em domicílios naquele mesmo período (Tabela 5).

Tabela 5 - Registro Civil no Estado do Tocantins - 2009 a 2012.

\begin{tabular}{|c|c|c|c|c|c|}
\hline & 2009 & 2010 & 2011 & 2012 & \\
\hline Nascidos vivos -ocorridos no ano- - por lugar de residência da mãe & 23.085 & 22.955 & 23.766 & 23.373 & pessoas \\
\hline $\begin{array}{l}\text { Nascidos vivos em hospital - ocorridos no ano - por lugar de residên- } \\
\text { cia da mãe }\end{array}$ & 22.762 & 22.659 & 23.429 & 23.056 & pessoas \\
\hline $\begin{array}{l}\text { Nascidos vivos em Domicílio - ocorridos no ano - por lugar de resi- } \\
\text { dência da mãe }\end{array}$ & 282 & 254 & 289 & 275 & \\
\hline Casamentos - registrados no ano - lugar do registro & 7.310 & 6.534 & 6.618 & 7.253 & casamentos \\
\hline Óbitos - ocorridos no ano & 5.706 & 6.225 & 6.268 & 6.242 & pessoas \\
\hline Óbitos em hospital - ocorridos no ano & 3.495 & 3.816 & 3.860 & 3.950 & pessoas \\
\hline Óbitos em domicílio - ocorridos no ano & 1.516 & 1.639 & 1.624 & 1.512 & pessoas \\
\hline $\begin{array}{l}\text { Óbitos - ocorridos no ano - menores de } 1 \text { ano - lugar de residência do } \\
\text { falecido }\end{array}$ & 295 & 273 & 275 & 255 & pessoas \\
\hline $\begin{array}{l}\text { Óbitos fetais - ocorridos e registrados no ano - lugar de residência da } \\
\text { mãe }\end{array}$ & 180 & 162 & 211 & 169 & pessoas \\
\hline $\begin{array}{l}\text { Separações judiciais - concedidas no ano - em 1a instância -por Na- } \\
\text { tureza e Fundamento da Ação- lugar da ação do processo }\end{array}$ & 411 & 217 & 41 & 30 & separações \\
\hline $\begin{array}{l}\text { Divórcios - concedidos no ano - em 1a instância - sem recurso por } \\
\text { tipo e natureza }\end{array}$ & 1.185 & 1.023 & 1.921 & 1.855 & divórcios \\
\hline Divórcios por escritura pública - tabelionatos de notas & 426 & 729 & 886 & 862 & divórcios \\
\hline
\end{tabular}

Fonte: IBGE - Estatística do Registro Civil e Censo 2010/SEPLAN-TO/Diretoria de Pesquisa e Informações Econômicas 
Introdução

Em 2010, a maior taxa de analfabetismo era $17,14 \%$ para a população acima de 25 anos de idade, enquanto a menor taxa era 2,05\% para a população entre 15 a 17 anos de idade. Neste mesmo ano, o menor percentual de frequência educacional era de $14,16 \%$ para a população entre 25 a 29 anos de idade e a maior era 97,02\% para a população entre 06 e 14 anos (SEPLAN, 2015).

O Índice de Desenvolvimento Humano (IDH) representa uma forma resumida de medir o progresso em longo prazo considerando renda, educação e saúde. O objetivo do IDH consiste em oferecer uma alternativa a outro indicador muito utilizado, o Produto Interno Bruto (PIB) per capita, que considera apenas a dimensão econômica do desenvolvimento. O IDH permite classificar os países em desenvolvidos, em desenvolvimento e subdesenvolvidos (BRASIL, 2016b).

O IDH para o Brasil passou de 0,752 em 2013 para 0,755 em 2014, porém apesar do aumento o Brasil ocupa o $75^{\circ}$ lugar no ranking mundial de desenvolvimento humano entre 188 países. Em 2015 o país foi ultrapassado pelo Sri Lanka, queda explicada pela redução do ritmo de crescimento do país naquele ano (AGÊNCIA BRASIL, 2015). No Tocantins o IDH passou de 0,369 em 1991 para 0,699 em 2010 (SEPLAN, 2015).

Segundo o Atlas do Desenvolvimento Humano no Brasil, em 2010 a escolaridade do Estado do Tocantins apresentava percentual de 74,76\% referente a população de 18 a 24 anos com ensino fundamental completo e $10,25 \%$ referente a população de 25 anos ou mais com ensino superior completo (SEPLAN, 2015).

A taxa de mortalidade infantil para os anos de 2010, 2011 e 2012 apresentaram os respectivos percentuais regressivos de 19,39, 18,69 e,18,04 por mil nascidos vivos. Para o ano de 2015 a taxa de mortalidade foi de 16,32 por mil habitantes. A taxa bruta de mortalidade para o triênio 2010, 2011, 2012 foi de 5,62, 5,59 e 5,57 por mil habitantes e para o ano de 2015 foi de 5,56 por mil habitantes (SEPLAN, 2015).

O número total de leitos para o ano de 2014 era de 2.550 divididos em 2.147 públicos e 403 privados. Em 2013, havia 5.220 técnicos e auxiliares de enfermagem, 1.522 enfermeiros, 945 odontólogos e 2.350 médicos. O número 
Introdução

de médicos por 10.000 habitantes passou de 9,51\% em 2007 para 9,66\% em 2011 (SEPLAN, 2015).

Para garantir o acesso resolutivo e de qualidade à rede de saúde constituída por ações e serviços da atenção primária, vigilância à saúde, atenção psicossocial, urgência e emergência, atenção ambulatorial especializada e hospitalar foram organizadas pelo SUS as regiões de saúde por meio do Decreto 7.508-11 pelo Estado e pelos municípios para representar um espaço privilegiado de gestão (BRASIL, 2014).

O Decreto 7.508/11 estabelece a organização do SUS em Regiões de Saúde, instituídas pelos Estados em articulação com os seus municípios. O objetivo é garantir o acesso resolutivo e de qualidade à rede de saúde constituída por ações e serviços de atenção primária, vigilância à saúde, atenção psicossocial, urgência e emergência, atenção ambulatorial especializada e hospitalar além de efetivar o processo de descentralização, com responsabilização compartilhada, favorecendo a ação solidária e cooperativa entre os entes federados (BRASIL, 2014).

No Tocantins foram criadas oito regiões de saúde: Região de Saúde Bico do Papagaio, Médio Norte Araguaia, Cerrado Tocantins Araguaia, Cantão, Capim Dourado, Amor Perfeito, llha do Bananal e Sudeste (Figura 3) (TOCANTINS, 2016). 
Introdução

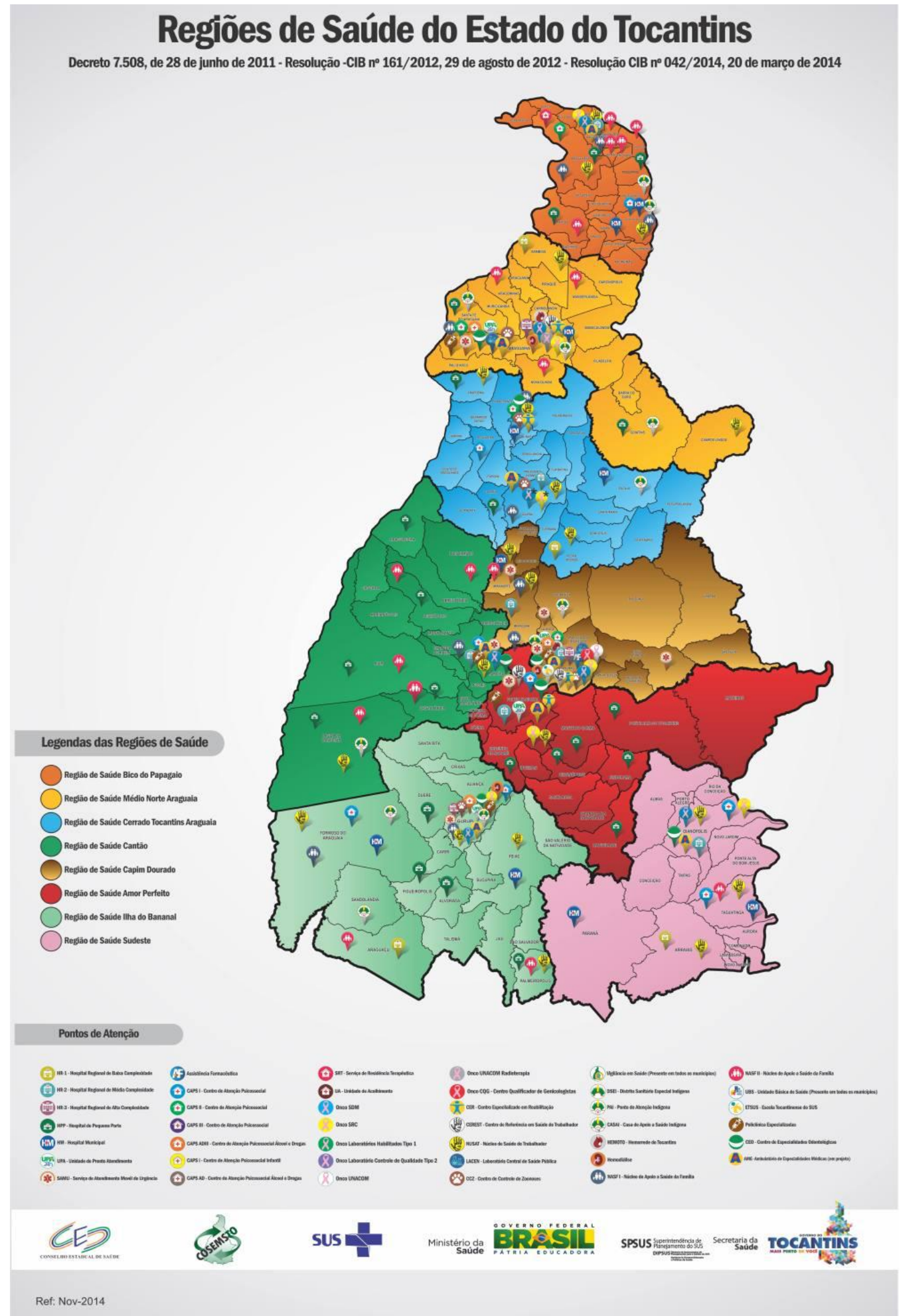

Figura 3 - Regiões de Saúde do Estado do Tocantins - Decreto 7.508, de 28 de junho de 2011 - Resolução CIB n 161/2012, 29 de agosto de 2012 Resolução CIB no 42/2014, 20 de março de 2014.

Fonte: IBGE/PNAD2013/SEPLAN-TO/Diretoria de Pesquisa e Informações Econômicas 


\subsection{Causas Básicas de Óbitos}

Segundo LAURENTI et al. (2006) a "Causa Básica de Morte" é a doença ou lesão que iniciou a cadeia de acontecimentos patológicos que conduziram diretamente à morte, ou as circunstâncias do acidente ou violência que produziram a lesão fatal.

A Classificação Internacional de Doenças (CID) foi construída no passado baseada em apresentações de mortalidade por "causa básica de óbito". Desde a primeira classificação em 1893, houve modificações nos códigos, maior difusão da CID e gradativo reconhecimento da importância da classificação das doenças para a elaboração de estatísticas vitais (SAUDE, 2007).

Nos países em desenvolvidos, os números mostram uma melhora na qualidade dos dados de vitalidade a cada ano, chegando a menos de $1 \%$ de óbitos com causas mal definida (MATHERS et al., 2001).

Após codificação, as informações referentes às causas de morte oriundas das declarações de óbitos são lançadas na plataforma do SIM, conhecida como "Seletor de Causa Básica (SCB)". O SCB analisa as informações sobre mortalidade e morbidade seguindo as regras de seleção de causa básica. A linha A representa causas de morte, as causas intermediárias são representadas pelas linhas B e C, e a causa básica descrita na linha D. É selecionada uma única causa básica primária de óbito, que é a lesão que desencadeou os acontecimentos que causaram diretamente a morte, podendo ser classificada em um grupo na CID (MENDONÇA et al., 1994).

Contudo, para que o sistema de informações funcione, é importante o preenchimento adequado da DO e ausência de falhas humanas nas transferências dos dados para a plataforma. A análise retrospectiva de diversos indicadores de qualidade dos dados sobre mortalidade, dentre os quais a proporção de mortes classificadas como mal definidas enviadas à OMS, classificou o Brasil entre os países com dados de qualidade intermediaria (MATHERS et al., 2005).

Concomitante à implantação do SIM, alguns conceitos básicos foram estabelecidos para que as estatísticas vitais pudessem ser comparadas em níveis regionais, nacionais e internacionais. Estes conceitos básicos 
denominados de "Eventos Vitais" foram estabelecidos no Brasil utilizando os conceitos básicos da OMS. Os principais eventos vitais são o "Nascimento vivo", o "Óbito fetal", as "Causas da Morte" e a "Causa Básica da Morte" (LAURENTI et al., 2006).

No Brasil, em meados da década de 80 as causas mal definidas de óbitos constituíam cerca de $20 \%$ dos registros totais de causas de óbitos. A Organização Pan-americana para a Saúde (OPAS) recomendava, neste mesmo período, melhor esclarecimento das causas de óbitos por meio de aperfeiçoamento dos sistemas de informação. A OPAS orientava ainda a sensibilização de gestores da saúde pública e das instituições de ensino médico quanto a importância da fidedignidade dos indicadores de saúde no Brasil (LAURENTI et al., 2006).

No ano de 2003 a principal causa de óbito no Brasil foi definida como causa externa (13\%) (OLIVEIRA, 2007). Segundo parâmetros da OMS mortes com causas básicas externas devem ser registradas de acordo com o capitulo XX do CID-10 (MELLO JORGE et al., 2002). O Artigo no 162 do Código de Processo Penal brasileiro preconiza que, para toda causa de morte externa ou até mesmo suspeita de violência, a DO será fornecida por um médico perito do IML, após exame necroscópico (BRASIL, 1941).

Em 2005 o Ministério da Saúde deu inicio a um projeto de melhoria na qualidade dos dados sobre mortalidade, com ênfase para as regiões norte e nordeste. Dentre as ações buscou contratar apoiadores para os estados, desenvolver instrumentos para elucidação de óbitos com causas mal definidas, relacionar os registros do SIM com os demais sistemas de informação, monitorar continuamente os resultados das investigações de óbito, além de projeto de qualificação dos médicos para preenchimento da DO (FRANÇA et al., 2014).

As estatísticas de mortalidade brasileiras no ano 2013 revelaram que 13,3 \% das informações sobre "causas básicas" de mortes obtidas por meio das DO foram classificadas como mal definidas com índices proporcionalmente maiores nas regiões Norte e Nordeste. A região Norte do Brasil apresentou $13,5 \%$ e a região Nordeste $18,9 \%$ das "causas básicas" classificadas como mal definidas (SANTO, 2008). Estudo realizado na região nordeste revelou que a 
proporção de óbitos mal definidos se manteve acima de 20\% de 1980 a 2003. (MARTINS et al., 2005).

No Estado do Tocantins o percentual de causas mal definidas é de $7 \%$, bem abaixo da média nacional. Dentre os municípios tocantinenses 70\% apresentam índices de até $10 \%$ de causas mal definidas e apenas $12 \%$ ou 17 municípios possuem índices maiores ou iguais à 20\% (BRASIL, 2005).

A qualidade dos dados sobre mortalidade sofre influência quando uma grande quantidade de causas básicas de óbitos é classificada como mal definida de acordo com o Capitulo XVIII da CID 10. No Brasil, a proporção de óbitos por causa mal definida representou 14\% das causas básicas em 2001. Contudo esses valores ainda são muito elevados, principalmente quando comparados com os números dos países desenvolvidos, onde menos de $1 \%$ dos óbitos são classificados como mal definidos (MATHERS et al., 2001). No ano de 2003 , cerca de $13,3 \%$ dos óbitos registrados no Brasil tiveram a causa básica de morte classificada no capítulo XVIII da CID-10, dita mal definida (SANTO, 2008).

A OMS considera que "causa externa" de óbito, ou causa de morte nãonatural corresponde a morte que sobrevém de acidentes ou de qualquer tipo de violência. Entretanto a "causa básica" externa de óbito é o produto da análise, codificação e seleção realizada pelo SIM e consiste no evento, lesão, circunstâncias do acidente ou violência que produziram a lesão fatal (LAURENTI, 1996).

Em casos de óbitos por causas externas a DO deverá ser, obrigatoriamente, emitida pelos médicos do IML. Nas localidades onde houver apenas um médico, este será o responsável pela emissão da D.O, podendo ser nomeado pela autoridade policial como perito "ad hoc" (BRASIL, 2007).

As estatísticas vitais para causas externas apresentam pouca credibilidade sobre as causas de mortalidade e de morbidade, mormente a realização das necropsias por médicos legistas. $O$ compromisso epidemiológico dos médicos legistas com as quantidades e qualidades das causas externas é pouco observado. Com base no artigo 162 do Código de Processo Penal, o legista precisa apontar uma causa legal ou jurídica da morte, isento o compromisso com morbidades de interesse epidemiológico, que porventura vier a descobrir durante o procedimento necroscópico. Os legistas 
alegam dificuldades ou impossibilidades de conhecerem as naturezas dos acidentes ou das lesões que provocaram as mortes (LAURENTI, 1996).

As causas externas de óbitos são as principais causas de óbitos dentre a população jovem no Brasil (BRASIL, 2007). A análise do perfil dos óbitos por causas externas é prejudicada pela baixa qualidade das informações sobre mortalidade (MELLO JORGE et al., 2010). As causas externas de mortalidade são a segunda causa de óbito mais prevalente no Estado do Tocantins atrás apenas das causas relacionadas a doenças do aparelho cardiocirculatório (DATASUS, 2014).

Uma revisão recente nos dados do SUS revelou que os índices de causas externas de óbitos por acidentes de trânsito aumentaram em $13 \%$ entre 2013 e 2014 no Tocantins, enquanto a média nacional cresceu 2\% (GOTHE, 2016).

\subsection{Justificativa do Estudo}

A análise dos registros no Sistema de Informação de Mortalidade para o Estado do Tocantins no período entre 2010 e 2012 permitirá avaliar a fidedignidade dos dados que servem de base para a elaboração de políticas públicas sanitárias no Estado.

O estudo da completude de dados registrados do Sistema de Informação de Mortalidade para o Estado do Tocantins entre 2010 e 2012 por codificadores após coleta de informações descritas por médicos assistentes, médicos substitutos, médicos legistas, médicos necropsistas do SVO e Outros poderá avaliar a qualidade dos dados e o compromisso de cada atestante na geração de informações sobre mortalidade e de morbidade.

A comparação da completude de dados do SVO com a completude de dados dos demais atestantes poderá determinar o impacto do SVO do Tocantins na elucidação das causas de óbitos naturais mal definidas e no cumprimento dos objetivos estabelecidos pela Rede Nacional de SVO do Ministério da Saúde no exercício da epidemiologia e promoção das políticas de saúde públicas regionais e nacionais.

O estudo dos registros sobre causas de mortalidade e morbidade de residentes no Estado do Tocantins poderá estabelecer a completude dos 
registros discriminados em cada uma das linhas contidas no bloco de informações médicas sobre as causas de morte (Linhas A, B, C e D) e morbidades (Parte II) de modo específico para cada um dos atestantes.

A avaliação das "causas básicas" de óbitos permitirá a determinação das cinco principais "causas básicas" de óbitos selecionadas pelo SIM registradas para o SVO do Tocantins e para os demais atestantes, mormente a completude total dos registros de "causas básicas" de óbitos para os 19.780 registros dentro do SIM para o Estado do Tocantins.

Por meio da avaliação dos dados registrados nas varáveis: hora do óbito, data do óbito, naturalidade, faixa etária, sexo, raça/cor, escolaridade, situação conjugal e ocupação, local de residência e local de ocorrência, todas relacionadas ao perfil social e demográfico dos óbitos de residentes no Estado do Tocantins, pretende-se elencar o perfil social e demográfico dos óbitos registrados no SIM pelo Tocantins e pelo SVO do Estado do Tocantins pertencente à Rede Nacional do Ministério da Saúde.

Estabelecendo a completude de dados dentro do SIM para o SVO do Estado do Tocantins e para os diferentes atestantes, procura-se sensibilizar a população médica que compila a base de dados de mortalidade e morbidade nas declarações de óbitos codificadas e consolidadas no SIM. O estudo pretende fortalecer a criação sustentável de uma "cultura da informação médica" capaz de elaborar estatísticas vitais críveis e realistas que possam orientar gestores na promoção de políticas epidemiológicas tocantes à sociedade.

Divulgando a análise de dados de uma instituição publica de saúde como o SVO, pretende-se refletir e avaliar a expansão e a sustentabilidade de serviços médicos de interesse epidemiológico instituídos pelo Ministério da Saúde. Em tempo, procura-se atentar aos elaboradores dos planos diretores de ensino superior na área de saúde quanto a importância de instituir nas grades e matrizes curriculares a compreensão e a capacidade analítica das informações em saúde por parte dos futuros profissionais da vigilância do óbito e da promoção sanitária. 
Objetivos

\section{OBJETIVOS}

\subsection{OBJETIVO GERAL}

Avaliar a quantidade e a qualidade das informações registradas no Sistema de Informação de Mortalidade pelo Serviço de Verificação de Óbitos do Estado do Tocantins 2010-2012.

\subsection{OBJETIVOS ESPECÍFICOS}

Avaliar a completude das informações no Sistema de Informação de Mortalidade registradas pelo Estado do Tocantins 2010-2012;

Avaliar a completude das informações no Sistema de Informação de Mortalidade registradas pelo Serviço de Verificação de Óbitos do Estado do Tocantins 2010-2012;

Elaborar o Perfil Social e Demográfico dos registros de óbitos no Sistema de Informação de Mortalidade para o Estado do Tocantins entre 20102012;

Avaliar a completude dos dados sobre as causas de mortalidade e de morbidade no Sistema de Informação de Mortalidade do Tocantins 2010-2012; 
MATERIAIS E MÉTODOS 


\section{MATERIAIS E MÉTODOS}

\subsection{Delineamento do estudo}

Estudo retrospectivo, transversal, quantitativo e qualitativo em série histórica de dados secundários em sistema de informação em saúde.

\subsection{Fonte de Dados e Variáveis do Estudo}

O SIM consiste em software desenvolvido pelo Departamento de Informação de Saúde (DATASUS) com capacidade de consolidar, analisar e disponibilizar publicamente os dados sobre mortalidade em geral.

Foram selecionados 19.780 registros de óbitos de residentes do Estado do Tocantins no período de 2010 a 2012 do Sistema de Informação de Mortalidade (SIM). Os dados do SIM estão disponíveis publicamente por meio do site (DATASUS, 2014) e foram coletados por meio de acesso virtual em agosto de 2014.

Cada óbito gera um único registro no SIM, com 90 variáveis relacionadas tanto a informações médicas, sociais e geográficas, quanto a informações codificadas no SIM. Para o estudo foram selecionadas 23 variáveis, favorecendo uma análise estatística fidedigna sobre os registros totais do SVO e dos demais atestantes (Figura 4).

1 TIPO DE ÓBITO

2 ANO DO ÓBITO

3 HORA DO ÓBITO

4 NATURALIDADE

5 DATA NASCIMENTO

6 IDADE

7 SEXO

8 RAÇA OU COR

9 ESTADO CIVIL

10 ESCOLARIDADE

11 OCUPAÇÃO

12 CÓD. MUN. RESIDÊNCIA
13 LOCAL DE OCORRÊNCIA

14 CÓD. MUN. OCORRÊNCIA

15 ASSISTÊNCIA MÉDICA

16 NECROPSIA

17 LINHA A

18 LINHA B

19 LINHA C

20 LINHA D

21 LINHA II

22 CAUSA BÁSICA

23 ATESTANTE

Figura 4- Variáveis analisadas no estudo

Fonte: SIM/Datasus 
As 23 variáveis selecionadas consistiam: tipo de óbito, data do óbito, hora do óbito, naturalidade, data de nascimento, idade, sexo, raça/cor, situação conjugal, escolaridade, ocupação, código do município de residência, local de ocorrência, código do município de ocorrência, assistência médica, necropsia, linha $A$, linha $B$, linha $C$, linha $D$, parte II, causa básica de óbito e atestante.

São variáveis correspondentes à dados codificados no SIM e relacionados à identificação do falecido: Tipo de óbito (se fetal ou não fetal), Data do óbito, Hora do óbito, Naturalidade (que corresponde aos dados sobre o município de nascimento do falecido), Data de Nascimento, Idade, Sexo Raça/Cor. A variável Situação conjugal (correspondente aos dados sobre o estado civil do falecido). Escolaridade (variável com dados codificados no SIM referente ao grau de escolaridade do falecido). A variável Ocupação (correspondente aos dados codificados no SIM sobre o tipo de trabalho que o falecido desenvolveu na maior parte de sua vida produtiva).

A variável Código do município de residência refere-se ao nome do município de residência do falecido codificado no SIM. A variável Código do município de ocorrência corresponde aos dados codificados referentes ao nome do município onde ocorreu o óbito. O variável Código do local de ocorrência corresponde aos dados referentes ao local de ocorrência do óbito: óbitos hospitalares, óbitos domiciliares, óbitos em outras unidades de saúde, óbitos em via pública, "Outros" se o óbito não ocorreu em estabelecimento de saúde, nem domicílio ou em via pública e Ignorado se não houver como saber onde ocorreu o óbito.

Os dados referentes à variável Assistência médica correspondem às condições de assistência médica dispensadas ao falecido durante a doença que ocasionou a morte. A variável Necropsia corresponde aos dados que confirmam ou não a execução do exame necroscópico por médicos dos Serviços de Verificação de Óbitos ou pelos médicos dos Institutos Médicos Legais.

A Linha A correspondente à variável sobre registros de causas de morte. Duas variáveis sobre registros de causas intermediárias de óbitos: Linhas B e Linha C. Uma variável para registros de causas básicas de óbitos: Linha D. A Parte II na DO apresenta duas linhas para descrição médica de causas de morbidades que contribuem para o óbito. 
Materiais e Métodos

Os dados contidos na variável Causa básica são produtos das informações médicas coletadas das DO que, após análises e codificações são lançadas no SIM por profissionais das secretarias de saúde municipais ou estaduais, denominados codificadores.

É ato médico constatar e atestar óbitos (CONSELHO FEDERAL DE MEDICINA, 2005). Os médicos que descrevem as informações sobre os óbitos nas DO são chamados Atestantes. Os atestantes podem ser médicos assistentes, que prestaram assistência médica prévia ao falecido, médicos substitutos, plantonistas ou prestadores de serviço de saúde que não assistiram previamente o falecido, médicos do SVO, que realizam exame necroscópico para óbitos com causas naturais mal definidas, médicos do IML, que realizam exame necroscópico para óbitos com causas externas suspeitas ou confirmadas e Outros são médicos que não se enquadram nas condições de assistentes, substitutos, SVO e IML.

As 23 variáveis selecionadas continham campos preenchidos ou não preenchidos (vazios). Foram considerados campos vazios ou não preenchidos aqueles que não apresentavam informações (incompletos) e campos preenchidos os que apresentavam alguma informação (completos).

Os dados codificados e consolidados no SIM advieram de informações compiladas por ato médico ao preencherem as $\mathrm{DO}$, entretanto os codificadores interpretaram as informações contidas nas DO e alimentaram o SIM com dados objetivos, sob a forma de códigos padronizados pelo Manual do SIM.

A presença de dados discriminados e disponibilizados no SIM como “ignorado (correspondente ao número 9)", em variáveis que possuíam a possibilidade de serem informadas como ignoradas, foram considerados como campos preenchidos e não como campos vazios ou não preenchidos.

Os dados selecionados para o estudo compreenderam os registros de óbitos não fetais. Os registros de óbitos fetais foram excluídos da análise, pois - SVO-TO não recebe óbitos fetais para exame necroscópicos em cumprimento da portaria 116 de fevereiro de 2009 (BRASIL, 2009a) e da resolução 1.779 do Conselho Federal de Medicina (CONSELHO FEDERAL DE MEDICINA, 2005). Foram excluídas as variáveis contendo dados subjetivos oriundos de informações descritivas da DO e que não apresentaram codificações no SIM. 


\subsection{Análise da Completude de Dados Gerais}

A tabulação e análise descritiva dos dados foram realizadas no software Microsoft Excel 2013. Para verificar a existência da relação entre completude dos dados com o atestante, foi utilizado o teste de independência QuiQuadrado, considerando-se estatisticamente significativos aqueles com $\mathrm{P}<0,05$. As análises de frequência relativa da média de variáveis com informações completas, dentro dos 19.780 registros e para os registros de cada um dos atestantes foram realizadas no software BioEstat 5.3 (AYRES et al., 2007; 2011).

\subsection{Análise da Completude de Dados sobre Causas de Mortalidade e de Morbidade}

Para analisar a completude das causas de mortalidade foram estudadas 4 variáveis no SIM: "Linha $A$, Linha $B$, Linha $C$, Linha D". As variáveis correspondem às informações contidas nas Linhas $A, B, C$, e D da DO sobre mortalidade, que foram transformadas em dados no SIM.

Os dados foram submetidos à análise quantitativa e estudados quanto à completude por frequência absoluta e relativa de variáveis com campos vazios ou não preenchidos para os 19.780 registros e para os registros de cada um dos cinco possíveis atestantes (assistentes, substitutos, IML, SVO e outros).

Apesar de se apresentar com duas Linhas na DO, no SIM a variável Parte II é codificada em uma única variável, que foi submetida à análise quantitativa e estudada quanto à completude por frequência absoluta e relativa de campos vazios ou não preenchidos para os 19.780 registros e para os registros de cada um dos cinco possíveis atestantes (assistentes, substitutos, IML, SVO e outros).

Para os registros que não permitiram a identificação do atestante, pois a variável Atestante encontrava-se vazia ou não preenchida, as variáveis Linhas A, B, C, D e Parte II foram analisadas quanto à frequência absoluta e relativa de campos vazios ou não preenchidas para os 19.780 registros.

A avaliação qualitativa por capítulo da Classificação Internacional de Doenças (CID-10) das causas de mortalidade e de morbidade dentro dos registros do SIM foi prejudicada, direcionando o estudo para uma avaliação 
quantitativa sobre completude. Este redirecionamento ocorreu pela presença de completude, com um ou mais de um dado sobre mortalidade e morbidade nas variáveis $A, B, C, D$ e Parte II.

\subsection{Análise dos registros das Causas Básicas}

O SIM apresenta uma única variável Causa básica para cada um dos registros de óbitos. Os dados contidos na variável Causa básica (CAUSBAS, no SIM) são os produtos das informações médicas coletadas da Parte I e Parte II do bloco V (condições e causas de óbitos) das DO que após análises, codificações e aplicadas regras de Seleção de Causa Básica (SCB) (Figura 5), são transformadas em dados e lançadas no SIM pelas secretarias de saúde municipais ou estaduais.

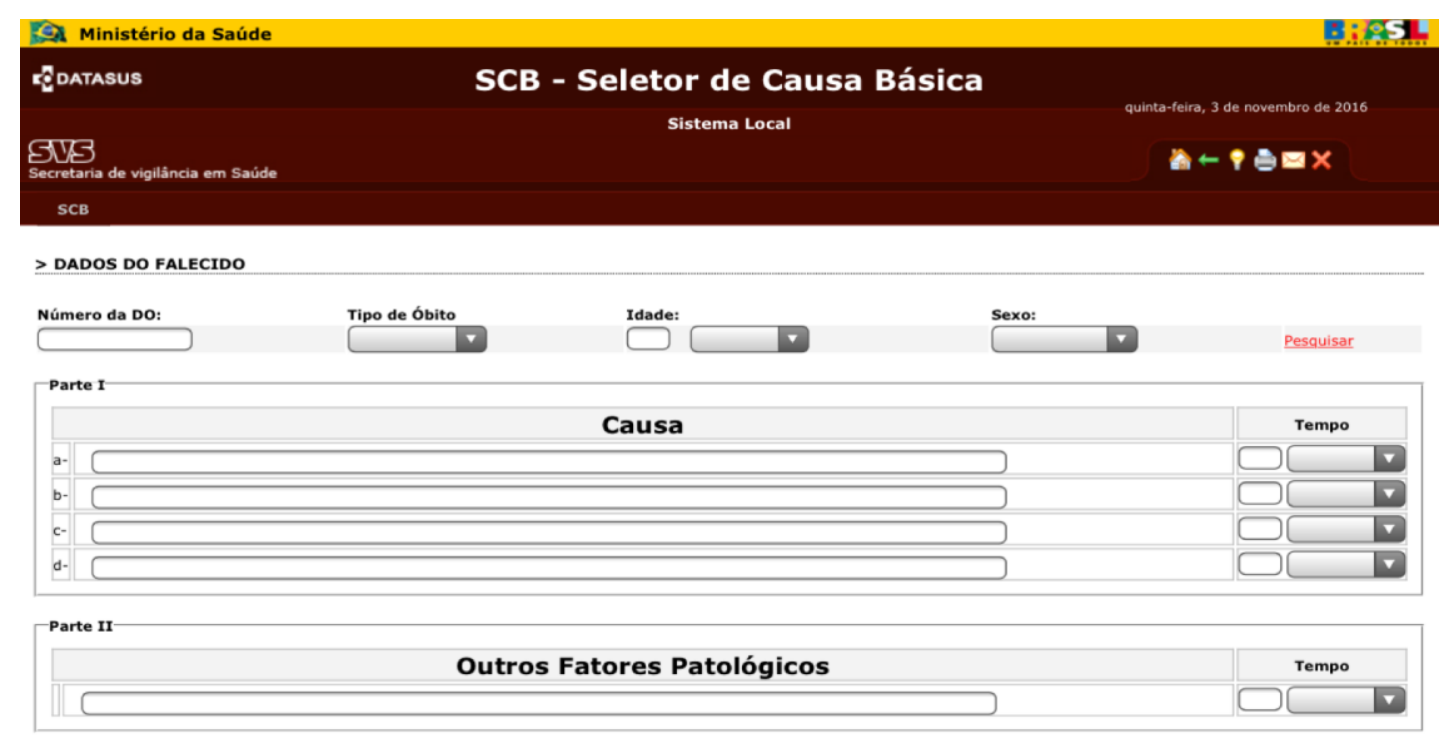

Figura 5 - Seletor de Causa Básica Fonte: SIM/Datasus.

A completude das Causas básicas de óbitos no SIM é obrigatória para realização dos registros civis de falecimentos no Estado do Tocantins. Para emissão das Certidões de Óbitos imprescindíveis para o sepultamento, os cartórios do Tocantins exigem que os familiares enlutados apresentem DO com informações médicas completas sobre as Causas básicas de óbitos. 
Materiais e Métodos

As Causas básicas nos registros do SIM para o Estado do Tocantins foram analisadas quanto à completude dentro dos 19.780 registros e nos dados registrados para cada atestante.

Dentre os 19.780 registros totais e nos registros para cada um dos atestantes especificamente, as cinco "Causas básicas" de óbitos mais frequentes foram analisadas de modo qualitativo de acordo com a classificação por capítulos da CID-10, inclusive nos registros de causa básica registrados com a variável Atestante vazia ou não preenchida.

\subsubsection{Análise dos registros das Causas Básicas Mal Definidas}

A CID-10 possui 22 capítulos dispostos em algarismos romanos e 0 capítulo XVIII refere-se a "Sintomas, sinais e achados anormais de exames clínicos e de laboratório não classificados em outra parte (R00-R99)". As causas básicas de óbitos classificadas no capítulo XVIII da CID-10 são denominadas causas básicas mal definidas.

Foram analisadas as frequências relativas e absolutas das causas básicas de óbitos mal definidas para os 19.780 registros de óbitos e para cada atestante especificamente, mormente para os registros que apresentavam a variável Atestante vazia ou não preenchida. Os números e as proporções de registros inclusos no capítulo XVIII pelo número de registros específicos para cada atestante também foram estudados.

\subsubsection{Análise dos registros das Causas Básicas Externas}

As causas básicas externas de óbitos consistem em registros classificados no capítulo XX da CID-10, disponibilizados na variável "CAUSBAS" do SIM, após coleta e codificação de informações sobre causas de óbitos e morbidades contidas no bloco $\mathrm{V}$ das DO.

Foram estudadas a frequência absoluta e relativa de óbitos com causas básicas externas para os 19.780 registros e a frequência absoluta e relativa de causas básicas contidas no capítulo XX para cada atestante. A frequência 
absoluta e relativa de registros inclusos no capítulo $X X$ pelo número de registros específicos para cada atestante também foram estudados.

\subsection{Elaboração do Perfil Social de Demográfico dos Registros de Óbitos no Sistema de Informação de Mortalidade para o Tocantins (SIM-TO) entre 2010 e 2012.}

Para a elaboração do perfil social e demográfico relativo aos registros de óbitos no SIM para o Estado do Tocantins entre os anos de 2010 e 2012, foi realizada uma análise descritiva das variáveis relacionadas à identificação dos pacientes que apresentaram dados sob a forma de códigos.

Dentre os 19.780 registros de óbitos no SIM para o Estado do Tocantins, foram analisadas as variáveis: tipo de óbito, hora do óbito, naturalidade, sexo, raça/cor, situação conjugal, escolaridade, ocupação, local de ocorrência e município de residência.

Ao elaborar o perfil social demográfico dos óbitos registrados no SIM para o Estado do Tocantins, os registros de óbitos fetais foram excluídos e os 19.780 registros de óbitos não fetais incluídos.

A variável data de óbito e hora de óbito foram analisadas com o intuito de identificar o ano, o mês e a hora de maior e de menor frequência de óbitos dentre os 19.780 casos registrados no SIM para o Estado do Tocantins.

Foram identificados os cinco Estados de maior prevalência ao analisar a variável Naturalidade, além de estabelecer a frequência relativa de dados referentes ao campo Outro e a frequência relativa de campos vazios ou não preenchidos.

A variável Faixa etária foi analisada por ano especificamente, enquanto a variável ldade foi analisada conforme a faixa etária utilizada pelo SIM/DATASUS, iniciando pelos registros de óbitos de menores de 1 ano a 75 anos e mais. A idade, em específico, foi discriminada por faixas etárias de $5 \mathrm{em}$ 5 anos iniciando a partir da faixa: menores de 1 ano. As faixas seguintes foram detalhadas: de 1 a 4 anos, 5 a 14 anos, 15 a 24 anos, 25 a 34 anos, 35 a 44 anos, 45 a 54 anos, 55 a 64 anos, 65 a 74 anos e finalizando em 75 anos e mais.

A variável Sexo foi analisada diferenciando os registros de óbitos para 0 sexo masculino e feminino observando que os dados para esta variável se 
encontravam com completude de 100\%. A variável Raça foi analisada diferenciando os registros para pardos (as), brancos (as), pretos (as), Indígenas, Amarelos (as) e estabelecendo a frequência relativa e absoluta para as variáveis vazias ou não preenchidas.

Para a variável Estado civil ou Situação conjugal, os registros foram analisados conforme os dados referentes à casados (as), solteiros (as), viúvos (as), união consensual, ignorados e com relação ao número absoluto e percentual de campos vazios ou não preenchidos.

A variável Escolaridade foi discriminada e analisada por anos de estudo iniciando pelos números e percentuais referentes aos dados sobre "nenhuma escolaridade, seguidos pelos números relacionados a intervalos de "1 a 3 anos", "4 a 7 anos", "8 a 11 anos", "12 e mais anos de escolaridade", números de informações assinaladas como "ignorados, números e percentual de campos vazios ou não preenchidos.

Para a análise descritiva da variável Ocupação foram decodificados os códigos lançados no SIM por meio do Código de Ocupações Brasileiras (COB) utilizado pelo SIM/DATASUS e classificadas de acordo com a prevalência. Foram descritas, as frequências relativas e absolutas de campos vazios relacionados à variável Ocupação.

Município de Residência consiste em variável relacionada ao local de residência do falecido que, no presente estudo, sofreu análise das frequências absolutas dos cinco municípios mais frequentes, enquanto a variável Local de ocorrência foi estudada por meio da descrição das frequências absolutas de registros para os cinco municípios mais prevalentes, relacionados aos campos "Hospital”, "Domicílio”, "Via Pública”, “Outros”, "Outros Estabelecimentos de Saúde" e "Ignorado".

\subsection{Aspectos Éticos}

Foram preservados os aspectos éticos da privacidade e da confidencialidade sem prejuízo a indivíduos ou às populações, de acordo com a Resolução CNS 466/12 do Conselho Nacional de Saúde que tratam de aspectos éticos em pesquisa. 
Materiais e Métodos

A pesquisa foi submetida ao Comitê de Ética e Pesquisa do Hospital das Clínicas da Faculdade de Medicina de Ribeirão Preto que dispensou o estudo de avaliação ética por se tratar de pesquisa em dados secundários em software disponível e de livre acesso público via internet. O documento oficial de dispensa consiste em Carta do Comitê de Ética e Pesquisa (ANEXO 1). 
RESULTADOS 


\section{RESULTADOS}

\subsection{Perfil Social e Demográfico dos Registros de Óbitos no Sistema de Informação de Mortalidade para o Estado do Tocantins (SIM-TO)}

Dos 19.780 registros analisados no SIM para o Estado do Tocantins, $100 \%$ dos registros tratava-se de óbitos não fetais de residentes no Estado.

A análise da variável Data do óbito revelou que o mês de setembro $(8,9 \%)$ foi o mês no qual ocorreram mais registros de óbitos e que o mês de novembro $(7,8 \%)$ consistiu no mês no qual ocorreu menor percentual, conforme a Figura 3. Já dentre os anos de registros de óbitos estudados verificou-se que em 2010 houve 32,7\% dos registros, 33,7\% em 2011 e 33,6\% foram registrados em 2012 (Figura 6).

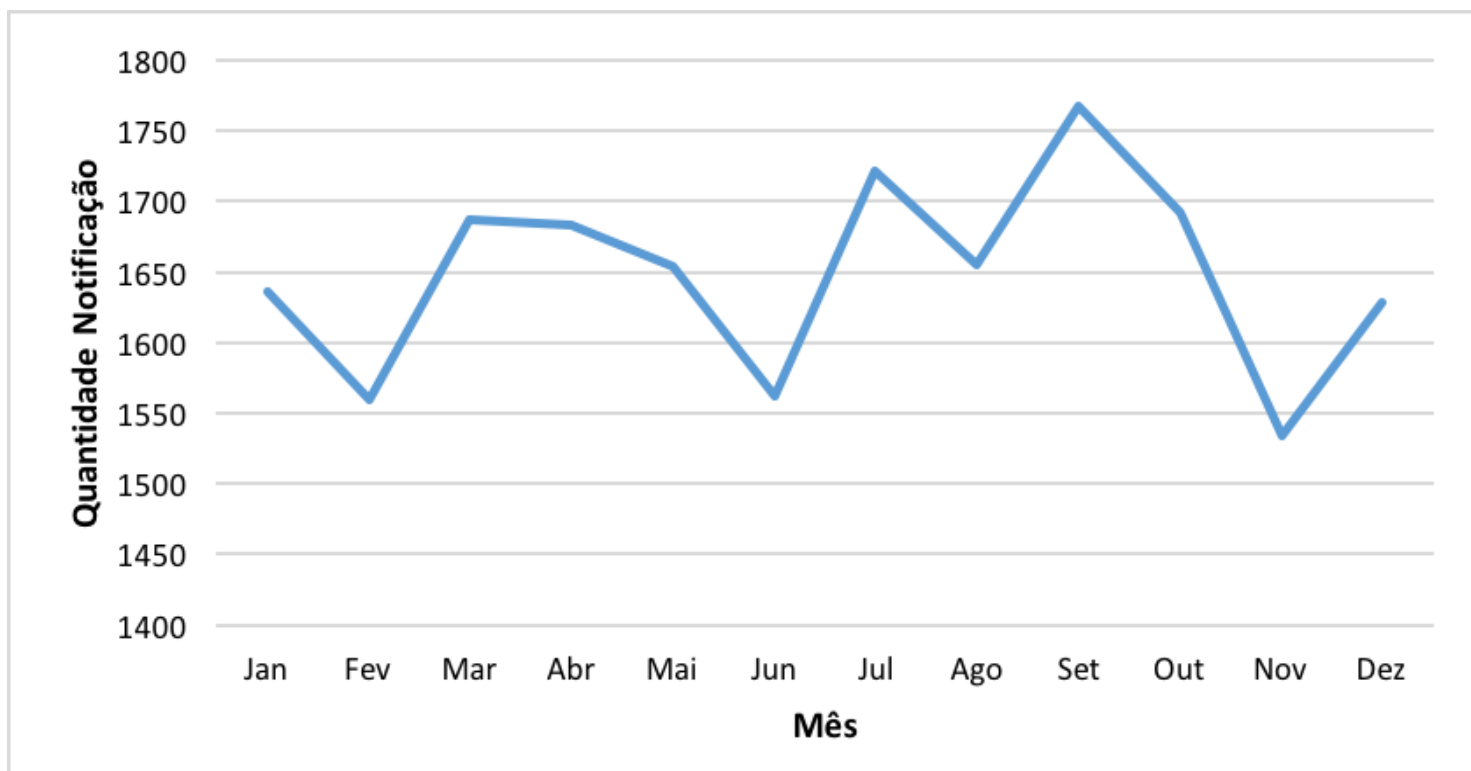

Figura 6 - Média de notificações de óbitos não fetais e residentes no Tocantins por mês do ano, ocorridos no período de 2010 a 2012.

Fonte: SIM

Quanto ao horário dos óbitos foi verificado que a maior ocorrência de registros de óbitos ocorreu da $17^{\mathrm{a}}$ hora à $20^{\mathrm{a}}$ hora, conforme Figura 7 . Cerca de $6,1 \%$ da variável hora do óbito estavam vazias ou não preenchidas (Figura 7). 


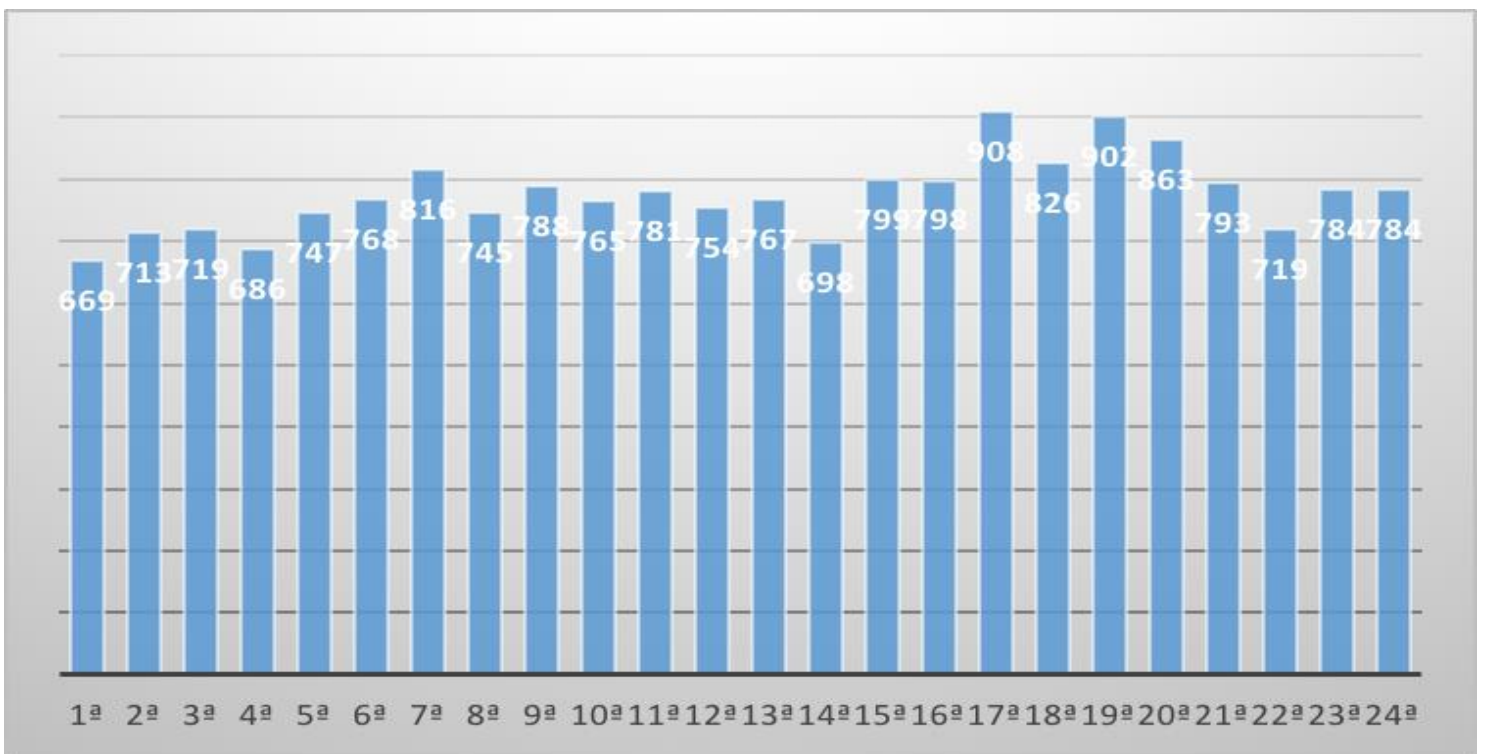

Figura 7 - Número de óbitos não fetais e residentes no Tocantins por hora de ocorrência, no período de 2010 a 2012.

Fonte:SIM

A variável naturalidade encontrou-se vazia ou não preenchida em $61,3 \%$ dos registros. Dentre as variáveis preenchidas, $3.379(17,1 \%)$ correspondiam à naturalidade de Tocantins, $1552(7,8 \%)$ correspondiam à naturalidade de Maranhão, 713 (3,6\%) de Goiás, 501 (2,5\%) de Piauí, 269 (1,4) do Ceará e $1237(6,2 \%)$ como "Outros" Estados (Figura 8).

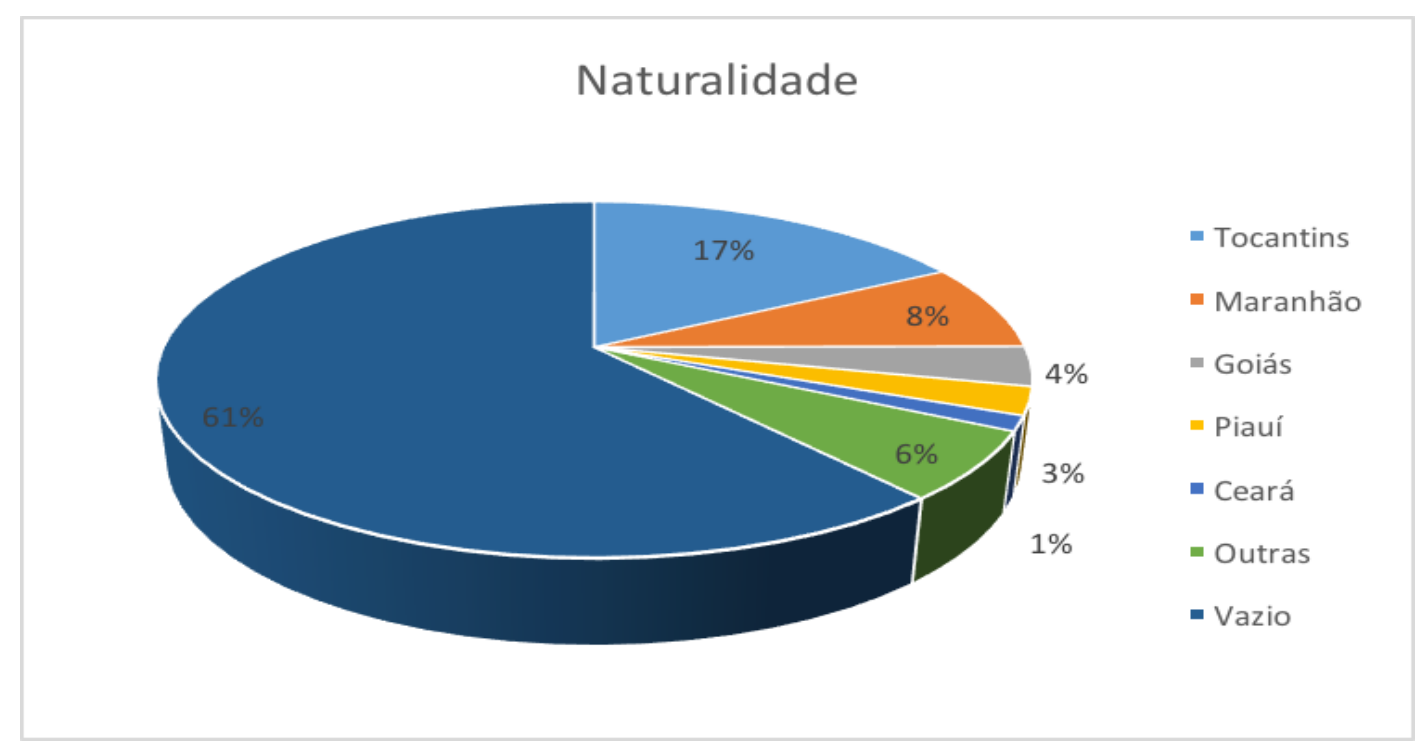

Figura 8 - Naturalidade dos óbitos não fetais e residentes, ocorridos no Tocantins no período de 2010 a 2012.

Fonte:SIM 
Resultados

Quanto aos dados para a variável data de nascimento, uma alta proporção de preenchimento foi observada, o campo "vazio" foi assinalado em $108(0,54 \%)$ registros e para os dados referentes à faixa etária, 50 (0,25\%) registros apresentaram o campo "ignorado" assinalado. O número absoluto de registros de óbitos apresentou aumento proporcional à faixa etária (Figura 9).

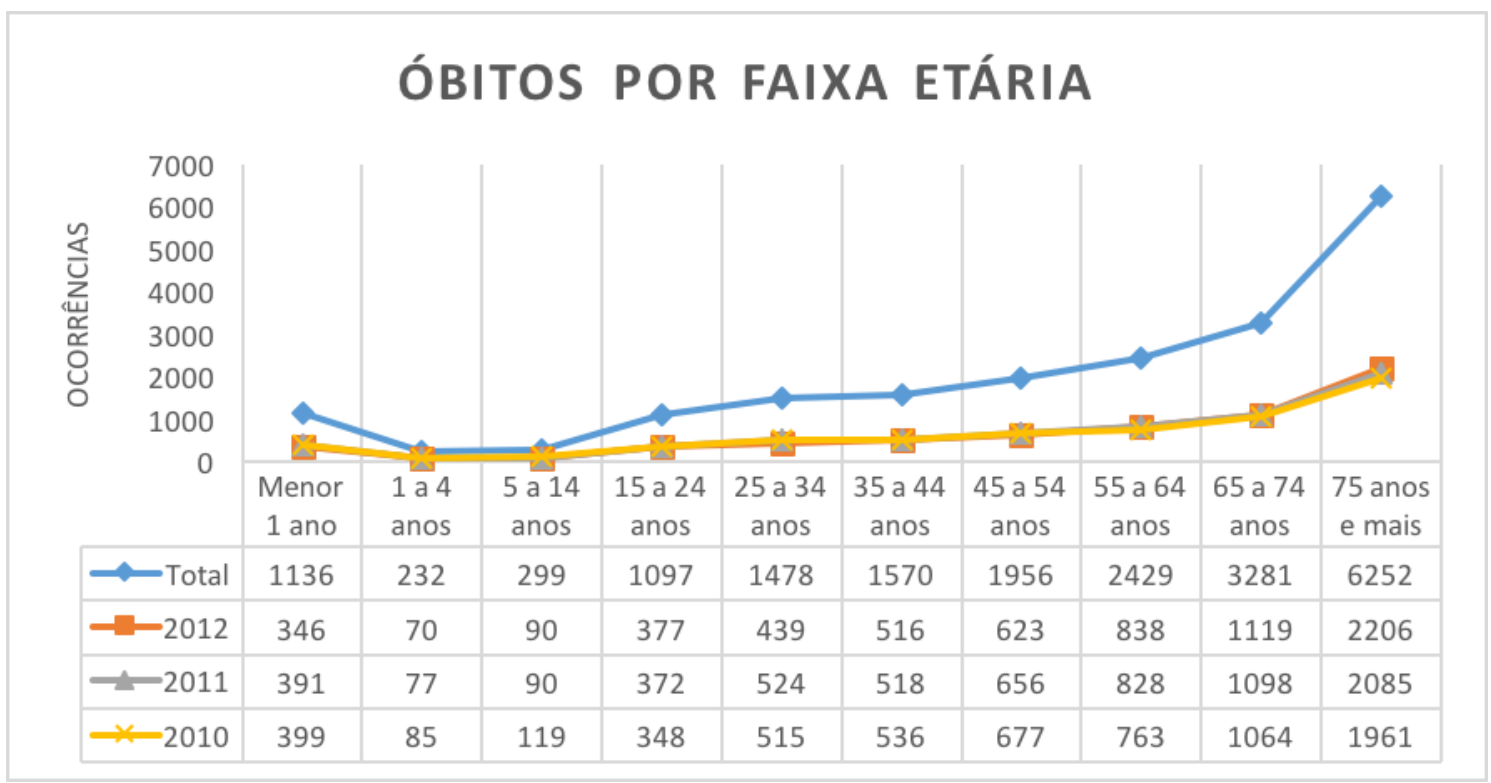

Figura 9 - Número de óbitos não fetais e residentes no Tocantins por faixa etária, ocorridos no período de 2010 a 2012.

Fonte: SIM

Para a variável sexo foram verificados 12.193 (61,6\%) registros com campos assinalados para sexo masculino, enquanto $7.572(38,3 \%)$ para sexo feminino. Foram encontrados 15 (0,07\%) registros vazios ou não preenchidos (Figura 10).

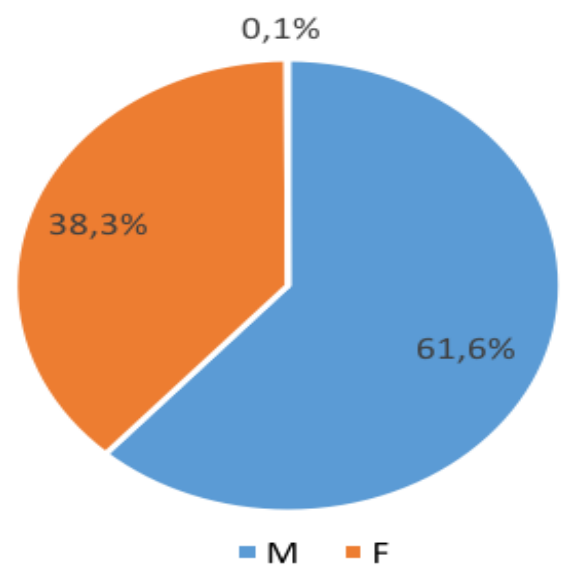

Figura 10 - Óbitos não fetais e residentes no Tocantins por sexo ocorrido no período de 2010 a 2012.

Fonte: SIM 
Resultados

Os registros para a variável Raça/Cor com maior prevalência dentre os 19.780 registros foram os relacionados à raça/cor parda com 12.024 (60,8\%) registros. A variável Raça/Cor apresentou 753 (3,8\%) registros vazios ou não preenchidos (Figura 11).

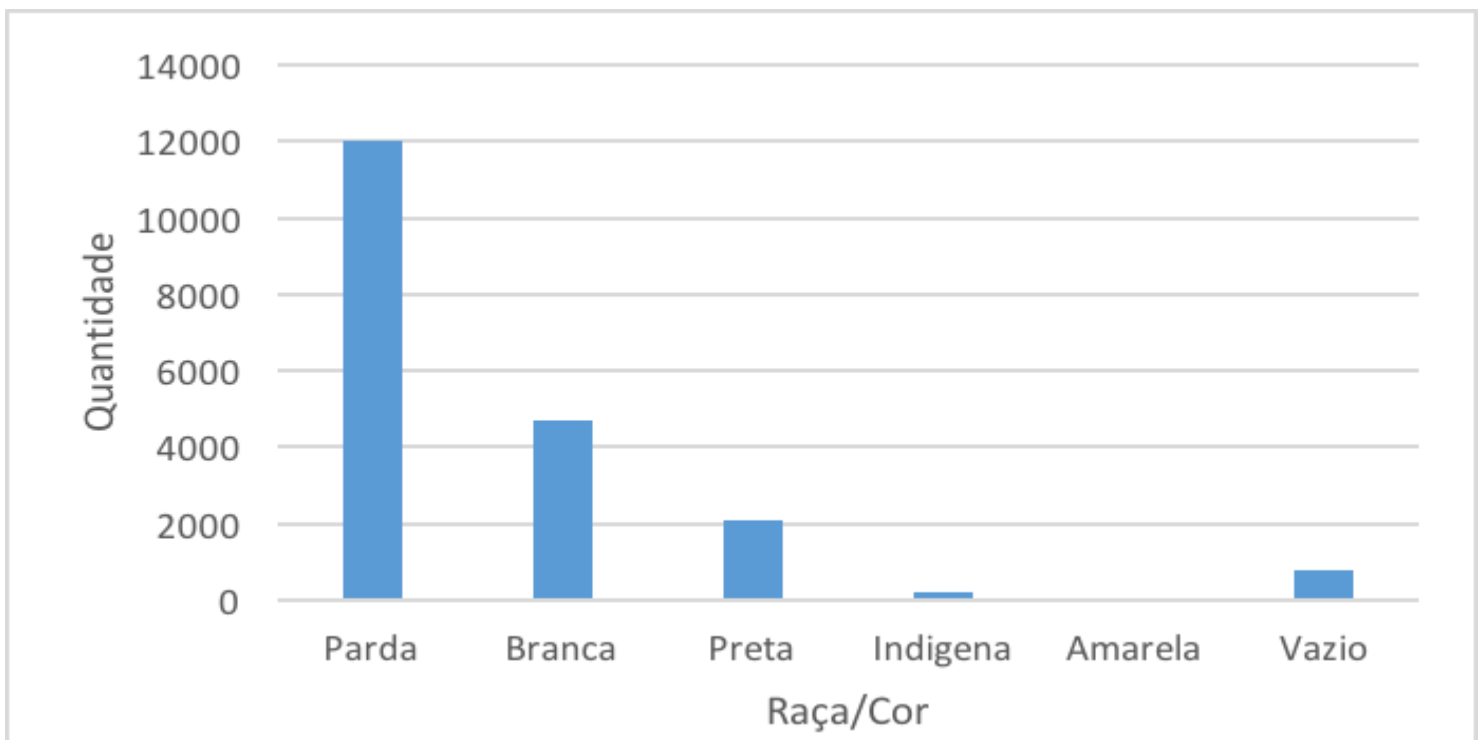

Figura 11 - Registros de óbitos não fetais e residentes no Tocantins por raça/cor, ocorridos no período de 2010 a 2012.

Fonte:SIM

A variável Estado Civil apresentava-se vazia em 1.961 (9,9\%) registros e $691(3,5 \%)$ foram registrados como "ignorado". A maior frequência relativa e absoluta com 6.488 óbitos (32,8\%) foi registrada no campo "casado" (Figura 12).

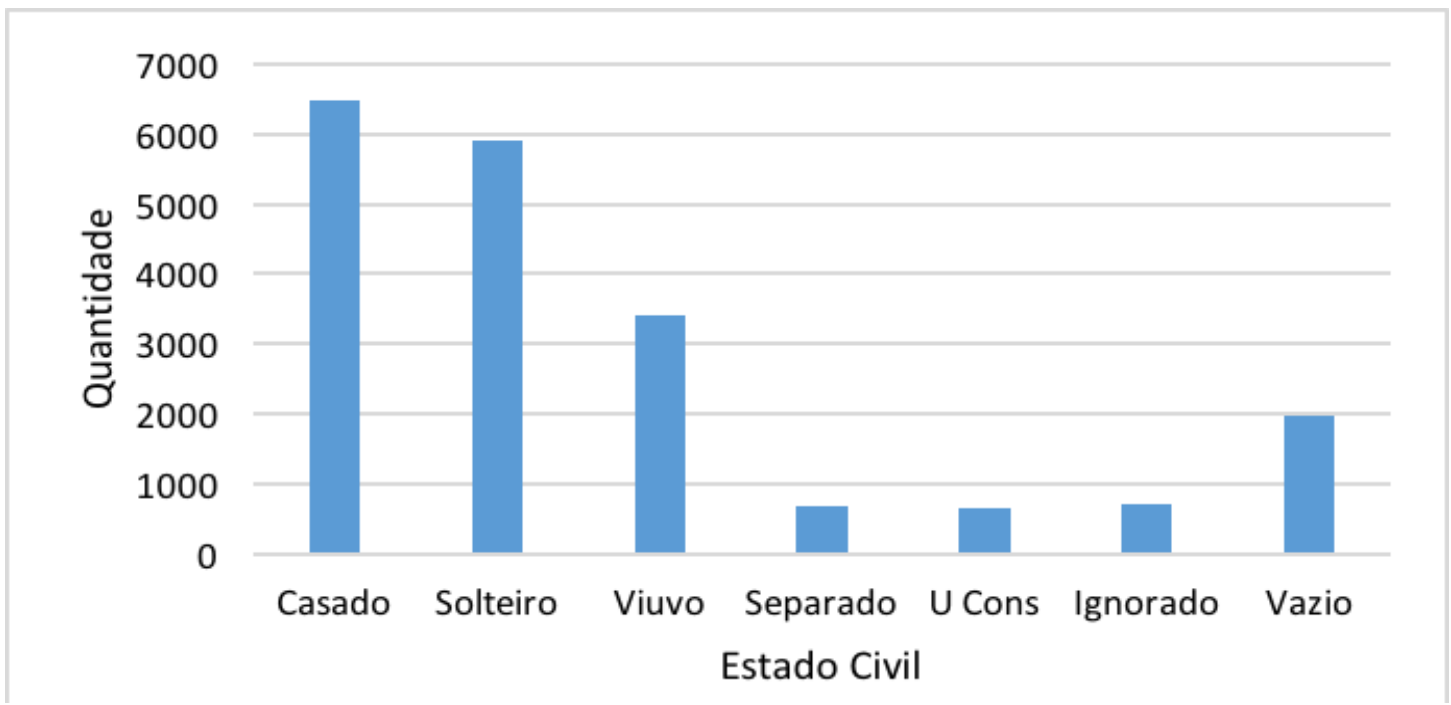

Figura 12 - Número de óbitos não fetais e residentes no Tocantins por estado civil, no período de 2010 a 2012.

Fonte: SIM 
Resultados

Para a variável Escolaridade, 2.049 (10,4\%) registros foram encontrados vazios. A maior ocorrência de registros de óbitos aconteceu entre os indivíduos "sem escolaridade" com $5.762(29,1 \%)$ registros. Foi observada redução do número e do percentual de registros de óbitos conforme o aumento do tempo de escolaridade (Figura 13).

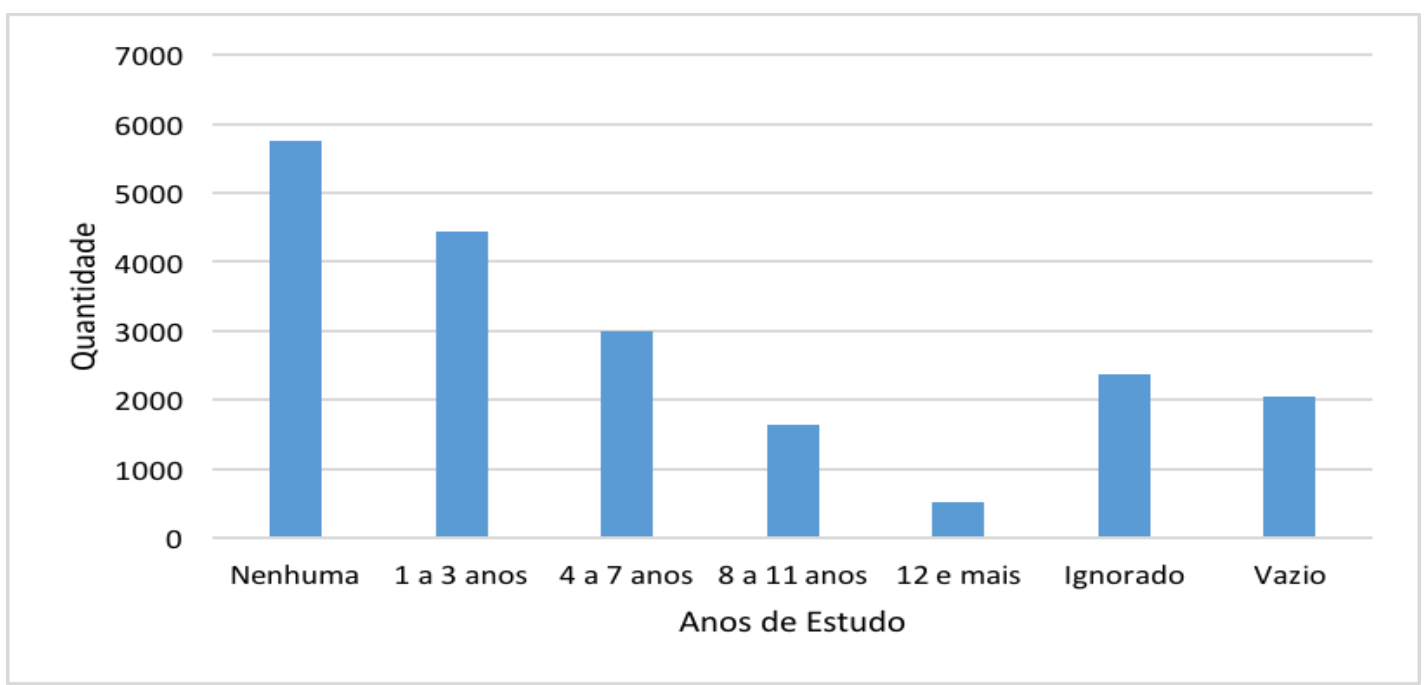

Figura 13 - Número de óbitos não fetais e residentes no Tocantins por escolaridade, ocorridos no período de 2010 a 2012.

Fonte: SIM

A variável Ocupação apresentou-se vazia em 5.512 (27,9\%) registros. Dentre os registros com a variável ocupação preenchida, após a decodificação e a análise descritiva, a ocupação "aposentado/pensionista" com 4.223 (21,3\%), seguida por trabalhador agropecuário com 3293 (16,6\%) foram as ocupações mais prevalentes (Figura 14).

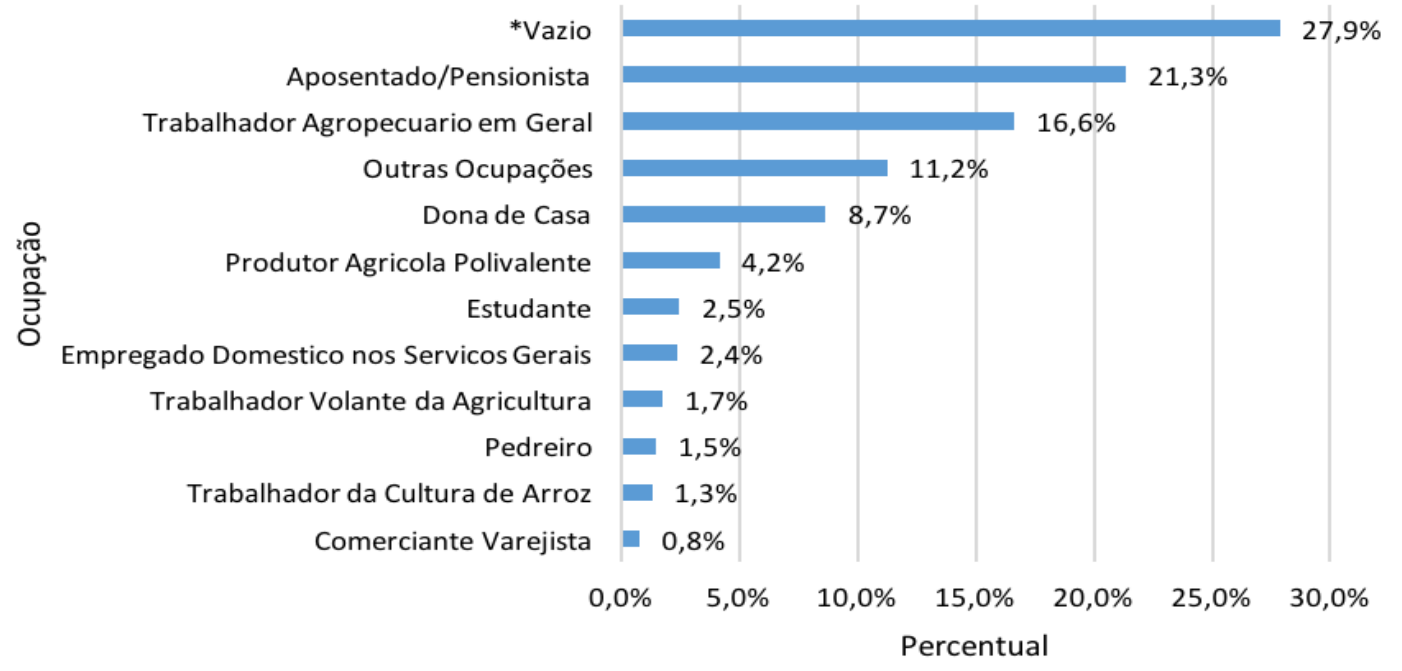

Figura 14 - Número de óbitos não fetais e residentes no Tocantins por ocupação, ocorridos no período de 2010 a 2012.

Fonte: SIM 
Resultados

A variável Município de Residência apresentou completude de 100\% dos registros. As cidades de Araguaína com 2.241 (11,3\%) e Palmas com 2.231 $(11,3 \%)$ foram os municípios assinalados com maior número e percentual de registros de óbitos dentre os 19.780 (Figura 15).

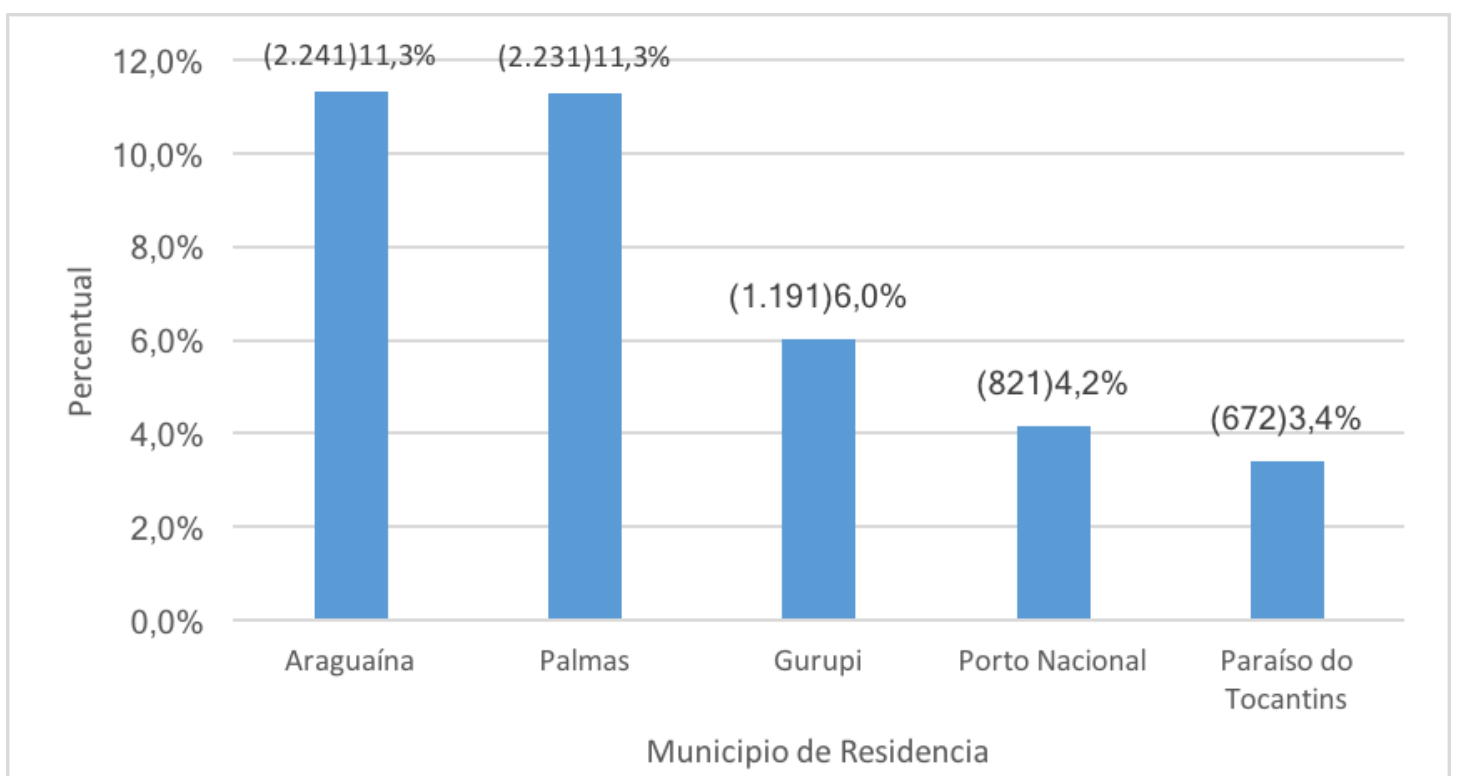

Figura 15 - Número de óbitos não fetais e residentes no Tocantins por município de residência, ocorridos no período de 2010 a 2012.

Fonte:SIM

Para a variável Local de Ocorrência, a maior quantidade de registros foi relacionada ao campo "Hospitais" com 11.986 (60,6\%) registros, seguido pelos registros relacionados ao campo “domicílio" com $4.827(24,4 \%)$ registros (Figura 16).

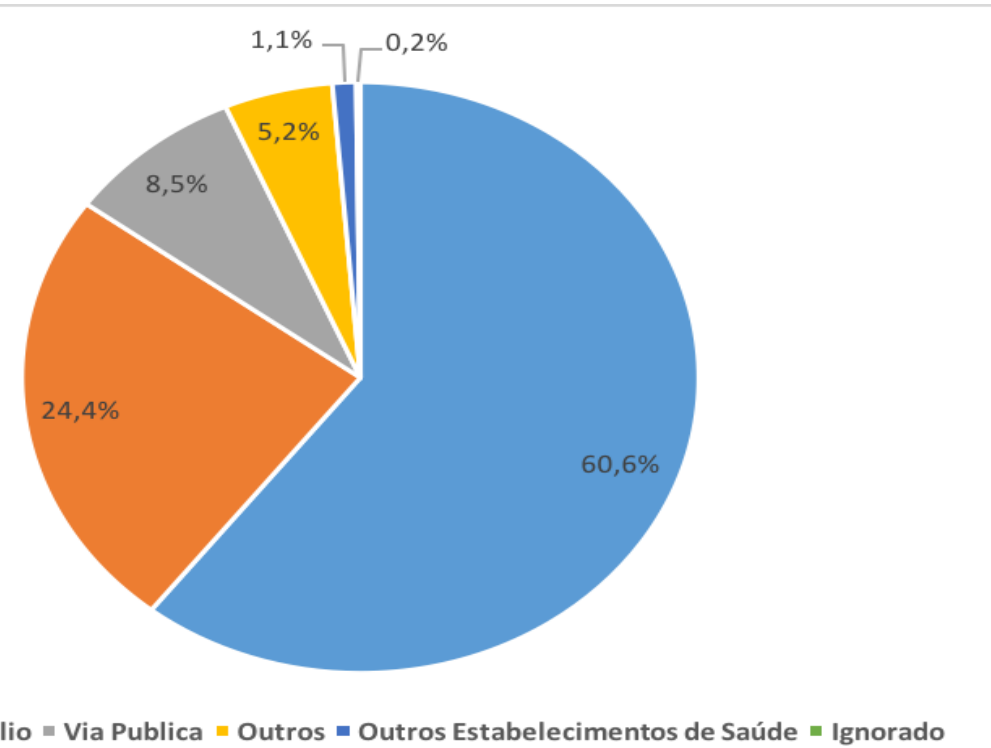

Figura 16 - Número de óbitos não fetais e residentes no Tocantins por local de ocorrência, ocorridos no período de 2010 a 2012.

Fonte: SIM 
Resultados

Os resultados serão apresentados em tópicos para facilitar a discussão seguindo a ordem: Completude de dados dentro do SIM, perfil social e demográfico dos óbitos registrados no SIM para o Estado do Tocantins, causas básicas de óbitos, causas de mortalidade e de morbidade dentro do SIM para o Estado do Tocantins.

Foram encontrados 19.780 registros dentro do SIM, referentes aos óbitos de residentes no Estado do Tocantins no período de 2010 a 2012. Os registros foram provenientes de informações descritas por cinco tipos diferentes de atestantes: Assistentes, Substitutos, IML, SVO e Outros.

\subsection{Completude de dados dentro do Sistema de Informação de Mortalidade para o Estado do Tocantins, 2010-2012}

No total de 19.780 registros analisados para os cinco diferentes atestantes, foram encontrados 6.942 (35,1\%) registros para o atestante Assistente, 3.843 (19,4\%) para Substituto, 3.518 (17,8\%) IML, 818 (4,1\%) SVO, $2.895(14,6 \%)$ para Outros e 1.764 (8,9\%) exibiram a variável atestante vazia ou não preenchida (Tabela 6).

Tabela 6 - Frequência absoluta e relativa de registros no Sistema de Informação de Mortalidade segundo atestante para o Estado do Tocantins, Brasil, 2010 a 2012.

\begin{tabular}{lcr}
\hline Atestante & No De Registros & $\%$ \\
\hline Assistente & 6.942 & 35,10 \\
Substituto & 3.843 & 19,43 \\
IML & 3.518 & 17,79 \\
SVO & 818 & 4,14 \\
Outros & 2.895 & 14,64 \\
Vazio & 1.764 & 8,92 \\
\hline Total & $\mathbf{1 9 . 7 8 0}$ & $\mathbf{1 0 0 , 0 0}$
\end{tabular}

Os demais atestantes como IML, substitutos, assistentes e outros representaram em conjunto 86,95\% (17.198) e o Serviço de Verificação de Óbitos registrou 4,13\% (818). A variável atestante vazia ou não preenchida apresentou 1.764 registros (8,92\%), impossibilitando determinar o atestante das informações.

Dentre as 23 variáveis, 39,13\% (8) eram compostas por campos $100 \%$ preenchidos: tipo de óbito, data do óbito, idade, sexo, código do município de residência, código do município de ocorrência, local de ocorrência, causa 
básica de óbito enquanto 60,87\% (15) variáveis apresentavam-se vazias ou não preenchidas: hora do óbito, naturalidade, data de nascimento, raça/cor, estado civil, escolaridade, ocupação, assistência médica, necropsia, Linha $A$, Linha B, Linha C, Linha D, parte II, causa básica de óbitos e atestante.

Não houve diferença na completude de registros entre os atestantes. A frequência absoluta de número de variáveis com campos preenchidos e a frequência absoluta de variáveis com pelo menos um campo não preenchido ou vazio, entre os cinco atestantes foi estatisticamente insignificante quando realizadas comparações ( $P>0,127)$ (Tabela 7$)$.

Tabela 7 - Frequência absoluta e relativa de registros com todas as variáveis preenchidas e com pelo menos uma variável não preenchida ou vazia no SIM para o Estado do Tocantins segundo atestante, 2010 a 2012.

\begin{tabular}{lcccccc}
\hline Atestante & Preenchido & $\%$ & Vazio & $\%$ & Total & P-Valor \\
\hline Médico & 5.784 & 83,3 & 1.158 & 16,7 & 6.942 & \\
Substituto & 3.257 & 84,7 & 586 & 15,3 & 3.843 & \\
IML & 2.930 & 83,3 & 588 & 16,7 & 3.518 & 0,127 \\
SVO & 672 & 82,1 & 146 & 17,9 & 818 & \\
Outros & 2.393 & 82,7 & 502 & 17,3 & 2.895 & \\
\hline
\end{tabular}

Fonte: SIM

\subsection{Completude de dados dentro do Sistema de Informação de Mortalidade para o SVO.}

O percentual médio de variáveis não preenchidos por dados considerando o SVO foi 17,9\% (146/818) e considerando os demais atestantes: $16,5 \%$ (2.980/15.036). Estatisticamente não houve diferença significativa proporcional na quantidade de variáveis vazias e preenchidas comparando SVO e demais atestantes $(P>0,05)$.

Dentre os registros do SVO, $96(11,7 \%)$ apresentaram a variável necropsia não preenchida ou vazia, enquanto $2.367(13,8 \%)$ registros dos demais atestantes estavam com a variável necropsia vazia. Analisados os registros exclusivos do SVO, a data de nascimento foi a variável com menor percentual de vazios $(0,1 \%)$ e a Linha $D$ foi a variável com maior percentual de vazios $(80,9 \%)$.

Dentre as linhas analisadas, a Linha $A$ foi a que demonstrou menor percentual de vazios, tanto nos registros do SVO quanto dos demais atestantes com $1,7 \%$ e $2,1 \%$ respectivamente. A Linha $D$ foi a variável com maior percentual de vazios tanto nos registros do SVO quanto dos demais atestantes 
Resultados

com $80,9 \%$ e 76,2\% respectivamente. A média de campos preenchidos dentro das 23 variáveis analisadas nos 19.780 registros foi de $16.313(82,5 \%)$ e de campos vazios dentro das 23 variáveis foi 3.467 (17,5\%). A média de campos preenchidos dentro das 23 variáveis analisadas nos 818 registros exclusivos do SVO foi de 669 (81,8\%) e de campos vazios dentro das 23 variáveis foi de 149 $(18,2 \%)$. A média de campos preenchidos dentro das 23 variáveis nos 17.198 registros dos demais atestantes foi de 14.309 (83,20\%), e a média de campos vazios ou não preenchidos 2.889 (16,80\%).

Excluindo as 8 variáveis com campos $100 \%$ preenchidos dentre as 23 variáveis analisadas, a variável Linha $D$ foi a variável que se apresentou com maior porcentagem de campos não preenchidos ou vazios tanto para nos registros do SVO $(80,93 \%)$, quanto nos registros dos demais atestantes em conjunto $(76,15 \%)$.

Ainda excluindo as 8 variáveis com campos 100\% preenchidos, a variável com maior porcentagem de campos preenchidos dentro dos registros do SVO foi a variável data nascimento $(99,88 \%)$ e dentro dos registros dos demais atestantes em conjunto a variável Linha $A(97,87 \%)$ foi a variável com maior percentual de campos preenchidos.

\subsection{Resultado da Análise sobre as "Causas Básicas" de óbitos dentro do Sistema de Informação de Mortalidade para o Estado do Tocantins, 2010-2012.}

A avaliação das causas básicas de óbitos foi realizada de modo qualitativo, mormente a completude de $100 \%$ dos dados encontrados na variável "CAUSBAS" (causa básica de óbito) dentro do SIM. Para cada um dos cinco possíveis atestantes foram discriminadas as cinco causas básicas mais prevalentes.

Foram analisadas de modo quantitativo as causas básicas de óbitos mal definidas e as causas básicas externas de óbitos para cada um dos atestantes. As causas básicas de óbitos foram discriminadas em capítulos de acordo com a Classificação Internacional de Doenças (CID-10).

$\mathrm{Na}$ análise dos 19.780 registros, os cinco principais capítulos de causas básicas de óbitos encontrados foram: o capítulo IX referente às doenças do aparelho circulatório com total de 6.147 óbitos $(31,08 \%)$, o capítulo XX 
relacionado às causas externas de morbidade e mortalidade com 3.632 (18,36\%), o capítulo II compreendendo as neoplasias com 2.592 (13,10\%). O capítulo $X$ das doenças do aparelho respiratório com 1.499 (7,58\%) e o capítulo IV das doenças endócrinas, nutricionais e metabólicas com 1.455 $(7,36 \%)$ foram os capítulos com menor frequência relativa e absoluta dentre os 19.780 registros (Tabela 8 ).

Tabela 8 - Frequência absoluta e relativa no SIM, segundo os principais capítulos (CID-10) de causas básicas de óbitos, Tocantins, Brasil, 2010 a 2012.

\begin{tabular}{lcc}
\hline Capítulos CID-10 & No DE REGISTROS & $\%$ \\
\hline Cap. IX - Doenças do Aparelho Circulatório & 6.147 & 31,08 \\
Cap. XX - Causas Externas de Morbidade e & 3.632 & 18,36 \\
Cap. II - Neoplasias (Tumores) & 2.592 & 13,10 \\
Cap. X - Doenças do Aparelho Respiratório & 1.499 & 7,58 \\
Cap. IV - Doenças Endócrinas, Nutricionais & 1.455 & 7,36 \\
Outros Capítulos & 4.455 & 22,52 \\
\hline Total & $\mathbf{1 9 . 7 8 0}$ & $\mathbf{1 0 0 , 0 0}$ \\
\hline
\end{tabular}

Fonte: SIM

Entre os 6.942 registros exclusivos para o atestante Assistente, o capítulo IX referente às doenças do aparelho circulatório com 2.471 (35,59\%) consistiu em principal capítulo de causa básica de óbito dentre os cinco capítulos mais prevalentes, seguido em ordem decrescente pelo capítulo II das neoplasias $1.153(16,61 \%)$, capítulo $X$ para as doenças do aparelho respiratório 635 (9,15\%), capítulo IV das doenças endócrinas, nutricionais e metabólicas $568(8,18 \%)$, e capítulo XI envolvendo as doenças do aparelho digestivo 417 (6,01\%) (Tabela 9).

Tabela 9 - Frequência absoluta e relativa de registros no SIM, segundo principais capítulos (CID-10) de causas básicas de óbitos informados pelo atestante Assistente, Tocantins, Brasil, 2010 a 2012.

\begin{tabular}{lcr}
\hline Capítulos CID-10 & No DE REGISTROS & $\%$ \\
\hline Cap. IX - Doenças do Aparelho Circulatório & 2.471 & 35,59 \\
Cap. II - Neoplasias (Tumores) & 1.153 & 16,61 \\
Cap. X - Doenças do Aparelho Respiratório & 635 & 9,15 \\
Cap. IV - Doenças Endócrinas, Nutricionais e & 568 & 8,18 \\
Metabólicas & 417 & 6,01 \\
Cap. XI - Doenças do Aparelho Digestivo & 1.698 & 24,46 \\
Outros Capítulos & $\mathbf{6 . 9 4 2}$ & $\mathbf{1 0 0 , 0 0}$ \\
\hline Total &
\end{tabular}


Para os 3.843 óbitos registrados pelo atestante Substituto, o capítulo IX referente às doenças do aparelho circulatório foi a principal causa básica de óbito entre os cinco capítulos que mais predominaram em frequência relativa e absoluta com 1.311 (34,11\%). Em sequência, o capítulo II das neoplasias com $773(20,11 \%)$, o capítulo $X$ das doenças do aparelho respiratório com 375 $(9,76 \%)$, o capítulo IV das doenças endócrinas, nutricionais e metabólicas com $356(9,26 \%)$ e o capítulo XI das doenças do aparelho digestivo com 292 $(7,60 \%)$ (Tabela 10).

Tabela 10 - Frequência relativa e absoluta de registros no SIM, segundo os principais capítulos (CID-10) de causas básicas de óbitos informadas pelo atestante Substituto, Tocantins, Brasil, 2010 a 2012.

\begin{tabular}{lcr}
\hline Capítulos CID-10 & № DE REGISTROS & \multicolumn{1}{c}{$\%$} \\
\hline Cap. IX - Doenças do Aparelho Circulatório & 1.311 & 34,11 \\
Cap. II - Neoplasias (Tumores) & 773 & 20,11 \\
Cap. X - Doenças do Aparelho Respiratório & 375 & 9,76 \\
Cap. IV - Doenças Endócrinas, Nutricionais e & 356 & 9,26 \\
Metabólicas & 292 & 7,60 \\
Cap. XI - Doenças do Aparelho Digestivo & 736 & 19,15 \\
Outros Capítulos & $\mathbf{3 . 8 4 3}$ & $\mathbf{1 0 0 , 0 0}$ \\
\hline Total &
\end{tabular}

Para os 3.518 registros de óbitos do atestante IML no SIM, a ordem decrescente de frequência absoluta e relativa de classificação pela CID-10 foi: capítulo $X X$ relacionado às causas externas de morbidade e mortalidade com $3.120(88,69 \%)$, capítulo IX para doenças do aparelho circulatório com 140 (3,98\%), capítulo XVIII para sintomas, sinais e achados anormais de exames clínicos e de laboratório, não classificados em outra parte com 137 (3,89\%), capítulo V alusivo a Transtornos Mentais e Comportamentais com 27 (0,77\%) e capítulo X para doenças do aparelho respiratório 26 (0,74\%) (Tabela 11). 
Tabela 11 - Frequência absoluta e relativa de registros no Sistema de Informação de Mortalidade segundo os principais capítulos (CID-10) de causas básicas de óbitos informadas pelo atestante IML, Tocantins, Brasil, 2010 a 2012.

\section{Capítulos CID-10}

Cap. XX - Causas Externas de Morbidade e Mortalidade

\section{№ DE REGISTROS}

3.120

140

137

Cap. XVIIII - Sintomas, Sinais e Achados

Anormais de Exames Clínicos e de

Laboratório, Não Classificados em Outra Parte

Cap. V - Transtornos Mentais e Comportamentais

Cap. X - Doenças do Aparelho Respiratório

Outros Capítulos

Total

Fonte: SIM

26

68

3.518
$\%$

88,69

3,89

0,74

1,93

100,00

Dentre os 818 registros atestados especificamente pelo SVO, 348 $(42,54 \%)$ foram registrados como causa básica de óbito. As doenças do aparelho circulatório, referentes ao capítulo IX, representaram a principal causa básica de óbito para o atestante SVO entre os anos de 2010, 2011 e 2012. O capítulo X, para doenças do aparelho respiratório com 100 (12,22\%) expressou a segunda principal causa básica de óbito, o capítulo XI para doenças do aparelho digestivo com $68(8,31 \%)$ retratou a terceira principal. A quarta e o quinto lugar ficam para o capítulo XVIII pautado em sintomas, sinais e achados anormais de exames clínicos e de laboratório, não classificados em outra parte com $57(6,97 \%)$ e capítulo II para neoplasias 55 (6,72\%), respectivamente (Tabela 12).

Tabela 12 - Frequência absoluta e relativa de registros no Sistema de Informação de Mortalidade segundo os principais capítulos (CID-10) de causas básicas de óbitos informadas pelo atestante SVO, Tocantins, Brasil, 2010 a 2012.

\begin{tabular}{lcr}
\hline Capítulos CID-10 & No DE REGISTROS & \multicolumn{1}{c}{$\%$} \\
\hline Cap. IX - Doenças do Aparelho Circulatório & 348 & 42,54 \\
Cap. X - Doenças do Aparelho Respiratório & 100 & 12,22 \\
Cap. XI - Doenças do Aparelho Digestivo & 68 & 8,31 \\
Cap. XVIIII - Sintomas, Sinais e Achados & & \\
Anormais de Exames Clínicos e de & 57 & 6,97 \\
Laboratório, Não Classificados em Outra Parte & & \\
Cap. II - Neoplasias (Tumores) & 55 & 6,72 \\
Outros Capítulos & 190 & 23,23 \\
\hline Total & $\mathbf{8 1 8}$ & $\mathbf{1 0 0 , 0 0}$ \\
\hline
\end{tabular}

Fonte: SIM 
Resultados

Considerando as cinco principais causas básicas de óbito dentre os 2.895 registros preenchidos no SIM para atestante Outros, notou-se que o capítulo XI de doenças do aparelho digestivo com 147 (5,08\%) corresponde à causa básica com menor frequência absoluta e relativa, 0 capítulo $X$ para doenças do aparelho respiratório com 232 (8,01\%) condiz com a segunda causa com menor frequência absoluta e relativa. Já as três principais causas básicas de óbito compreendem, respectivamente, o capítulo IX para doenças do aparelho circulatório com 1.253 (43,28\%), o capítulo II para neoplasias com $402(13,89 \%)$ e o capítulo IV para doenças endócrinas, nutricionais e metabólicas com 273 (9,43\%) (Tabela 13).

Tabela 13 - Frequência absoluta e relativa de registros no Sistema de Informação de Mortalidade segundo os principais capítulos (CID-10) de causas básicas de óbitos informadas pelo atestante Outros, Tocantins, Brasil, 2010 a 2012.

\begin{tabular}{lcc}
\hline Capítulos CID-10 & № DE REGISTROS & \multicolumn{1}{c}{$\%$} \\
\hline Cap. IX - Doenças do Aparelho Circulatório & 1.253 & 43,28 \\
Cap. II - Neoplasias (Tumores) & 402 & 13,89 \\
Cap. IV - Doenças Endócrinas, Nutricionais & 273 & 9,43 \\
e Metabólicas & 232 & 8,01 \\
Cap. X - Doenças do Aparelho Respiratório & 147 & 5,08 \\
Cap. XI - Doenças do Aparelho Digestivo & 588 & 20,31 \\
Outros Capítulos & $\mathbf{2 . 8 9 5}$ & $\mathbf{1 0 0 , 0 0}$ \\
\hline Total & &
\end{tabular}

Dos 1.764 registros preenchidos para atestante vazia, considerando as cinco principais causas básicas de óbito, notou-se que o capítulo XX para causas externas de Mortalidade e morbidade com 128 (7,26\%) corresponde à causa básica com menor frequência, o capítulo $X$ para doenças do aparelho respiratório com $131(7,43 \%)$ condiz com a segunda causa com menor frequência. Já as três principais causas básicas de óbito compreendem, respectivamente, o capítulo IX para doenças do aparelho circulatório com 624 (35,37\%), o capítulo II para neoplasias com 202 (11,45\%) e o capítulo IV para doenças endócrinas, nutricionais e metabólicas com 195 (11,05\%) (Tabela 14). 
Tabela 14 - Frequência absoluta e relativa de registros no Sistema de Informação de Mortalidade segundo os principais capítulos (CID-10) de causas básicas de óbitos onde o campo atestante se encontra vazio, Tocantins, Brasil, 2010 a 2012.

\begin{tabular}{lcc}
\hline Capítulos CID-10 & No DE REGISTROS & \% \\
\hline Cap. IX - Doenças do Aparelho Circulatório & 624 & 35,37 \\
Cap. II - Neoplasias (Tumores) & 202 & 11,45 \\
Cap. IV - Doenças Endócrinas, Nutricionais e & 195 & 11,05 \\
Metabólicas & 131 & 7,43 \\
Cap. X - Doenças do Aparelho Respiratório & 128 & 7,26 \\
Cap. XX - Causas Externas de Morbidade e & 484 & 27,44 \\
Mortalidade & $\mathbf{4 8 4}$ & $\mathbf{1 0 0 , 0 0}$ \\
Outros Capítulos & &
\end{tabular}

Dos 19.780 registros de óbitos, 586 (2,9\%) foram atestados como causa básica de óbito mal definida, isto é, causas contidas no capítulo XVIII (Sintomas, Sinais e Achados Anormais de Exames Clínicos e de Laboratório, Não Classificados em Outra Parte) do CID-10. A quantidade de registros de mortalidade que exibem a causa básica de óbito como mal definida para o atestante Assistente representa 120 óbitos (20,48\%), para o Substituto 38 óbitos (6,48\%), para o IML 137 óbitos (23,38\%), para o SVO 57 óbitos (9,73\%) e para Outros 141 óbitos (24,06\%). Dos registros que apresentaram a variável Atestante vazia, observou-se que 93 (15,87\%) foram declarados causa básica mal definida (Tabela 15).

Tabela 15 - Frequência absoluta e relativa de registros no Sistema de Informação de Mortalidade segundo Capítulo XVIII-Causas Básicas de Óbito Mal Definidas e atestante, Tocantins, Brasil, 2010 a 2012.

\begin{tabular}{lcc}
\hline Atestante & $\begin{array}{c}\text { No de Registros inclusos no } \\
\text { Cap. XVIII }\end{array}$ & $\begin{array}{c}\text { Registros inclusos no } \\
\text { Cap. XVIII (\%) }\end{array}$ \\
\hline Assistente & 120 & 20,48 \\
Substituto & 38 & 6,48 \\
IML & 137 & 23,38 \\
SVO & 57 & 9,73 \\
Outros & 141 & 24,06 \\
Vazio & 93 & 15,87 \\
\hline Total & $\mathbf{5 8 6}$ & $\mathbf{1 0 0 , 0 0}$
\end{tabular}

Fonte: SIM 
Resultados

Quando relacionados o número de registros de causas básicas de óbitos inclusas no capítulo XVIII com o número total de registros no SIM para cada atestante, o SVO apresentou a maior proporção de registros de causas básicas de óbitos mal definidas por número total de registros no SIM. O atestante substituto foi o atestante que apresentou menor proporção de causas básicas de óbitos mal definidas por número total de registros no SIM (Tabela 16).

Tabela 16 - Frequência absoluta e relativa de registros inclusos no Capítulo XVIII-Causas Básicas de Óbito Mal Definidas por número total de registros para cada atestante.

\begin{tabular}{lccc} 
Atestante & $\begin{array}{c}\text { No Registros no } \\
\text { Cap. XVIII }\end{array}$ & $\begin{array}{c}\text { Total de Registros } \\
\text { no SIM }\end{array}$ & $\begin{array}{c}\text { Registros no Cap. } \\
\text { XVIII (\%) }\end{array}$ \\
\hline Assistente & 120 & 6.942 & 1,73 \\
Substituto & 38 & 3.843 & 0,99 \\
IML & 137 & 3.518 & 3,89 \\
SVO & 57 & 818 & 6,97 \\
Outros & 141 & 2.895 & 4,87 \\
Vazio & 93 & 1.764 & 5,27 \\
\hline Total & $\mathbf{5 8 6}$ & $\mathbf{1 9 . 7 8 0}$ & $\mathbf{2 3 , 7 2}$ \\
\hline
\end{tabular}

Considerando os 19.780 registros, 3.632 (18,36\%) possuem registros de Causas Básicas Externas de Morbidade e Mortalidade (capítulo XX do CID-10). Dentre os 3.632 registros, 185 (5,09\%) foram atestados pelo Assistente, 95 $(2,62 \%)$ pelo Substituto, $3.120(85,90 \%)$ pelo IML, $16(0,44 \%)$ pelo SVO, 88 $(2,42 \%)$ por Outros e $128(3,52 \%)$ apresentaram a variável atestante vazia (Tabela 17).

Tabela 17 - Frequência absoluta e relativa de registros no SIM, segundo Capítulo XX-Causas Externas e Atestantes, Tocantins, Brasil, 2010 a 2012.

\begin{tabular}{lcc}
\hline \multicolumn{1}{c}{ Atestante } & $\begin{array}{c}\text { No de Registros inclusos } \\
\text { no Cap. } \mathbf{X X}\end{array}$ & $\begin{array}{c}\text { Registros inclusos no } \\
\text { Cap. } \mathbf{X X}(\%)\end{array}$ \\
\hline Assistente & 185 & 5,09 \\
Substituto & 95 & 2,62 \\
IML & 3.120 & 85,90 \\
SVO & 16 & 0,44 \\
Outros & 88 & 2,42 \\
Vazio & 128 & 3,52 \\
\hline Total & $\mathbf{3 . 6 3 2}$ & $\mathbf{1 0 0 , 0 0}$
\end{tabular}

Fonte: SIM 
Resultados

Quando relacionados o número de registros de causas básicas de óbitos inclusas no capítulo XX com o número total de registros no SIM para cada atestante, o SVO apresentou a menor proporção de registros de causas básicas externas de óbitos por número total de registros no SIM. O atestante IML foi o atestante que apresentou maior proporção de causas básicas externas de óbitos por número total de registros no SIM (Tabela 18).

Tabela 18 - Frequência absoluta e relativa de registros inclusos no Capítulo XX-Causas externas, por número total de registros para cada Atestante.

\begin{tabular}{lccc}
\hline \multicolumn{1}{c}{ Atestante } & $\begin{array}{c}\text { No Registros no } \\
\text { Cap. XX }\end{array}$ & $\begin{array}{c}\text { Total de Registros } \\
\text { no SIM }\end{array}$ & $\begin{array}{c}\text { Registros no Cap. } \\
\text { XX (\%) }\end{array}$ \\
\hline Assistente & 185 & 6.942 & 2,66 \\
Substituto & 95 & 3.843 & 2,47 \\
IML & 3.120 & 3.518 & 88,68 \\
SVO & 16 & 818 & 1,90 \\
Outros & 88 & 2.895 & 3,03 \\
Vazio & 128 & 1.764 & 7,25 \\
\hline Total & $\mathbf{3 . 6 3 2}$ & $\mathbf{1 9 . 7 8 0}$ & $\mathbf{1 8 , 3 6}$ \\
\hline Fonte: SIM & & &
\end{tabular}

4.5 Resultado da Análise sobre a Completude dos registros sobre as Causas de Mortalidade e Morbidade dentro do Sistema de Informação de Mortalidade para o Estado do Tocantins, 2010-2012.

As causas de mortalidade dentro do SIM compreendem os registros referentes às variáveis Linhas $A, B, C$ e $D$, enquanto os registros contidos dentro da variável Parte II referem-se às morbidades. Foi analisada a completude dos dados registrados no SIM, provenientes dos cinco atestantes referentes às causas de mortalidade e morbidade.

Dentre os 19.780 registros analisados, 1.764 exibiram a variável atestante vazia, impedindo a discriminação dos atestantes: Assistentes, Substitutos, IML, SVO e Outros. No total de 18.016, foi possível discriminar os principais atestantes.

Dentre as linhas analisadas, a Linha $A$ foi a que obteve menor quantidade de campos vazios (413 de $19.780-2,1 \%$ ). A Linha $D$ foi a variável com maior quantidade de campos vazios (15.225 de $19.780-76,9 \%$ ). As 
linhas B, C e Parte II obtiveram campos vazios em 2.855 (14,4\%), 7.733 $(39,1 \%)$ e $14.740(74,3 \%)$, respectivamente (Tabela 19).

Tabela 19 - Frequência absoluta e relativa de campos vazios no SIM, segundo causas de mortalidade e morbidade para o total de registros no SIM, Tocantins, Brasil, 2010 a 2012.

\begin{tabular}{lcc}
\hline \multicolumn{1}{c}{ Variáveis } & No de campos vazios & Campos vazios (\%) \\
\hline Linha A & 413 & 2,1 \\
Linha B & 2.855 & 14,4 \\
Linha C & 7.733 & 39,1 \\
Linha D & 15.225 & 76,9 \\
Parte II & 14.740 & 74,3 \\
\hline
\end{tabular}

Fonte: SIM

Para o atestante Assistente, que totalizou 6.942 registros, a linha D foi a variável com maior número de campos vazios (5.266 de 6.942 - 75,9\%), enquanto a linha A obteve menor número de campos vazios (164 de 6.942 2,3\%). Seguindo em ordem decrescente para as demais linhas: parte II com 4.996 (71,9\%) campos vazios, linha C com 2.752 (39,6\%) e linha B com 869 $(12,5 \%)$ (Tabela 20$)$.

Tabela 20 - Frequência absoluta e relativa de campos vazios no SIM, segundo causas de mortalidade e morbidade para o campo atestante Assistente, Tocantins, Brasil, 2010 a 2012.

\begin{tabular}{lcc}
\hline \multicolumn{1}{c}{ Variáveis } & № de Campos vazios & Campos vazios (\%) \\
\hline Linha A & 164 & 2,3 \\
Linha B & 869 & 12,5 \\
Linha C & 2.752 & 39,6 \\
Linha D & 5.266 & 75,9 \\
Parte II & 4.996 & 71,9 \\
\hline
\end{tabular}

Fonte: SIM

O atestante Substituto obteve 3.843 registros no total. Descrevendo os dados em ordem decrescente, a linha $D$ obteve o maior número de campos vazios, com 2.897 (75,3\%), seguido pela Parte II com 2.518 (65,5\%); 1.561 (40,6\%) para linha C; 491 (12,7\%) para linha B; e linha A com 125 (3,2\%), sendo a variável mais preenchida (Tabela 21). 
Resultados

Tabela 21 - Frequência absoluta e relativa de campos vazios no SIM, segundo causas de mortalidade e morbidade para o atestante Substituto, Tocantins, Brasil, 2010 a 2012.

\begin{tabular}{lcc}
\hline \multicolumn{1}{c}{ Variáveis } & № de Campos Vazios & Campos vazios (\%) \\
\hline Linha A & 125 & 3,2 \\
Linha B & 491 & 12,7 \\
Linha C & 1.561 & 40,6 \\
Linha D & 2.897 & 75,3 \\
Parte II & 2.518 & 65,5 \\
\hline Fonte: SIM & &
\end{tabular}

No total de 3.518 registros do atestante $I M L$, foi obtida como variável com maior número de campos vazios a Parte II (3.134 de 3.1518 - 89,1\%), desviando do padrão apresentado pelos outros atestantes. Segue em ordem decrescente, as outras variáveis: linha D com 2.613 (74,3\%); 1.469 (41,7\%) para a linha C; linha B com $342(9,7 \%)$ e linha A como variável mais preenchida, com $26(0,7 \%)$ campos preenchidos (Tabela 22$)$.

Tabela 22 - Frequência absoluta e relativa de campos vazios no SIM, segundo causas de mortalidade e morbidade para o atestante IML, Tocantins, Brasil, 2010 a 2012.

\begin{tabular}{lcc}
\hline \multicolumn{1}{c}{ Variáveis } & № de Campos vazios & Campos vazios (\%) \\
\hline Linha A & 26 & 0,7 \\
Linha B & 342 & 9,7 \\
Linha C & 1.469 & 41,7 \\
Linha D & 2.613 & 74,3 \\
Parte II & 3.134 & 89,1 \\
\hline
\end{tabular}

Fonte: SIM

O atestante SVO com 818 registros apresentou a variável linha D (662 de 818 - 80,9\%) com menor número de campos preenchidos, seguido pela Parte II com 564 (68,9\%); linha C com 495 (60,5\%); 271 (33,1\%) para linha B e a linha $A$ foi a variável com menor número de campos vazios, com $14(1,7 \%)$ registros. (Tabela 23 ). 
Tabela 23 - Frequência absoluta e relativa de campos vazios no SIM, segundo causas de mortalidade e morbidade para o atestante SVO, Tocantins, Brasil, 2010 a 2012.

\begin{tabular}{lcc}
\hline \multicolumn{1}{c}{ Variáveis } & № de Campos vazios & Campos vazios (\%) \\
\hline Linha A & 14 & 1,7 \\
Linha B & 271 & 33,1 \\
Linha C & 495 & 60,5 \\
Linha D & 662 & 80,9 \\
Parte II & 564 & 68,9 \\
\hline Fonte: SIM & &
\end{tabular}

Dentre os registros do atestante Outros (2.895), a variável que se destacou por apresentar menor número de campos preenchidos foi a linha $D$ com $2.312(80,1 \%)$, dando sequência em ordem decrescente: Parte II (2.074 71,6\%); linha C com 1.456 (50,3\%); 545 (18,8\%) para a linha B e linha A seguindo o padrão de campo mais preenchidos, com 52 de 2.895 (1,7\%) (Tabela 24).

Tabela 24 - Frequência absoluta e relativa de campos vazios no SIM, segundo causas de mortalidade e morbidade para o atestante Outros, Tocantins, Brasil, 2010 a 2012.

\begin{tabular}{lcc}
\hline \multicolumn{1}{c}{ Variáveis } & № de Campos vazios & Campos vazios (\%) \\
\hline Linha A & 52 & 1,7 \\
Linha B & 545 & 18,8 \\
Linha C & 1.456 & 50,3 \\
Linha D & 2.312 & 80,1 \\
Parte II & 2.074 & 71,6 \\
\hline Fonte: SIM & &
\end{tabular}

Para os registros com o campo atestante vazio, sem discriminação de qual atestante registrou os dados, foram colhidos 1.764 registros no total. A linha D, seguindo o padrão do total de atestantes, teve $1.466(83,1 \%)$ campos vazios dos 1.764 registros, seguida pela Parte II com $1.454(82,4 \%)$. Seguem as demais variáveis: linha C com 900 (51\%); linha B com 337 (19,1\%) e linha A com $32(1,8 \%)$ (Tabela 25). 
Resultados

Tabela 25 - Frequência absoluta e relativa de campos vazios no SIM, segundo causas de mortalidade e morbidade para o campo atestante Vazio, Tocantins, Brasil, 2010 a 2012.

\begin{tabular}{lcc}
\hline \multicolumn{1}{c}{ Variáveis } & № de Campos Vazios & Campos vazios (\%) \\
\hline Linha A & 32 & 1,8 \\
Linha B & 337 & 19,1 \\
Linha C & 900 & 51,0 \\
Linha D & 1.466 & 83,1 \\
Parte II & 1.454 & 82,4 \\
\hline
\end{tabular}

Fonte: SIM 


\section{DISCUSSÃO}

\subsection{O Sistema de Informação de Mortalidade}

Para a Organização Mundial de Saúde o controle de qualidade e a verificação do uso de informações em saúde, associados ao treinamento de recursos humanos são ações necessárias para o aprimoramento da informação (WHO, 2015). As incompetências e negligencias de profissionais que lidam com óbitos parecem sustentar a problemática de completude, confiabilidade e credibilidade dos sistemas de informação em mortalidade nos países subdesenvolvidos (WHO, 2010).

O Index Nacional de Mortalidade nos Estados Unidos é composto por informações de mortalidade oriundas de subsistemas diversos como o VHA (Veterans Health Administration) e SSA (Social Security Administration) que se apresenta como um parâmetro para determinar a sensibilidade (percentual de dados corretamente registrados em um sistema) dos sistemas de mortalidade nos EUA. Esta combinação de subsistemas aumenta a fidedignidade dos dados sobre mortalidade, pois reduz a incompletude de dados (SOHN, MINWOONG, 2006).

No Brasil, o SIM foi idealizado em 1976 para funcionar como ferramenta de captação de dados e produção de estatísticas vitais para facilitar a gestão pública sanitária. A municipalização de serviços de saúde do SUS alavancou a necessidade de descentralizar os sistemas de informações (ALMEIDA, 1998). Consoante com o projeto de municipalização e regionalização do SIM/MS em 1995, os registros sobre as causas de óbitos sofreram aumento progressivo no SIM para o Estado do Tocantins, porém os baixos índices completude e a alta incidência de causas básicas de óbitos mal definidas parecem dificultar 0 estabelecimento da confiabilidade e da credibilidade do SIM para o Estado do Tocantins.

A coleta dos dados sobre mortalidade para o SIM é permanente, com consolidação mensal por municípios, estados e consolidação anual em nível federal. A divulgação nacional dos dados é realizada anualmente, sob forma de anuários, boletins e CD-ROM (IBGE, 2016), entretanto durante a coleta de dados secundários para este estudo foi observada diferença quantitativa entre 
Discussão

os registros de óbitos no SIM do Ministério da Saúde e os registros de óbitos no SIM para o Estado do Tocantins.

A diferença quantitativa de dados encontrada entre o SIM do Ministério da Saúde e o SIM para o Estado do Tocantins pode ser explicada pela persistência de captação de dados pelo sistema estadual, mesmo após a consolidação e o envio de dados ao sistema nacional. Ao pré-determinar este prazo de entrega de dados, o SIM do Ministério da Saúde parece perder quantidade de registros que poderiam influenciar a quantidade e a qualidade da análise estatística nacional.

A existência de subregistros dos eventos vitais e falhas na cobertura do SIM podem interferir na fidedignidade dos dados de mortalidade (HARAKI, GOTILIEB, LAURENTI, 2005). A cobertura do SIM/TO exibiu valores que flutuaram entre $42 \%$ e $80 \%$ nos últimos dez anos. Em 2004, o Tocantins apresentou cobertura de $71 \%$, valor inferior à cobertura para a região Norte de 76,2\% (BRASIL, 2005), entretanto em 2015 a cobertura alcançou mais de 80\%, classificando o SIM para o Estado do Tocantins entre os três mais abrangentes sistemas da região norte (TOCANTINS, 2016).

A Secretaria de Saúde do Estado do Tocantins possui um setor com profissionais especializados em codificar as informações das Declarações de Óbitos e digitá-las no SIM. A alta rotatividade de servidores públicos nos setores que lidam com o SIM em nível municipal e estadual parece também dificultar a sustentabilidade a qualidade de codificação, digitação e envio de dados ao SIM nacional.

A qualidade e a completude das informações médicas sobre mortalidade que alimentam o SIM no Tocantins podem sofrer influência dos codificadores, alterando resultados relacionados à qualidade e completude de informações exclusivamente descritas por médicos no SIM do Tocantins. Os codificadores interpretam e analisam as informações médicas da DO e quando detectam campos ou variáveis na DO não preenchimento ou vazios, promovem busca ativa de informações frente aos municípios.

Contudo, após a busca ativa de informações negligenciadas no preenchimento das DO contidas nas DO, os codificadores lançam informações buscadas ativamente no SIM, visando contribuir para a completude de dados sobre a mortalidade no Tocantins. 


\subsection{Completude de dados}

Conhecer a completude de dados sobre mortalidade permite ajustar metodologias de trabalho que aprimoram a qualidade e a confiabilidade dos dados, viabilizando a utilização de informações em estudos demográficos para projetar o futuro das populações (EDUARDO, 1994).

Nos EUA (Estados Unidos da América), o arquivo de mortalidade do BIRLS em (Subsistema de Registro, Locação e Identificação de Beneficiários), que contem dados sobre mortalidade de beneficiários do Departamento de Cônjuges de Veteranos dos EUA, é uma das bases de dados sobre mortalidade existente naquele país, entretanto não é uma fonte de informações fidedigna pela incompletude de dados (SOHN, MIN-WOONG, 2006).

Ao avaliarmos a completude de dados registrados pelos cinco possíveis atestantes no SIM do Estado do Tocantins verificamos que a qualidade dos dados registrados no Sistema de Informações em Saúde do Ministério da Saúde pode corroborar com o relato da Organização Mundial de Saúde quanto a baixa confiabilidade dos dados e estatísticas de mortalidade de países subdesenvolvidos (RAMPATIGE, 2014).

Ao estudarmos os registros de óbitos no SIM/TO provenientes dos 5 possíveis atestantes, não foi possível identificar o atestante em 10\% dos 19780 registros de óbitos no SIM do Estado do Tocantins entre os anos de 2010 e 2012. A dificuldade em identificar o tipo de atestante pode ser explicada pelo preenchimento inadequado das DO. A negligência de informações na DO, mormente as omissões no preenchimento das variáveis de preenchimento médico exclusivo, contidas na DO refletem o desconhecimento do médico sobre o seu papel (VANDERLEl et al, 2002).

O livreto "A Declaração de Óbitos, 2006" do Ministério da Saúde não especifica o significado, tampouco esclarece quando o item outros na variável Atestante deverá ser assinalado. Entretanto de acordo com o Manual de Preenchimento da DO, a diferença entre quando assinalar outros ou substitutos pode não parecer claro para médicos e não médicos.

Para assinalar no campo atestante a variável outros, os médicos que assinam a DO serão aqueles que: não assistiram ao falecido durante a doença ou na ocasião da morte para casos de óbitos não fetais, não assistiram à mãe 
para casos de óbitos fetais, ou aqueles médicos que assistiram óbitos que não estão enquadrados nas categorias assistente, substituto, IML e SVO.

A variável substitutos é assinalada por médicos que assinam a DO como plantonistas, residentes ou chefes de equipe e que não acompanharam o falecido durante a doença, mas apenas por ocasião da morte (BRASIL, 2011a).

A identificação, a interpretação e o ato de assinalar a variável Atestante pelos profissionais que lidam com a emissão de DO parece apresentar dúvidas quanto ao seu significado, e.g. dentro da variável Atestante existe a alternativa Outros que, apesar de ser uma variável de preenchimento médico exclusivo, pode ser interpretada e assinalada por não médicos quando a DO é emitida em localidades sem médicos, alterando a qualidade das informações e estudos analíticos sobre o tipo de atestante (BRASIL, 2011a).

A imperícia por parte de médicos e de demais profissionais da saúde em lidar com as variáveis contidas na DO pode explicar os $8,92 \%$ de registros com a variável Atestante vazia ou não preenchida dentre os 19.780 registros estudados no SIM para o Estado do Tocantins. A variável Atestante vazia impossibilita a identificação do atestante responsável pelos dados registrados no SIM para o Estado do Tocantins. A emissão de DO por patologistas, o cuidado na formação de médicos e de codificadores pode reduzir a subnotificação e melhorar a qualidade dos dados sobre mortalidade (MCCAWBINNS; HOLDER; MULLINGS, 2015)

A ausência de uma "cultura de uso" dos sistemas de informação em saúde pública gera em alguns gestores sensação de insuficiência e desconfiança das informações contidas no DATASUS (NOVATO-SILVA, 2009). A carência de disciplinas epidemiológicas, nos planos diretores de ensino médico e de programas de educação médica continuada em epidemiologia associadas à ineficiência dos núcleos de vigilância hospitalares e da gestão em saúde pública parecem contribuir para insensibilidade dos profissionais da saúde sobre a importância e prioridade em qualificar informações no SIM.

Questões de legalidade sobrepõem às questões epidemiológicas, o que parece dificultar os esclarecimentos sobre a importância das estatísticas vitais para o setor de saúde no Tocantins. Pela lei de registros públicos não se pode sepultar um cadáver com morte natural ou externa sem a devida identificação da causa da morte. A emissão da certidão de óbito pelos cartórios no Estado 
Discussão

do Tocantins parece ocorrer apesar da ausência de informações médicas definidas e especificadas sobre as causas de mortalidade e de morbidade, contrariando a legislação nacional (BRASIL, 2016a).

No presente estudo, algumas variáveis selecionadas para a avaliação da completude dos dados no SIM para o Estado do Tocantins apresentaram-se $100 \%$ preenchidas ou completas. As informações que compilaram dados com máxima completude no SIM foram àquelas relacionadas à identificação do falecido e que são exigidas pelos cartórios para registros dos óbitos e para as emissões de Certidões de Óbitos.

Entretanto as variáveis, cujas informações deveriam ser fornecidas por médicos, sobre as causas da morte apresentaram-se não preenchidas ou vazias. A variável Linha $D$ relacionada à causa básica de óbito encontrou-se vazia ou não preenchida em $80 \%$ dos casos tanto nos registros do SVO quanto nos registros dos demais atestantes. Estas variáveis, relacionadas as causas dos óbitos, deveriam ser exigidas pelos cartórios seguindo a Lei de Registros Públicos, mas no Estado do Tocantins parece não haver legal exigência cartorial.

A baixa diferença estatística entre os dados registrados pelo SVO e pelos demais atestantes dentro do SIM para o Estado do Tocantins pode sugerir uma homogenia insensibilidade da classe médica sobre a importância epidemiológica das informações sobre mortalidade, independente do local onde os atestantes médicos exercem a medicina: Unidades nosocomiais, Institutos Médicos Legais e Serviços de Verificação de Óbitos. A ativa busca por dados sobre os óbitos de residentes no Tocantins pelos codificadores de DO das Secretarias Municipais e Estaduais também pode ter contribuído para diminuta diferença de completude entre os dados do SVO e dos demais atestantes para o SIM para o Estado do Tocantins.

\subsection{Completude de Dados no Serviço de Verificação de Óbitos}

Os SVO foram criados para, dentre outras obrigações, aumentarem a quantidade e a qualidade das informações sobre óbitos no SIM do Ministério da Saúde (BRASIL, 2006b). Em 2012 no estado de Pernambuco, as DO emitidas pelos SVO que geraram registros de óbitos no SIM representaram $14,4 \%$ 
Discussão

(AZEVEDO, 2016). No Estado do Tocantins, o SVO foi instituído em 2006 e entre os anos de 2010, 2011 e 2012 registrou 818 registros dentre os 19.780 registros analisados compreendendo apenas $4,14 \%$.

A recente implantação do SVO no Estado do Tocantins, a precária divulgação, o desentendimento das finalidades deste serviço pelos médicos que atuam nas unidades de saúde em Palmas e Araguaína, associado à dificuldades estruturais físicas e logísticas de remoções cadavéricas podem constituir o cerne da baixa prevalência de óbitos encaminhados ao SVO-TO e da reduzida proporção de óbitos registrados no SIM.

ALMEIDA et al. (2011) descreveu que é necessário aprimorar a completude de causas de óbitos fetais, entretanto revelou que uma elevada proporção de necropsias fetais não contribui para a qualidade das informações das causas de óbitos. A não admissibilidade de necropsias fetais no Serviço de Verificação de Óbitos no Estado do Tocantins não permitiu análise dos dados registrados pelo SVO sobre óbitos fetais no SIM para o Estado do Tocantins.

Segundo BRASIL 2009a, os óbitos fetais são declarados por médicos que assistiram à mãe ou à criança e mesmo os nascidos vivos que pouco tempo depois falecem, segue obrigatoriamente esta determinação ministerial no Estado do Tocantins. Médicos pediatras e ginecologistas podem sentir-se confusos, principalmente para casos de nascidos vivos cujo "pouco tempo depois" parece ser diferente para cada profissional medico e eventualmente, esses médicos acionam para óbitos fetais naturais mal definidos, porém o SVO-TO os orienta conforme a portaria ministerial.

CARVALHO et al. (2016) ao analisar 23 variáveis nos registros do SVO do Estado do Tocantins no SIM descreveu que o percentual médio de campos não preenchidos por variáveis no SVO-TO foi de $18,2 \%$ e considerando os demais atestantes (IML, assistentes, substitutos e Outros), de 16,8\%. Estatisticamente não havia diferença significativa proporcional na quantidade de campos vazios e preenchidos comparando SVO e demais atestantes.

Nos 818 registros do SVO, 11,7\% apresentaram a variável Necropsia vazia ou não preenchida ratificando a imperícia ou mesmo indicando negligência entre os médicos do SVO-TO ao declararem nas DO do SVO informações sobre os óbitos e sobre a realização do exame necroscópico. 
Discussão

A completude de dados dentro do SIM para o Estado do Tocantins registrado pelo SVO parece não diferir da completude de dados registrados pelos demais atestantes, pois o percentual da variável com maior completude e o percentual da variável com menor completude dentre os registros do SVO foram os mesmos percentuais das variáveis de maior e de menor completude dentre os registros dos demais atestantes.

De acordo com MENDONÇA, DRUMOND e CARDOSO 2010, mesmo os médicos preocupando-se apenas com as informações sobre as causas de mortalidade e de morbidade permanece a dificuldade em sequenciar os eventos de modo cronológico desde a causa básica do óbito, passando pelas causas intermediárias e culminando na causa da morte.

O alto percentual de completude da variável Linha $A$ referente às informações sobre o evento final da causa da morte e o baixo percentual de completude da variável Linha $D$ referente à causa básica de óbito pode indicar o modo de preenchimento das declarações de óbitos pelo SVO e pelos demais atestantes.

A semelhança entre o percentual médio de completude das 23 variáveis para o SVO e para os demais atestantes sugere reflexões sobre a eficácia do SVO em melhorar as informações sobre mortalidade no Estado do Tocantins. Criado como instrumento de elucidação das causas mal definidas por meio de necropsias, esperava-se melhores percentuais de completude de dados sobre mortalidade no SVO.

\subsection{Causas básicas de óbitos}

No presente estudo, o IML que deveria registrar apenas causas básicas externas de óbitos, apresentou significativo número de registros de causas básicas não externas. Entretanto, as causas básicas de óbitos relacionadas ao aparelho cardiocirculatório foram as causas básicas mais registradas pelos demais atestantes no SIM para o Estado do Tocantins.

As causas de óbitos mal definidas, incompletas e os registros sobre óbitos fetais e maternos causam dificuldades no conhecimento da realidade sobre a mortalidade nacional (MELLO JORGE et al., 2002). Em Santa Catarina 
o percentual de óbitos com causas mal definidas passou de 8,6\% em 2007 para 3,5\% em 2013 (SESC, 2016).

Os números para as causas básicas mal definidas no SIM para o Estado do Tocantins estão abaixo da media nacional. Em 2003, a média nacional de causas básicas de óbitos mal definidas era de 13,3\% (SANTO, 2008). A proporção nacional de causas mal definidas passou de 15,1\% em 2006 para 12,4 em 2004 (BRASIL, 2011a). Dentre os 19.780 registros estudados encontramos $100 \%$ de completude para a variável causa básica de óbitos, entretanto o índice de causas básicas mal definidas foi de 2,9\% com 586 registros.

ROZMAN e NETO 2006, concluíram que baixas proporções de causas de óbitos mal definidas ocorrem em virtude da realização de um maior número de necropsias. No SVO do Tocantins todos os cadáveres admitidos são necropsiados antes da emissão da $\mathrm{DO}$, entretanto ao analisarmos os registros de causas básicas mal definidas por atestantes, o SVO-TO possui proporcionalmente o maior percentual de causas básicas mal definidas.

O descaso dos médicos necropsistas ao preencherem a DO, a imperícia na realização dos exames necroscópicos, irregularidades no fluxo de informações entre SVO e SIM, dificuldades técnicas laboratoriais e administrativas podem justificar a alta proporção de registros com causas de óbitos mal definidas no SVO.

Determinar e especificar as causas básicas externas de óbitos no Brasil constitui um desafio, pois apesar da melhoria na especificação entre óbitos por causa externas acidentais ou intencionais, permanecem altos índices de óbitos com diagnósticos incompletos somadas ao interesse dos médicos legistas com a natureza da morte não sendo conhecidas as circunstâncias do falecimento (MELLO JORGE et al., 2012).

A presença de registros de causas básicas externas contidas nos registros do SVO no SIM para o Estado do Tocantins sugere irregularidades no fluxo cadavérico e desconhecimento dos médicos que solicitam o exame necroscópico ao SVO e dos médicos necropsistas do SVO sobre as implicações legais que podem ser imputadas à médicos não legistas que emitem DO para óbitos por causas externas. 
Discussão

A proporção de registros de causas básicas externas fora do IML pode demonstrar a baixa cobertura do IML dentre as regiões de saúde do Estado do Tocantins, a presença de áreas com cobertura por médicos nomeados peritos "ad hoc", ou a revelar a imperícia, negligência e imprudência médica ao discriminar os óbitos em naturais ou externos.

\subsection{Completude dos registros sobre causas de mortalidade e morbidade}

FÉLIX et al., 2012 ao analisar a completude de dados do SIM no Espírito Santo sugeriu formação epidemiológica para profissionais de saúde em faculdades de medicina como medida para aprimorar a habilidades nos registros de dados em sistemas de saúde.

A habilidade no preenchimento da DO parece ser semelhante dentre os atestantes no Estado do Tocantins. A variável Linha A referente a causa do óbito apresentou maior completude e a variável Linha $D$ referente à causa básica do óbito revelou menor completude, independente do tipo de atestante, em todos os registros analisados.

No estudo epidemiológico de 625 casos de suicídio em idosos, (RIOS et al., 2013) relatou que houvera redução da incompletude de dados quando a necropsia era utilizada para elucidação da causa básica. Nos 19.780 registros analisados, a realização do exame necroscópico pareceu não aprimorar a completude de dados no SIM para IML e SVO, pois houve semelhança estatística quando comparados os dados sobre mortalidade e morbidade entre os atestantes IML e SVO com os dados de substitutos, assistentes e outros. 


\section{CONCLUSÕES}

No triênio 2010, 2011 e 2012 foram registrados com maior frequência óbitos do sexo masculino, cor parda, naturais do Estado do Tocantins, maiores que 75 anos, casados, sem escolaridade, ocorridos em hospitais na $17^{\mathrm{a}}$ hora do mês de setembro e de aposentados e/ou pensionistas residentes em Araguaína.

Os resultados indicaram que existe uma incompletude de dados superior a $10 \%$ dentre os registros de óbitos para o SIM do Estado do Tocantins. O SVO e o IML deveriam fornecer mais informações sobre as causas da morte, as morbidades e sobre a natureza das lesões externas, em razão da execução de necropsias. Não houve diferença estatística significativa entre a completude de dados do SVO do Estado do Tocantins quando comparada com a completude de dados dos demais atestantes: IML, assistentes, substitutos e Outros.

Existe uma baixa captação de óbitos pelo SVO-TO associada a uma alta prevalência de registros de causas básicas mal definidas, mesmo após a realização de exames necroscópicos. Em 8,92\% dos registros de óbitos analisados no SIM para o Estado do Tocantins não foi possível identificar a fonte de dados, devido a incompletude da variável Atestante.

Nos registros para o SVO, a incompletude de dados totais foi de $18,2 \%$, a variável Necropsia apresentou incompletude de $11,7 \%$ e a variável que representa a causa básica de óbitos (LINHA D) encontra-se incompleta em $80 \%$ dos registros. A principal causa básica de óbitos encontrada dentre os registros do SVO estava relacionada ao Capítulo IXI das Doenças do Aparelho Circulatório. Existiam causas básicas externas de óbitos indevidamente registradas e números de causas básicas mal definidas acima da média nacional registradas pelo SVO-TO no SIM.

No triênio 2010, 2011 e 2012 foram registrados com maior frequência óbitos do sexo masculino, cor parda, naturais do Estado do Tocantins, maiores que 75 anos, casados, sem escolaridade, ocorridos em hospitais na $17^{\text {a }}$ hora do mês de setembro e de aposentados e/ou pensionistas residentes em Araguaína.

A habilidade e competência de registros de dados sobre mortalidade e morbidade não diferem entre os atestantes no Estado do Tocantins. A baixa 
Conclusões

completude de dados no SIM pode comprometer a eficácia, a manutenção, e geram dúvida quanto à acreditação da atividade médica no SVO, e nas instituições de saúde onde trabalham médicos assistentes, substitutos e médicos legistas que representam os demais atestantes.

Qualificar e creditar as informações sobre mortalidade parece envolver tanto a sensibilização da classe médica do Tocantins quanto a criação de uma "cultura da informação epidemiológica" e as instituições de ensino superior quanto a revisão de grades curriculares e de implantação de metodologias ativas que comtemplem a importância da epidemiologia no âmbito da saúde pública.

Ações visando à sensibilização do principal agente neste caso, o médico, devem ser implementadas com o objetivo de melhorar a qualidade do preenchimento da D.O., em especial, junto ao SVO por meio de educação médica continuada e fortalecimento do fluxo de informações entre instituições que lidam com óbitos podem fortalecer as elaboração e gestão de políticas públicas sanitárias. 


\section{REFERÊNCIAS}

ALMEIDA, M.F. Descentralização de Sistemas de Informação e o uso das informações a nível Municipal. Inf. Epidemiol. Sus, Brasília, v. 7, n. 3, p. 2733, set. 1998.

ALMEIDA, M.F.; ALENCAR, G.P.; SCHOEPS, D.; MINUCI, E.G.; SILVA, Z.P.; ORTIZ, L.P.; NOVAES, H.M.D.; ALENCAR, A.P.; RASPANTINI, P.R. ; SANTOS, P.C.; Qualidade das informações registradas nas declarações de óbito fetal em São Paulo, SP. Revista de Saúde Pública, [s.I.], v. 45, n. 5, p.845-853, out. 2011.

AYRES, Manuel; AYRES Jr, Manuel; AYRES, Daniel Lima; SANTOS, Alex de Assis dos Santos. BioEstat: aplicações estatísticas nas áreas das ciências biológicas e médicas. Belém; Sociedade Civil Mamirauá: MCT-CNPq, 2007.

AYRES, M. et al. BioEstat 5.3: Aplicações Estatísticas nas Áreas das Ciências Biológicas e Médicas. 5a ed. Belém-PA: Publicações Avulsas do Mamirauá, p. 361, 2011.

AZEVEDO, B.A.S. Avaliação da Implantação dos Serviços de Verificação de Óbito do Estado de Pernambuco. Dissertação. Instituto de medicina integral prof. Fernando Figueira, programa de pós-graduação em avaliação em saúde mestrado profissional em avaliação em saúde. Recife, 60f. 2014.

BRASIL. Art. nํ 162, de 1941. Código Processo Penal Brasileiro. Brasília, 1941.

BRASIL. Ministério da Saúde. Secretaria de Vigilância em Saúde. Sistema Nacional de Vigilância em Saúde: relatório de situação: Tocantins / Ministério da Saúde, Secretaria de Vigilância em Saúde. - Brasília: Ministério da Saúde, 2005. 20 p .: il. color. - (Série C. Projetos, Programas e Relatórios)

BRASIL. Ministério da Saúde. Sistema Nacional de Vigilância em Saúde: Relatório de Situação. 2 ed. Tocantins, $2006 a$.

BRASIL. Portaria no 1.405, de 29 de junho de 2006. Institui a Rede Nacional de Serviços de Verificação de Óbito e Esclarecimento da Causa Mortis (SVO). Diário Oficial da república Federativa do Brasil, Brasília, DF, 30 jun. Seção 1, p. 242-244, 2006b.

BRASIL. Ministério da Saúde. Portaria MS/GM no 116, de 11 de fevereiro de 2009. Regulamenta a coleta de dados, fluxo e periodicidade de envio das informações sobre óbitos e nascidos vivos para os Sistemas de Informações em Saúde sob gestão da Secretaria de Vigilância em Saúde. Diário Oficial da União da República Federativa do Brasil, Brasília, DF, 11 de fevereiro, 2009a.

BRASIL. Ministério da Saúde. Manual para Investigação do Óbito com 
Causa Mal Definida. Série A. Normas e Manuais Técnicos. Brasília-DF, 2009c.

BRASIL. Ministério da Saúde. Secretaria de Vigilância em Saúde. Departamento de Análise de Situação de Saúde. Manual de instruções para - preenchimento da declaração de óbito. Brasília: Ministério da Saúde. Fundação Nacional de Saúde, 4. ed, p. 55, 2011a.

BRASIL. Ministério da Saúde. Secretaria de Vigilância em Saúde. Departamento de Análise de Situação de Saúde. Instrutivo Busca direcionada de registro de nascimentos e óbitos em municípios da Região Nordeste e Amazônia Legal. 1. ed. Brasília: Ministério da Saúde, p. 60, 2011b.

BRASIL. O Decreto no 7.508/11 e os desafios da gestão do SUS. Ministério da Saúde. 2014.2 Disponível em <http://bvsms.saude.gov.br/bvs/folder/regionalizacao_saude_decreto_7508.pdf

BRASIL. Ministério da Saúde. Datasus: informações de saúde. Disponível em: www2.datasus.gov.br. Acesso em: 11 ago. 2015.

BRASIL. Lei 6.015, de 31 de dezembro de 1973. Dispõe sobre os registros públicos, e dá outras providências. Disponível em: <http://www.planalto.gov.br/ccivil_03/leis/L6015compilada.htm>. Acesso mar. $2016 \mathrm{a}$.

BRASIL. Programa das Nações Unidas para o Desenvolvimento. Índice de Desenvolvimento Humano. Disponível em: <http://www.pnud.org.br>. Acesso mar. 2016b.

CARIRI, Portal Tv. Portal TV Cariri. Disponível em: <http://www.portaltvcariri.com.br/>. Acesso em: 27 ago. 2016.

CARVALHO, A.A.B, GARCIA, E.G.; ARAÚJO, L.B; HAHMANN, L.; JUNIOR, M.L.C.; LIMA, R.C.; BATISTA, T.C.A.; Avaliação da Campletude de Dados do Serviço de Verificação de Óbitos do Estado do Tocanitns no Sistema de Informação de Mortalidade. Revista de Patologia do Tocantins, v.3, n.2, 2016. Disponível em: <http://revista.uft.edu.br/index.php/patologia/article/view/1819>

CEARÁ, Governo do Estado do. Governo do Estado do Ceará. Disponível em: <http://www.ceara.gov.br/>. Acesso em: 27 ago. 2016.

CENTERS FOR DISEASE CONTROL AND PREVENTION. Report of the panel to evaluate the US standard certificates. Division of Vital Statistics, National Center for Health Statistics, nov. 2001. Disponível em: http://www. cdc.gov/nchs/data/dvs/panelreport_acc. pdf. Acesso em: 30 de maio de 2015.

COLIN, M.; DORIS, M.F.; MIE, I.; CHALAPATI, R.; LOPES, D. Counting the dead and what they died from: an assessment of the global status of cause of death data. In: Bulletin of the World Health Organization; Past issues, v. 82, n. 3, 2005. 
CONSELHO FEDERAL DE MEDICINA (Brasil). Resolução $n \cong 1.179$, de 11 de novembro de 2005. Diário Oficial [da República Federativa do Brasil], Seção 1, Brasília - DF, p. 121, 5 dez. 2005.

DATASUS. Informações de Saúde. Disponível em: <http://www2.datasus.gov.br/DATASUS/index.php>. Acesso em: 27 ago. 2014.

EDUARDO, E. ARRIAGA, A.; PETER D. J.; JAMISON E. International Institute for Vital Registration and Statistics. Techniques for Evaluating Completeness of Death Reporting. n. 57, p. 15, jun, 1994.

\section{ELLINGER, F.; BEZERRA, K.C.A. Manual de Procedimentos do Serviço de Verificação de Óbitos de Marília. Famema, p. 15, 2011.}

FELIX, J. D. et al. Avaliação da completude das variáveis epidemiológicas do Sistema de Informação sobre Mortalidade em mulheres com óbitos por câncer de mama na Região Sudeste: Brasil (1998 a 2007). Ciênc. saúde coletiva, Rio de Janeiro, v. 17, n. 4, p. 945-953, Apr. 2012. Available from $<\mathrm{http}$ ://www.scielo.br/scielo.php?script=sci_arttext\&pid=S1413-

81232012000400016\&lng=en\&nrm=iso>. Acesso em: 02 Sept. 2016. http://dx.doi.org/10.1590/S1413-81232012000400016.

FIGUEIROA, Barbara de Queiroz et al. Análise da cobertura do Sistema de Informações sobre Mortalidade em Olinda, Pernambuco, Brasil. Cad. Saúde Pública, Rio de Janeiro , v. 29, n. 3, p. 475-484, Mar. 2013. Available from <http://www.scielo.br/scielo.php?script=sci_arttext\&pid=S0102-

311X2013000300006\&lng=en\&nrm=iso >. Acesso em: 25 June 2016. http://dx.doi.org/10.1590/S0102-311X2013000300006.

FRANCA, Elisabeth Barboza et al. Avaliação da implantação do programa "Redução do percentual de óbitos por causas mal definidas" em um estado do Nordeste do Brasil. Rev. bras. epidemiol., São Paulo , v. 17, n. 1, p. 119-134, Mar. 2014. Available from <http://www.scielo.br/scielo.php? script=sci_arttext\&pid=S1415-790X2014000100119\&Ing=en\&nrm=iso >. Acesso em: 30 Aug. 2016. http://dx.doi.org/10.1590/1415-790X201400010010ENG.

FRIAS, Paulo Germano de et al. Avaliação da adequação das informações de mortalidade e nascidos vivos no Estado de Pernambuco, Brasil. Cad. Saúde Pública, Rio de Janeiro, v. 26, n. 4, p. 671-681, Apr. 2010. Available from <http://www.scielo.br/scielo.php?script=sci_arttext\&pid=S0102-

$311 \times 2010000400010 \& \operatorname{lng}=$ en\& $n r m=$ iso $>$.

access on 02 Sept. 2016. http://dx.doi.org/10.1590/S0102-311X2010000400010.

GOTHE, Melaine. Jornal do Tocantins, 2016 disponível em $<$ http://www.jornaldotocantins.com.br/editorias/vida-urbana/quanto-vale-a-vidano-tr\%C3\%A2nsito-1.1058575>

HARAKI, Cristianne Aparecida Costa; GOTLIEB, Sabina Léa Davidson; LAURENTI, Ruy. Confiabilidade do Sistema de Informações sobre Mortalidade 
em município do sul do Estado de São Paulo. Rev. bras. epidemiol., São Paulo, v. 8, n. 1, p. 19-24, Mar. 2005. Available from $<$ http://www.scielo.br/scielo.php?script=sci_arttext\&pid=S1415-

790X2005000100003\&lng=en\&nrm=iso >. access on 30 Aug. 2016. http://dx.doi.org/10.1590/S1415-790X2005000100003

HOYERT, D. The autopsy, medicine, and mortality statistics. National Center for Health Statistics. Vital Health Stat, v. 3, n. 32, 2001.

IBGE. Sistema de Informações de Mortalidade. 2016. Disponível em: $<$ http://ces.ibge.gov.br/base-de-dados/metadados/ministerio-da-saude/sistemade-informacoes-de-mortalidade-sim.html>. Acesso em: 08 ago. 2016.

JUNDIAÍ, Jornal de. Jornal de Jundiaí. Disponível em: <http://www.jj.com.br/>. Acesso em: 27 ago. 2016.

LAURENTI, R. Pesquisas na área de classificação de doenças. Saúde e Sociedade, v. 3, n. 2, p. 112-126, 1994.

LAURENTI, R; MELLO JORGE, M.H.P. O Atestado de Óbito. São Paulo: CBCD, p. 87, 1996.

LAURENTI, R; MELLO JORGE M.H.P.; GOTLIEB, S.L.D. O Sistema de Informações sobre Mortalidade: passado, presente e futuro. CBCD, São Paulo, p. 107, 2006.

LUCENA, L. et al. Declaração de Óbito: preenchimento pelo corpo clínico de um hospital universitário. Rev. bioét, v. 22, n. 2, p. 318-24, 2014.

MARCO, C.P.A. Instituto de Historia de la Ciencia y Documentación (Universidad de Valencia-CSIC). Outubro, 1999.

MARTINS, J.D.F.; COSTA T.M.; SOUZA, N.J.F.N.; GUIMARÃES, C.A.S. Óbitos classificados como sinais, sintomas e afecções mal definidas na região nordeste do Brasil, 1980-2003. Universidade Federal de Feira de Santana, Bahia, 2005.

MATHERS C.D.; VOS T.; LOPEZ A.D.; SALOMON J.; EZZATI M. (ed.) National burden of disease studies: a practical guide. Edition 2.0. Global Program on Evidence for Health Policy. Genebra, World Health Organization, 2001.

MATHERS C.D.; FAT D.M.; INOUE M.; RAO C.; LOPEZ A.D. Counting the dead and what they died from: an assessment of the global status of cause of death data. Bull World Health Organ, v. 83, n. 3, p. 171-77, mar. 2005.

MCCAW-BINNS, A.; HOLDER, Y.; MULLINGS, J. Certification of Coroners cases by pathologists would improve the completeness of death registration in Jamaica. Journal Of Clinical Epidemiology, v. 68, n. 9, p.979-987, set. 2015. Elsevier BV. http://dx.doi.org/10.1016/j.jclinepi.2014.11.026.

MELLO JORGE M.H.P et al. Sistema de informação sobre nascidos vivos - 
SINASC / Information system onlivenewborn. Centro Brasileiro de Classificação de Doenças, São Paulo, 1992.

MELLO JORGE M.H.P.; GOTLIEB, S.L.D.; LAURENTI, R. O sistema de informações sobre mortalidade: problemas e propostas para 0 seu enfrentamento II - Mortes por causas externas. Rev. Bras. Epidemiol, São Paulo, v. 5, n. 2, p. 212-223, Ago. 2002.

MELLO JORGE M.H.P; LAURENTI R.; GOTLIEB S.L.D. Análise da qualidade das estatísticas vitais brasileiras: a experiência de implantação do SIM e do SINASC. Ciênc Saúde Coletiva, Rio de Janeiro, v.12 n.3, p. 643-54, mai/jun. 2007.

MELLO JORGE M.H.P; LAURENTI R.; GOTLIEB S.L.D. Avaliação dos Sistemas de Informação em Saúde no Brasil. Cad. Saúde Coletiva, Rio de Janeiro, v.18 n.1, p. 07-18, 2010.

MELLO JORGE M.H.P et al. Em busca de melhores informações sobre a causa básica do óbito por meio de linkage: um recorte sobre as causas externas em idosos-Estado do Rio de Janeiro, Brasil, 2006. Epidemiologia e Serviços de Saúde, v. 21, n. 3, p. 407-418, 2012.

MENDONÇA E.F.; GOULART E.M.A.; MACHADO J.A.D. Confiabilidade da declaração de causa básica de mortes infantis em região metropolitana do sudeste do Brasil. Revista de Saúde Pública, v. 28, n. 5, p. 385-391, 1994.

MENDONÇA, F.M.; DRUMOND, E.; CARDOSO, A.M.P. Problemas no preenchimento da Declaração de Óbito: estudo exploratório. Revista Brasileira de Estudos de População, Rio de Janeiro, v. 27, n. 2, p. 285-295, jul./dez. 2010.

NASCIMENTO, J.F.C.G.; GIL, J.L.A.; PASQUALUCCI, C.A; JACOB FILHO, W. Aspectos necrológicos do envelhecimento. Diagn. Tratamento, v. 17, n. 1, p. 58, 2012.

NOROESTE, Região. Região Noroeste. Disponível em: <http://regiaonoroeste.com/portal/home.php>. Acesso em: 27 ago. 2015.

NOVATO-SILVA, J.W., MARTELETO, R.M. Os Aspectos informacionais da cultura na gestão pública da saúde. In: editores. ANCIB 2009: Fórum de Coordenadores de Grupos de Trabalho da ANCIB, p. 15, 2009.

OLIVEIRA, Maria Liz Cunha de; SOUZA, Luiz Augusto Copati. Causas externas: investigação sobre a causa básica de óbito no Distrito Federal, Brasil. Epidemiol. Serv. Saúde, Brasília, v. 16, n. 4, p. 245-250, dez. 2007. Disponível em <http://scielo.iec.pa.gov.br/scielo.php?script=sci_arttext\&pid= S1679-49742007000400003\&lng=pt\&nrm=iso >. Acesso em: 30 ago. 2016. http://dx.doi.org/10.5123/S1679-49742007000400003. 
PAES, N. A. Qualidade das estatísticas de óbitos por causas desconhecidas dos Estados brasileiros. Rev. Saúde Pública, São Paulo, v. 41, n. 3, p. 436445, jun. 2007.

PAES N.A; ALBUQUERQUE M.E.E. Avaliação da qualidade dos dados populacionais e cobertura dos registros de óbitos para as regiões brasileiras. Rev. Saúde Pública, São Paulo, v. 33, n. 1, p. 33-43, fev. 1999.

PORTARIA DGP 14, de 23-2-2005. Disciplina a coleta, registro, processamento, análise e difusão das informações relativas às ocorrências de morte. Diário Oficial Poder Executivo - Seção I São Paulo, 115 (36) - 7, 24 de fevereiro de 2005.

RAMPATIGE, R.; MIKKELSEN, L.; HERNADEZ, I.R.; LOPEZ, A.D.; Systematic review of statistics on causes of deaths in hospitals: strengthening the evidence for policy-makers. Bull World Health Organ 2014;92:807-816 | doi: http://dx.doi.org/10.2471/BLT.14.137935.

REIS, L.M.; CORDEIRO, J,A; CURY, P.M. Análise da prevalência de morte súbita e os fatores de riscos associados: estudo em 2056 pacientes submetidos à necropsia. J Bras Patol Med Lab, v. 42, n. 4, 2006.

RIOS, Marcela Andrade et al . Completude do sistema de informação sobre mortalidade por suicídio em idosos no estado da Bahia. J. bras. psiquiatr., Rio de Janeiro, v. 62, n. 2, p. 131-138, June 2013. Available from <http://www.scielo.br/scielo.php?script=sci_arttext\&pid=S0047-

20852013000200006\&lng=en\&nrm=iso>. Acesso em: 02 Sept. 2016. http://dx.doi.org/10.1590/S0047-20852013000200006.

ROZMAN, M.A, NETO, E.J. Necropsia e mortalidade por causa mal definida no Estado de São Paulo. Rev Panam Salud Publica, v. 20, n. 5, p. 307-13, 2006.

SANTO A.H. Causas mal definidas de morte e óbitos sem assistência. Revista da Associação Médica Brasileira, São Paulo, v. 54, n. 1, p. 23-28, jan/fev. 2008.

SANTOS DE JESUS. W; RIOS, D. F. S.; BARROS, E. P; MIRANDA, D. P. A.; MOURA, V. A. Relatório Técnico. Cobertura do SIM (Sistema de Informação sobre Mortalidade) e SINASC (Sistema de Informação sobre Nascidos Vivos). Secretaria de Estado da Saúde do Tocantins. Palmas. 2016.

SAÚDE, Organização Mundial da. Classificação Estatística Internacional de Doenças e Problemas Relacionados à Saúde CID-10. 10. ed. São Paulo: Universidade de São Paulo, v.3, 2007.

SEPLAN. Indicadores Socioeconômicos do Estado do Tocantins. Diretoria de Pesquisa e Informações Econômicas. Palmas, Tocantins, p. 49. 2015.

SESC, Sistema de Informações Sobre Mortalidade. Mortalidade proporcional por causas mal definidas. Disponível em: <http://www.saude.sc.gov.br/ 
cgi/Ind_Mortalidade_Fichas/SC_mortalidade_Mal_Def2013.pdf $>$. Acesso em: 27 ago. 2016.

SOHN, Min-Woong et al. Accuracy and Completeness of Mortality Data in the Department of Veterans Affairs. Population Health Metrics, v. 4, n. 2, 2006.

STUQUE, C.O.; CORDEIRO, J.A.; CURY, P.M. Avaliação dos erros ou falhas de preenchimento dos atestados de óbito feitos pelos clínicos e pelos patologistas. J Bras Patol Med Lab, v. 39, n. 4, 2003.

SWAROOP, S. Estadística Sanitária, Fondo de Cultura Econômica, México, 1964. Apud: LAURENTI, R, MELLO JORGE, M.H.P.; GOTLIEB, S.L.D. O Sistema de Informações sobre Mortalidade: passado, presente e futuro. São Paulo: CBCD, p. 107, 2006.

TOCANTINS, Governo do. Regiões de Saúde. Disponível em: $<$ http://saude.to.gov.br/planejamento/desenvolvimento-de-politicas-desaude/regioes-de-saude/>. Acesso em: 27 ago. 2016.

VANDERLEI, L.C.; ARRUDA, B.K.G.; FRIAS, P.G.; ARRUDA, S. Avaliação da qualidade de preenchimento das declarações de óbito em unidade terciária de atenção a saúde materno-infantil. Informe Epidemiológico do SUS 2002;11(1):7-14.

WHO, Library Cataloguing-in-Publication Data World health statistics 2008. 1.Health status indicators. 2.World health. 3. Health services - statistics. 4.Mortality. 5.Life expectancy. 6.Demography. 7.Statistics. I.World Health Organization. ISBN 9789241563598 (NLM classifi cation: WA 900.1) ISBN 9789240682740 (electronic version) (C) World Health Organization 2008

WHO, Health Information Systems, 2010. Disponível em: http://www.who.int/healthinfo/systems/WHO MBHSS 2010 section3 web.pdf

WHO Library Cataloguing-in-Publication Data Human resources for health information system: minimum data set for health workforce registry 2015. 1.Health Personnel. 2.Health Manpower. 3.Data Collection - standards. 4. Health Information Systems. 5.National Health Programs. I.World Health Organization. (C) World Health Organization 2015. ISBN 9789241549226

ZILLMER, J. G. V.; et al. Avaliação da completude das informações do hiperdia em uma Unidade Básica do Sul do Brasil. Rev. Gaúcha Enferm. (Online). Porto Alegre, v. 31, n. 2, p. 240-246, June 2010. Available from $<$ http://www.scielo.br/scielo.php?script=sci_arttext\&pid=S1983-

14472010000200006\&lng=en\&nrm=iso>. Acesso em: 02 Sept. 2016. http://dx.doi.org/10.1590/S1983-14472010000200006 


\section{ANEXO}

\section{À ILMA. DRA. MÁRCIA GUIMARÃES VILLANOVA}

NOME: ARTHUR ALVES BORGES DE CARVALHO

MATRICULA: 9150237

CURSO: MESTRADO

PROGRAMA: PATOLOGIA

OPÇÃO: PATOLOGIA HUMANA

DEPARTAMENTO: PATOLOGIA E MEDICINA LEGAL- FMRP-USP

ORIENTADOR: PROF. DR. EDSON GARCIA SOARES

PREZADA DRA. MÁRCIA GUIMARÃES VILLANOVA,

POR MEIO DESTA, VENHO RESPEITOSAMENTE SOLICITAR DISPENSA DE SUBMISSÃO E ANÁLISE DE PROJETO DE PESQUISA QUE CONSTITUIRÁ DISSERTAÇÃO PARA OBTENÇÃO DO TITUULO DE MESTRE EM CIÊNCIAS MÉDICAS COM ÊNFASE EM PATOLOGIA HUMANA PELO DEPARTAMENTO DE PATOLOGIA E MEDICINA LEGAL DA FACULDADE DE MEDICINA DE RIBEIRÃO PRETO-USP

A PESQUISA SERÁ REALIZADA EM DADOS SECUNDÁRIOS DE LIVRE ACESSO E DOMINIO PÚBLICO DISPONIBILIZADOS PELO DEPARTAMENTO DE INFORMAÇÃO EM SAÚDE (DATASUS) DO MINISTÉRIO DA SAÚDE POR MEIO DE SITIO ELETROONICO WWW2.DATASUS.GOV.BR.

OS DADOS UTILIZADOS NA PESQUISA APRESENTAM INFORMAÇÕES CODIFICADAS EM SISTEMA DE INFORMAÇÃO DE SAU்DE PÚBLICA E NÃO ENVOLVEM DIRETA OU INDIRETAMENTE PESSOAS OU POPULAÇŐES. TRATAM-SE DE REGISTROS SOBRE MORTALIDADE NO ESTADO DO TOCANTINS ENTRE OS ANOS DE 2010 E 2012.

DISPONIBILIZO-ME PARA QUALQUER ESCLARECIMENTO OU ENVIO DE DOCUMENTAÇÃO QUE A VOSSA SENHORIA JULGAR NECESSÁRIO, DEDE JÁ AGRADEÇO!

ATT;

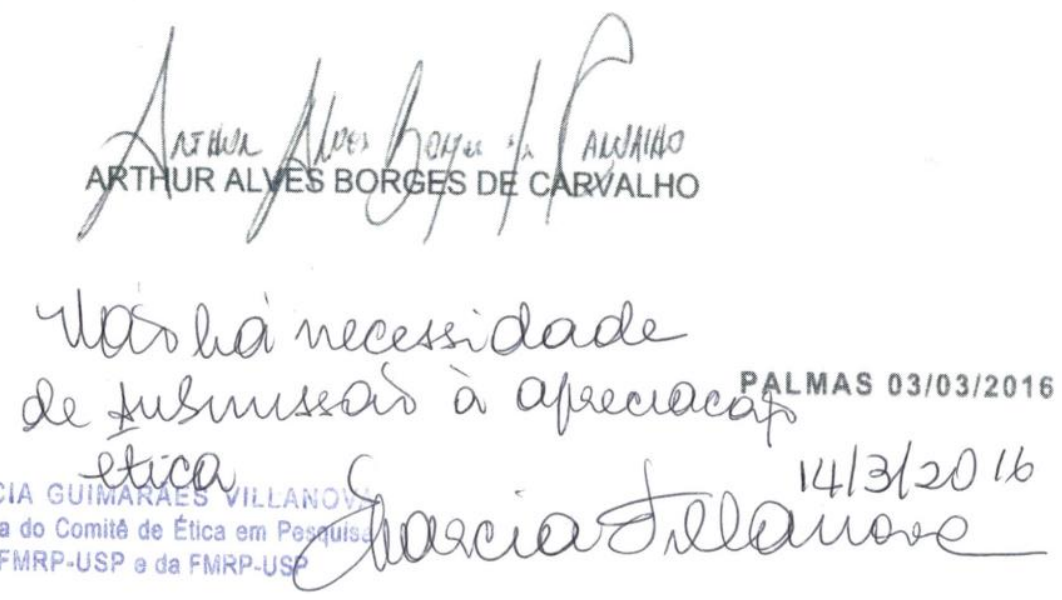

